\title{
ME
}
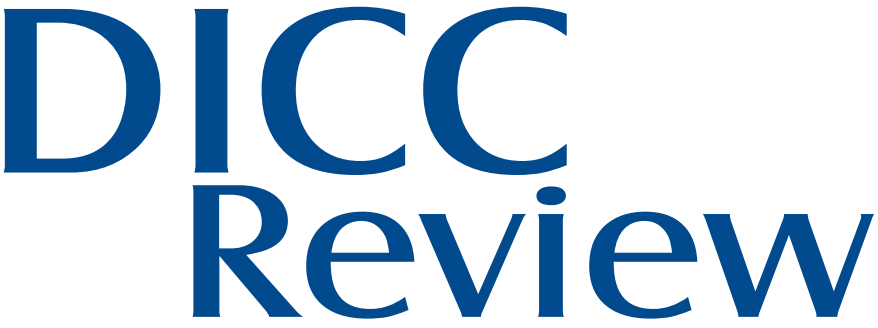

International Journal of Cuban Health \& Medicine

January 2018

Vol 20, No 1

Brain Metastases in Cuban

Cancer Patients

Reflections of a US Med Student in Cuba

Suicidality in Cuban Adolescents

Editors' Choice

Cuba's Drug Regulatory Agency

Treating Skin Cancer in Primary Care

Post-quake Dispatches from Haiti 42
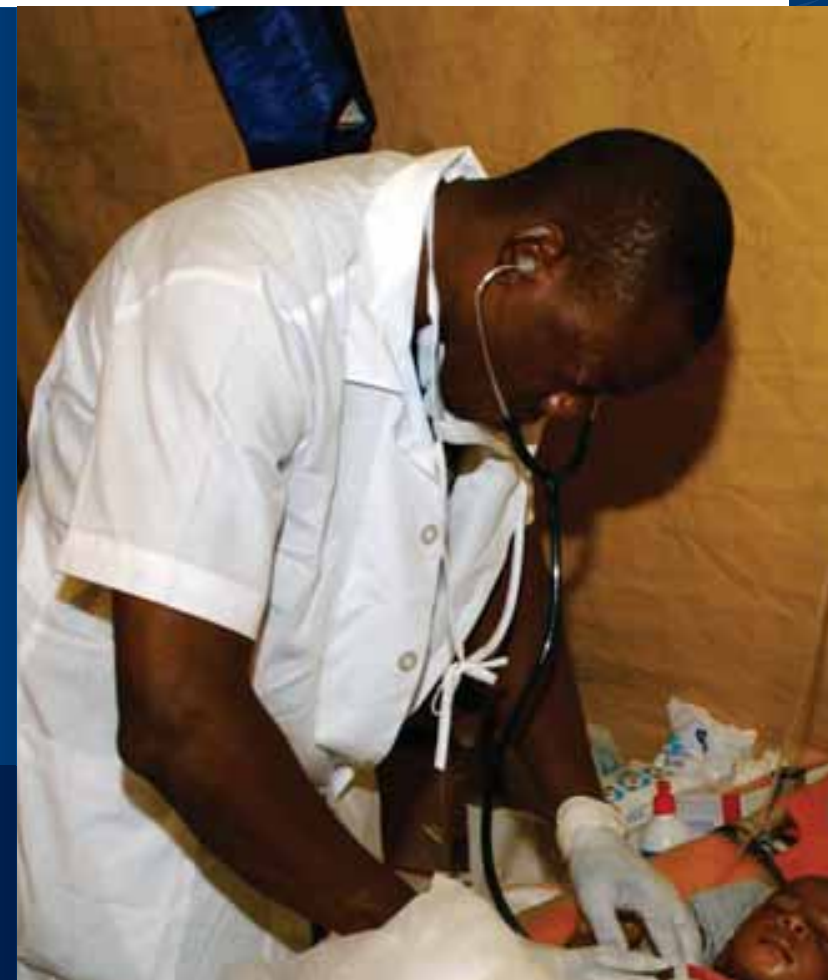
MEDICC Review is pleased to join in . . .

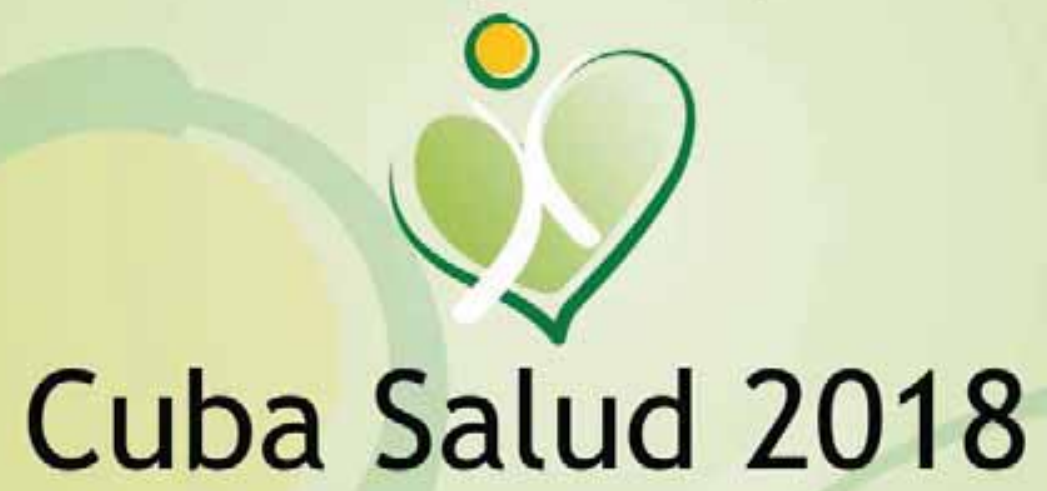

International Conference on Public Health

April 23-27, 2018

Havana's International Convention Center

... where these words*

are always welcome!

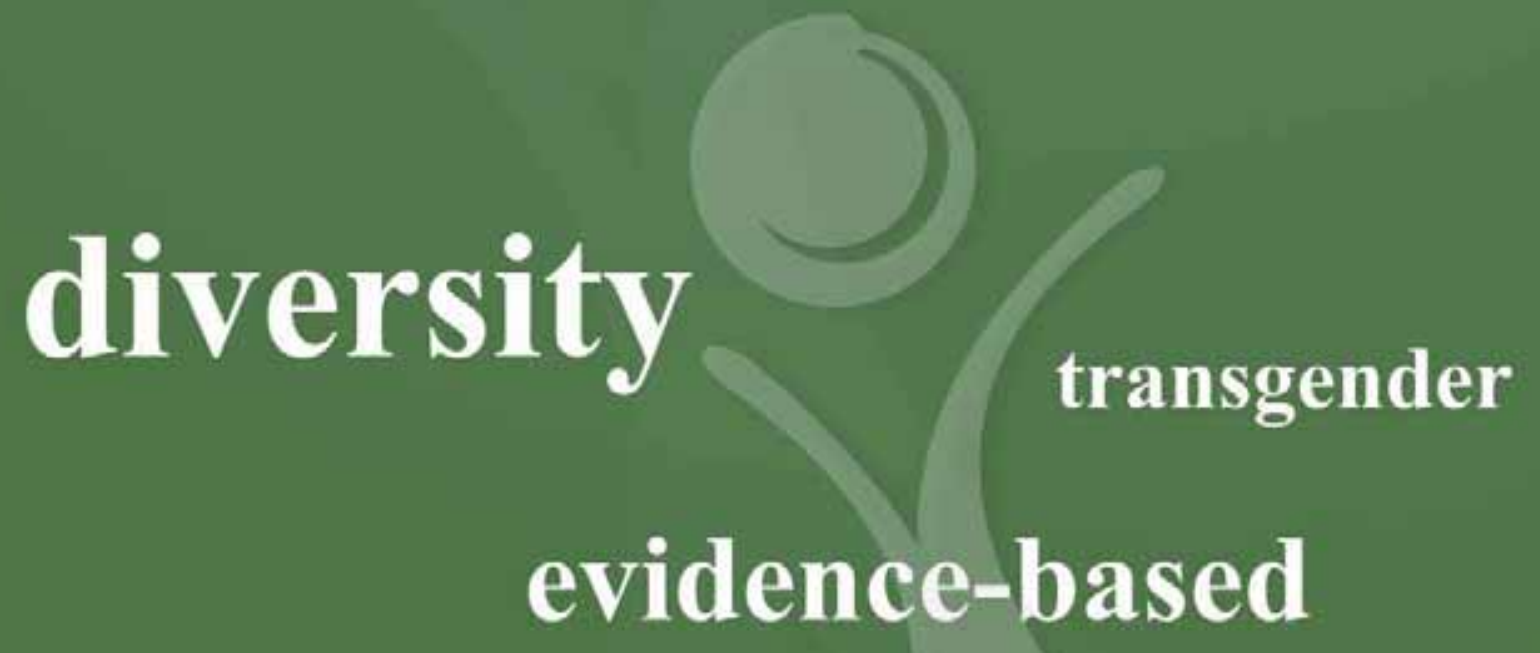

science-based

vulnerable

entitlement

fetus

* size proportional to frequency in web searches

Conference languages: Spanish and English Information: http://www.convencionsalud2018.sld.cu 


\section{MEDICC Review}

\section{January 2018, Vol 20, No 1}

\section{EDITORIAL}

3 Science: Necessarily in the Public Interest

\section{ABOUT THE CONTRIBUTORS}

\section{LETTERS}

5

\section{PEER REVIEWERS}

7

\section{Interview}

8 Science at the Service of Public Health:

Rafael Pérez Cristiá MD PhD

Center for State Control of Medicines and Medical Devices

Conner Gorry MA

\section{Original Research}

11 Treatment of Basal Cell Carcinoma

with Interferons Alpha-2b and Gamma in Primary Care

Meilyn Fernández-Martori MD MS, et al.

Brain Metastases in Havana Cancer Patients Joel Caballero-García MD, et al.

Liver Stiffness Reference Values for Healthy Cuban Adults Ángela Elvírez-Gutiérrez MD MS, et al.

Systemic Ozone Therapy by Rectal Insufflation for Immunoglobulin A Deficiency Jacqueline Díaz-Luis MD MS, et al.

Attempted and Completed Suicide in Cuban Adolescents, 2011-2014 Beatriz Corona-Miranda MD MS, et al.

\section{Retrospective}

42

Dispatches from Haiti, 2010

Conner Gorry MA

\section{Viewpoint}

52 A US Student Reflects on Her Cuban Medical Education Natalia Orihuela

\section{ABSTRACTS}

(3) Cuban Research in Current International Journals

Cover photo: J.Balán. Haitian graduate of Havana's Latin American School of Medicine treating 2010 earthquake patient.

(3) Available online only
Editor-in-Chief

C. William Keck MD MPH FACPM

Executive Editor

Gail Reed MS

Managing Editor

Christina Mills MD FRCPC

Senior Editor

Conner Gorry MA

Primary Issue Coordinator Jorge Bacallao PhD DrSc

Issue Coordinators

Alina Alerm MD

Lila Castellanos PhD DrSc

Gisele Coutin MD MS

Esther María Fajardo MS

Editorial Associates

Anna Kovac

Annet Sánchez

Copy Editor

Carolyn Gorry

Communications Consultant

Elizabeth Sayre MA

Publishing \& Marketing

Aram Álvarez MFA

Silvia García

Murlean Tucker

Translators

Pamela Boyle

Roxane K. Dow MA

Eloisa Le Riverend MS

MEDICC Review is indexed in:

\section{MEDLINE $^{\oplus} /$ PubMed $^{\circledR}$}

in THOMSON REUTERS

Global Health

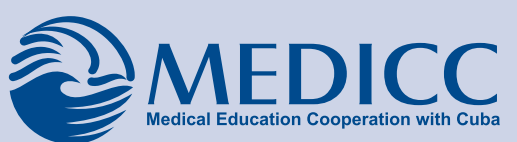

MEDICC Review is published by MEDICC (Medical Education Cooperation with Cuba), a nonprofit organization founded in 1997 to enhance cooperation among the US, Cuban, and global health communities aimed at better health outcomes. The organization's mission is to support education and development of human resources in health committed to equitable access and quality care.

MEDICC Review online (ISSN 1527-3172) is an Open Access publication, allowing readers to freely access, copy, use, distribute, transmit and display its contents, subject to proper attribution. See MEDICC Review's Creative Commons License online for details.

www.medicc.org/mediccreview Copyright $\odot 2018$ by MEDICC 
Neil Arya BASc MD CCFP FCFP

Director, Office of Global Health

Schulich School of Medicine and Dentistry

Western University, Canada

Rifat Atun MBBS MBA FRCGP FFPH FRCP

Professor of Global Health Systems

Director, Health Systems Cluster, Harvard University

School of Public Health, USA

\section{Michael Bird MSW MPH}

Public Health Consultant, Kewa Pueblo Health Board

Urban Indian Health Commission

Albuquerque, New Mexico, USA

\section{James Boex PhD MBA}

Emeritus Professor of Medical Education

Univ. of Cincinnati College of Medicine, USA

Peter Bourne MD MA

Visiting Senior Research Fellow

Green Templeton College, University of Oxford, UK

\section{Alfred Brann MD}

Professor of Pediatrics

Emory University School of Medicine, USA

Jaime Breilh MD PhD MSc

Director, Health Department

Universidad Andina Simón Bolívar, Ecuador

Paulo M. Buss MD MPH

Director, FIOCRUZ Center for Global Health

Oswaldo Cruz Foundation, Brazil

Pastor Castell-Florit MD PhD DrSc

Director, National School of Public Health, Cuba

José F. Cordero MD MPH

Patel Distinguished Professor of Public Health

Chair, Department of Epidemiology and Biostatistics

College of Public Health, University of Georgia, USA

Yamila de Armas MD

Professor, National School of Public Health, Cuba

Maria Cecilia de Souza Minayo MS PhD

Professor of Sociology

National School of Public Health, Brazil

Timothy De Ver Dye PhD MS MA MPA

Professor, OB-GYN, Pediatrics, Public Health

Sciences and Medical Informatics, University of

Rochester School of Medicine and Dentistry, USA

Roger Downer PhD DrSc FRSC MRIA

President Emeritus, University of Limerick, Ireland

Leith L. Dunn PhD

Senior Lecturer \& Head, Institute for Gender

\& Development Studies, Mona Unit

University of the West Indies, Jamaica

\section{Paul C. Erwin MD DrPH}

Professor and Department Head, Department of Public Health, College of Education, Health, and Human Sciences, University of Tennessee, USA

Dabney Evans PhD MPH

Assistant Professor, Rollins School of Public Health Executive Director, Institute of Human Rights Emory University USA

\section{Lowell Gerson PhD}

Professor Emeritus of Family \& Community Medicine Northeast Ohio Medical University, USA

Tee L. Guidotti MD, MPH, DABT

Consultant, Occupational + Environmental Health and Medicine, Toronto, Canada

\section{Jean Handy PhD}

Associate Professor of Microbiology \& Immunology

University of North Carolina School of Medicine, USA

Barbara J. Hatcher PhD MPH RN FAAN

Associate Professor, George Mason University

College of Nursing \& Health Sciences, USA

Raúl Herrera MD PhD DrSc

Distinguished Professor, Medical University of Havana

Chair, National Nephrology Group, Cuba

Eve J. Higginbotham SM MD

Vice Dean of Diversity \& Inclusion, University of

Pennsylvania, Perelmen School of Medicine, USA

Sharon K. Hull MD MPH

Division Chief of Family Medicine, Department of

Community and Family Medicine, Duke University

School of Medicine, USA

\section{William Keck MD MPH FACPM}

Professor Emeritus, Family and Community

Medicine Northeast Ohio Medical University

Chair, Council on Linkages, USA

Ann Marie Kimball MD MPH FACPM

Strategic Adviser, The Rockefeller Foundation, USA

Barry Kistnasamy MBChB Mmed

Executive Director, National Institute for Occupa-

tional Health \& the National Cancer Registry, South

Africa

Patrick Kuma-Aboagye MB-BCH MPH

Deputy Director and Head, Reproductive and Child

Health Department, Ghana Health Service, Ghana

Albert Kuperman PhD

Emeritus Associate Dean for Medical Education

Albert Einstein, College of Medicine of Yeshiva University, USA

Margaret Larkins-Pettigrew MD MEd MPPM

Asst. Professor, Global Health/OB-GYN and

Reproductive Biology, Univ Hospitals, Case Medical

Center \& MacDonald Women's Hospital, USA

Linh Cu Le MD MSc PhD

Associate Professor of Public Health

Vinmec International Hospital JSC, Viet Nam

Noni MacDonald MD MSc FRCPC FCAHS

Professor of Pediatrics and Computer Science

Dalhousie University, Canada

\section{Pedro Más MD PhD DrSc}

Full Professor, Medical University of Havana

Senior Researcher, Pedro Kourí Tropical Medicine Institute, Cuba

Nancy A. Myers PhD RN

System Director, Quality and Clinical Effectiveness

Summa Health System

USA
Daniel J. Ncayiyana MD FACOG

Emeritus Professor, University of Cape Town South Africa

André-Jacques Neusy MD DTM\&H

Executive Director, Training for Health Equity

Network (THEnet), Belgium

\section{F. Javier Nieto MD PhD}

Dean, College of Public Health \& Human Sciences,

Oregon State University, USA

Jorge Pérez MD MS

Adviser to the Director, and Full Professor

Pedro Kourí Tropical Medicine Institute, Cuba

Patricia Rodney PhD MPH RN

Partners in Health, Education and Development, USA

María Isabel Rodríguez MD

Health and Education Advisor to the President of the Republic, EI Salvador

Francisco Rojas Ochoa MD PhD

Distinguished Professor, Medical University of Havana,

Cuba

F. Douglas Scutchfield MD FACPM FAAP

Peter P. Bosomworth Professor of Health Services

Research and Policy, University of Kentucky

Colleges of Public Health and Medicine, USA

Stuart G. Shanker DPhil MA

Distinguished Research Professor of Philosophy and

Psychology; Director, Milton \& Ethel Harris Research

Initiative, York University, Canada

Augusto Sola MD

Neonatologist, St Jude's Hospital and Children's

Hospital, Orange County, California, USA

Ronald St. John MD MPH

President, St. John Public Health Consulting International, Canada

Pedro Urra MS

Full Professor, University of Havana, Cuba

Pedro A. Valdés-Sosa MD PhD

Deputy Director, Neuroscience Center, Cuba

Luis F. Vélez MD MPH PhD

Director, Program Development, Evaluation

and Quality Improvement

DePelchin Children's Center, USA

Howard Waitzkin MD PhD FACP

Distinguished Professor Emeritus,

University of New Mexico, USA

Suwit Wibulpolprasert MD

Senior Advisor on Disease Control

Ministry of Public Health, Thailand

Paul Worley MBBS PhD FACRRM FRACGP

Dean of Medicine

Flinders University, Australia

Emelia Ycart EdD Special Education

Director, La Castellana Psychopedagogical Center, Cuba
MEDICC Review (ISSN 1555-7960) is published quarterly by MEDICC (Medical Education Cooperation with Cuba) in January, April, July \& October

Submissions MEDICC Review publishes original peer-reviewed articles by Cuban and international authors. Send letters to editors@medicc.org. Guidelines for authors at: www.medicc.org/mediccreview.

Open Access MEDICC Review online (ISSN 1527-3172) is an Open Access publication; articles may be reproduced with proper attribution under Creative Commons License (www.medicc.org/mediccreview).

Advertising Rates at www.medicc.org/mediccreview or write review@medicc. org for ad swaps. Acceptance of advertising does not imply endorsement.
Ethics Opinions expressed in articles and letters in MEDICC Review are the views of their authors, and do not necessarily reflect those of the Editors, publishers or Editorial Board. Responsibility for originality of manuscripts, free of plagiarism or fraud, rests with the authors. MEDICC Review will retract any article found to contain plagiarized or fraudulent content.

Reprints Articles in the 'Reprints' section of MEDICC Review print edition may be reproduced or distributed only authorized by the original copyright holder

Print Copies Selected readers receive the print edition. Contact review@medicc.org for more information, and for prices of back issues or bulk copies. 


\section{Science: Necessarily in the Public Interest}

Securing science in the public interest implies two imperatives: a belief in science, in evidence, in facts; and a belief in the public, in people's right to a science that places their needs first. Cuba's Day of Science, celebrated every January 15 since 1960, embodies both, representing a research philosophy embedded in a universal public health system. In many cases, this has yielded not only novel drugs and vaccines, but also effective health strategies applicable in other resource-limited settings ... and also in resource-rich environments.

If science matters, then research and its findings also matter, are to be continually reviewed, debated, enhanced, and even overturned as science advances. Fact must be sifted from extraneous chaff, bias in particular, and examined in the scientific daylight of full disclosure. Science "in the public interest" requires political will as a jump-starter, but also research to determine the most important planetary, population and individual health issues to be tackled by investigators, clinicians, social scientists and-sometimes above all—the policymakers and others who hold the purse strings. This, in turn, means that tough questions must be asked about how to improve population health across the board, where the sticking points are, and how to best and self-critically address them.

\section{"Of all the forms of inequality, injustice in health is the most shocking and inhuman." -Dr Martin Luther King, Jr., March 25, 1966}

MEDICC Review is unequivocally devoted to science and to science in the public interest, to publication of articles that move the markers forward on health equity worldwide, and that do not hesitate to shine light on problems, as well as their solutions, in pursuit of universal health and wellbeing. In this context, we hope to provide examples from Cuban and other Latin American and Caribbean experiences in particular. And to reflect the Global South's science, medicine and population health with the respect and attention they deserve, thus far a presence woefully scant or even absent in international peerreviewed journals.

We are encouraged to see references to Cuba's own public health and biotech achievements in such publications as Nature Biotech, The Lancet and The New England Journal of Medicine. But much more needs to be done to fund and publicize such ground-breaking research from Latin America, the Caribbean, Africa and Asia .... and to give greater visibility to solutions developed there to pressing and urgent health problems. Global health cooperation, North-South, South-South and South-North (the latter, so-called "reverse innovation") are urgent needs not only to fight emerging diseases and epidemics, but also to save our planet from those who have no regard for science or for the public interest, present or future.

Priority accorded to science in the public interest by Cuba can contribute to fulfilling WHO's General Program of Work for 20192023, released in November 2017 under the vision of its new Director-General, Dr Tedros. WHO's "flagship initiatives" for the period are antimicrobial resistance, climate change in small island states, non-communicable diseases and human capital.
The pages of MEDICC Review have shared (and will continue to share) Cuban experiences relating to all of these. But perhaps, as Dr Paul Farmer has pointed out, Cuba's greatest contribution is to what WHO describes as its top strategic priority: universal health. This is especially relevant in 2018, in light of PAHO's call for renewed energies devoted to health for all, posed at its highlevel December meeting on Universal Health in the 21st Century: 40 Years of Alma-Ata. Cuba offers a living laboratory, in which staunch political will defending a free, universal public health system struggles to make the system sustainable in the face of often dire economic straits and predictions, complicated by the US embargo.

Among the Editors' Choice articles in this issue is an interview with Dr Rafael Pérez Cristiá, Director of Cuba's Center for State Control of Medicines and Medical Devices, the first regulatory agency in Latin America to receive WHO certification as qualified for vaccine regulation, and a participant (with Brazil) in the first bilateral Regulatory Technical Committee initiated in the region. The Center is charged with evaluation of all drugs and medical equipment produced or imported in Cuba, including those considered alternative or natural and traditional therapies.

Our second Editors' Choice reports and experience treating skin cancer patients in primary care settings, with skin cancer the most common form of the disease in Cuba.

And the final Editors' Choice brings us to Haiti: We are especially pleased to reprint here excerpts from Senior Editor Conner Gorry's blog, written in Haiti in the aftermath of the January 12, 2010 earthquake that devastated that country. Her writingfrom notes often scribbled on notebooks as she bounced in the back of a truck, in an ambulance or bus, or as she lay on her bunk in the tent city where she shared cramped quarters with the 1800-strong Cuban-led medical team-offers a poignant reminder of Haitians' strength of spirit and of the power of SouthSouth cooperation. Particularly noteworthy is the contribution of some 700 international students and graduates of Havana's Latin American School of Medicine, including Cuban-trained Haitian MDs, who volunteered for months with the Cuban team in Haiti.

At a time when powerful voices question the rights and value of those who are poor, immigrants, women, children or elderly; of those who are stricken with disaster or felled by unattended disease, we are reminded that undoubtedly, we are all Haiti.

For those of you attending Cuba Salud 2018, MEDICC Review offers you a hearty welcome to Havana and to the pages of our journal. Along with this, our warmest thanks go to all those authors and reviewers who made possible our 2017 array of articles, celebrating the journal's 10th anniversary last year. We are grateful to each of you, and look forward to deepening our relationships with you, expanding our pool of authors, and reaching ever more readers in the year ahead. -1 -

\section{The Editors}




\section{About the Contributors}
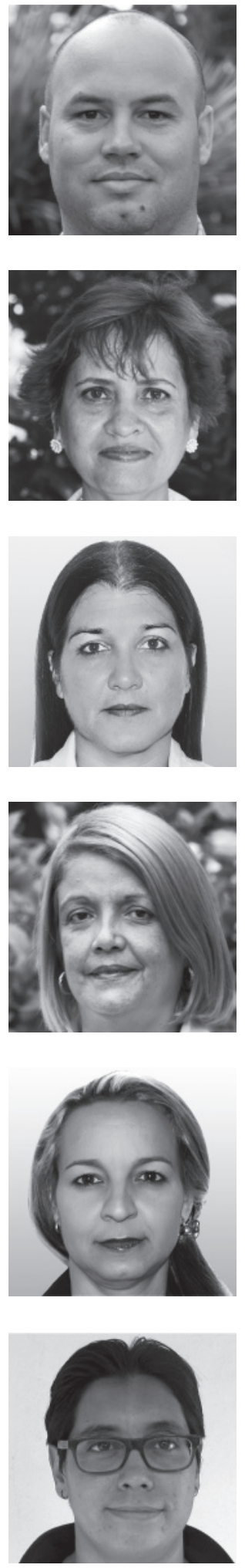

\section{Joel Caballero-García MD}

Physician with dual specialties in family medicine and neurosurgery. Dr Caballero-García is an assistant professor at the National Oncology and Radiobiology Institute, Havana. His professional interests concentrate on brain metastases, with research projects currently under way in three areas: neuro-oncology, stereotaxic and radiosurgery, and minimally invasive surgery for complex tumors of the skull base. His publications include a neurosurgery text and research articles in Cuban and international journals. Dr Caballero-García was awarded the 2014 Cuban Academy of Sciences Prize and the 2017 Dr Carlos Manuel Ramírez Corría Prize for best neurosurgeon under 35 .

\section{Beatriz Corona-Miranda MD MS}

Physician with dual specialties in family medicine and hygiene \& epidemiology, with a master's degree in environmental health. An assistant professor and adjunct professor at Cuba's National Hygiene, Epidemiology and Microbiology Institute, $\mathrm{Dr}$ Corona-Miranda's research focuses on mental health, injury-associated mortality, and economic evaluation of Heberprot-P, an innovative Cuban treatment for diabetic foot ulcer. She leads Cuba's national suicide prevention initiative. Dr Corona-Miranda is principal investigator for the mental health chapter of Cuba's National Health Survey, and a member of the team developing a national program to address depression.

\section{Jacqueline Díaz-Luis MD MS}

Physician specializing in immunology with a master's degree in infectious diseases; doctoral candidate in medical sciences. Dr Díaz-Luis is staff immunologist and professor of immunology at the Roberto Rodríguez Fernández General Teaching Hospital in Morón, Ciego de Ávila Province, Cuba. Her research interests include immunodeficiency management in primary care, environmental effects of medical waste, and therapeutic use of ozone. A founding member of the Cuban Immunology Society, she heads the Ciego de Ávila provincial immunology group.

\section{Ángela Elvírez-Gutiérrez MD MS}

Radiologist with a master's degree in diagnostic imaging. Dr Elvírez-Gutiérrez is assistant professor and associate researcher at Cuba's Gastroenterology Institute, Havana, where she focuses on applications of various imaging techniques in hepatic and other digestive system conditions. These include a comparison of conventional and hydrogastric ultrasound in gastric cancer detection, and diagnostic application of elastography in adults with no known liver disease. She is also involved in a project to assess the safety and efficacy of HeberNasvac (a Cuban vaccine for hepatitis B) in patients with chronic hepatitis B infection. Dr Elvírez-Gutiérrez has been awarded medals for international cooperation in Angola and Venezuela.

\section{Meilyn Fernández-Martori MD MS}

Dermatologist with a master's degree in infectious diseases. Dr Fernández-Martori practices at the Carlos J. Finlay University Polyclinic in Colón, Matanzas Province, Cuba. She is the provincial lead for skin cancer and dermatology teaching and research in the province. Her research focuses on cancer epidemiology and treatment. In addition to the research presented in this issue, she is involved in a clinical trial of a therapeutic vaccine for metastatic melanoma.

\section{Natalia Orihuela}

Fourth-year medical student. Ms Orihuela holds a bachelor's degree in film studies from San Francisco State University and took premedical courses in the USA and Mexico before beginning her studies at Havana's Latin American School of Medicine in 2014. Her work on HIV earned her an outstanding ranking at Havana's 7th Student Science Congress in 2016. 


\section{Nursing Leadership for Universal Health}

\section{To the Editors:}

Since the 1960s, the Cuban health care system has focused on primary preventive health care that meets community health needs and results in optimized population health outcomes. This foresight to train the Cuban health workforce has resulted in three significant milestones: free health professional education (1960s), establishment of community polyclinics (1970s), and development of family doctor-and-nurse teams in the 1980s (described in Gorry's Feature in January 2017).[1] The Cuban health system highlights the key role of nurses in clinical practice, following the World Health Organization's (WHO) promotion to strengthen nurses' training and leadership,[2] and serves as a model for international health systems in two ways.

First, high-quality academic training provides Cuban nurses with didactic and clinical training at three specialty levels: specialist (e.g., postgraduate level), professional (e.g., baccalaureate-level), and technical (e.g., associate-level). By promoting the continuous assessment and risk evaluation (CARE) process for medical evaluations in clinic and home visits, nurses can assess physical and psychosocial health, unhealthy behaviors (e.g., physical inactivity, toxic behaviors), and environmental risks (e.g., poor air and water quality, mosquito-breeding sites). Hence, nurses understand that social determinants of health can impede health equity and optimal family and community health. They are skilled in coordinating disease prevention and medical treatment plans in their designated communities or as part of the Henry Reeve International Medical Contingent global deployments to disaster sites.

Second, collaborative teamwork and communication between Cuban nurses and physicians in clinical practice foster increased efficiency of task coordination in community clinics and home visits. This practice emphasizes shared decision-making with patients, complemented by nurses' holistic training in health and wellness and physicians' expertise in the medical model. As they work side-by-side in domestic and international communities, they gain insight on fruitful interdisciplinary collaborations based on professional autonomy, respect, and solidarity in primary care.[3]

The future global health workforce requires highly trained nurses who can promptly identify health risks, participate in shared decision-making with patients, and provide appropriate holistic care in communities. Recognizing the universal health coverage targets of the Sustainable Development Goals, we are pleased to see that Cuban nurses, alongside their global counterparts, will continue to lead efforts in providing health service delivery to citizens of all ages.

1. Gorry C. Cuba's family doctor-and-nurse teams: A day in the life. MEDICC Rev. 2017:19(1):6-9.

2. World Health Organization. Nursing and midwifery in the history of the World Health Organization, 1948-2017. Geneva: World Health Organization; 2017.

3. House S, Havens D. Nurses' and physicians' perceptions of nurse-physician collaboration. J Nurs Adm. 2017;47(3):165-71.

Marianne Mathewson-Chapman PhD MSN ARNP (mmchap man60@gmail.com), independent nurse consultant, Treasure Island, FL.

Helena J. Chapman MD MPH PhD, Research Scientist, University of Florida College of Medicine, Gainesville, FL.

\section{Autism Management in Cuba}

(Edited for brevity and reprinted with permission fromAssociation for Science in Autism Treatment Media Watch. Original available from: https://www. asatonline.org/media-watch/asat-responds-medicc -reviews-autism-spectrum-disorder-cuba-comprehensive-coor dinated-response/)

\section{To the Editors:}

We are writing in response to Gorry's article, Autism Spectrum Disorder in Cuba: Comprehensive and Coordinated Response, in MEDICC Review's April-July 2017 issue. First, we applaud you for disseminating your analysis on autism prevalence in Cuba and how families receive services for their children. The Association for Science in Autism Treatment (ASAT) supports families and offers them resources on scientifically based autism practices. It can be difficult to access information on clinical and educational trends in Cuba, so we are pleased to see through your analysis that Cuba may be using such practices in their schools and with professionals working with children with autism spectrum disorder. By utilizing applied behavior analysis (ABA) and specific evidencebased practices within occupational and speech therapies, Cuba appears to be on the right track to assist this population by using the best available treatments.

You start your article with the personal accounts of three young Cubans who have been diagnosed with autism and who have received services through specialized schools and governmentbacked funding. Their notable improvements mirror what can often be seen in the USA when parents are able to take advantage of federally funded, evidence-based early intervention programs. We would welcome future articles with more details on how the programs you mentioned are run. For example, how many Board Certified Behavior Analysts work in a single specialized school or set of schools? Are there any experimental teaching practices occurring in these educational settings that you are aware of? Receiving more in-depth insight into practices from a country that has been relatively cut off is vital to increasing access to appropriate services for all, and we applaud you for your efforts.

In addition, it is wonderful to see that Cuba is using tools that many US pediatricians and professionals employ to help diagnose autism, such as the fifth edition of the Diagnostic and Statistical Manual of Mental Disorders. However, you mention that Cuba still needs an extensive research project to map national autism prevalence. This would improve efforts to collect as much empirical data as possible, which may help advance programs and assist professionals in the field. We hope the USA and Cuba will soon have increased opportunities to join forces and share with each other their knowledge and expertise in autism research, which may also help advance programs and assist professionals in the field. When we collaborate to advance scientific research and critically evaluate outcomes, we can more efficiently expand effective practices for all.

We take this opportunity to make a few clarifications. Regarding specific intervention, you mention, "Although autism has no cure, symptoms and functionality can improve through a combination of psychosocial interventions, speech therapy, behavioral modification, special education, and alternative and complimentary therapies," 


\section{Letters}

and you go on to say that "treatment must be individualized." While treatment should certainly be individualized (and we are grateful that you included Dr Whilby's cautionary statement to parents that "improvements aren't always made"), we would like to add that every individual treatment should be backed by scientific evidence of effectiveness. Hundreds of touted "treatments" exist that are not backed by adequate research, and they can end up causing more harm than good. These include some of the "therapies" mentioned in your article. You can find more information on the evidence behind potential treatments on the Learn More About Specific Treatments page of ASAT's website (https//www.asatonline.org). Our website contains information on a variety of topics that you might be interested in sharing with your readers in future articles focused on evidencebased treatment for individuals with autism.

You also mention that $A B A$ "is an integrated and individualized treatment protocol designed to modify behavior and increase skillset by using positive reinforcement; a baseline is established for each child measuring their responses to a series of trials- desired behavioral responses are rewarded, negative or incorrect responses are ignored-and their progress tracked as they improve, with positive reinforcement provided to motivate them to keep striving and learning." While there are aspects of this statement that are true, we would like to clarify that practitioners of ABA aim to improve socially important behavior by using interventions that are based on principles of learning theory and that have been evaluated in experiments using reliable and objective measurement. By and large, positive reinforcement is a key aspect of any ABA program, but it is not necessarily the only way to effect behavior change, nor are "negative or incorrect responses" always ignored or "responses to a series of trials" the only way behavior is measured. All ABA interventions should be based on the function of (or reason for) behavior, and are highly individualized.

Thank you for giving the world a glimpse of the essential job that Cuba is doing for its people in need. We hope Cuba will continue to refine their pursuit of evidence-based practices for individuals with autism.

Elena M. Escalona MS Ed (mediawatch@asatonline.org), Association for Science in Autism Treatment

Renee Wozniak PhD, BCBA-D, Association for Science in Autism Treatment $-\mathrm{M}$ 
All original articles appearing in MEDICC Review are subject to double-blind international peer review. MEDICC Review is indebted to the following colleagues for their collaboration as peer reviewers in 2017

Gladys Abreu Suárez MD PhD, Cuba

María del Carmen Alemán Lage MD MS, Cuba

Ismarys Alfonso Horta MD PhD, Cuba

Miguel M. Almaguer López MD, Cuba

Lorenzo Anazagasti Angulo MD, Cuba

Juan Ignacio Arrarás Urdániz MD PhD, Spain

Leticia Artiles Visbal PhD, Cuba

Juan A. Ayala Serrano MD PhD, Spain

Ricardo M. Barrera, Argentina

Carlos Bidot MD, USA

Miguel Angel Blanco Aspiazu MD MS PhD, Cuba

Luis Buceta Ríos MD, Spain

Marta Brown Martínez MD MS, Cuba

Emilio F. Buchaca Faxas MD PhD, Cuba

Raúl Calderín Bouza MD MS, Cuba

Rolando Camacho Rodríguez MS PhD, Cuba

Ignacio Casarini Saez MD, Argentina

lleana Castañeda Abascal DDR PhD, Cuba

Marta Castro Peraza MD MS PhD, Cuba

Franco Cavalli MD, Switzerland

Ernesto Chico Véliz PhD, Cuba

Glay Chinea Santiago PhD, Cuba

Camilo Cid MA PhD, Chile

Modesto Cruz MD PhD, Dominican Republic

Ovidio S. D’Angelo Hernández PhD, Cuba

James DeGregori PhD, USA

Mariana de Santis PhD, Argentina

Zoe Díaz Bernal PhD, Cuba

Félix O. Dickinson Meneses MD PhD, Cuba

Ariel Dogliotti MD, Argentina

Yeicy Donastorg Cabral MD, Dominican Republic

Carlos Duarte Cano MD PhD, Cuba

Celia Fernández Ortega PhD, Cuba

Heriberto Fernández Jaramillo MD, Chile

Omar Fuentes González MS, Cuba

Eberto García Silvera MD MS, Cuba

Remedios Giner Durán MD, Spain

Silvia B. Gorban de Lapertosa MD, Argentina

José Eduardo Guerrero Espinel MD MPH, Colombia

Henry Gutiérrez González MD MPH, Colombia

María Griselda Gutiérrez MD, Argentina

Raúl F. Gutiérrez Herrera MD MS, Mexico

Carlos E. Hernández Avila MD, El Salvador

Diego Hernández MD, Argentina

Víctor Hernández Escalante PhD, Mexico

Raúl Herrera Valdés MD PhD DrSc, Cuba

Vivian Huerta Galíndez MS, Cuba

Sergio Jorge Pastrana, Cuba

C. William Keck MD MPH FACPM, USA

Angel J. Lacerda Gallardo MD PhD, Cuba

Agustín Lage Dávila MD PhD, Cuba

Juan J. Lence Anta MD MPH PhD, Cuba

Lydia Lera Marqués PhD, Chile

Juan J. Llibre Rodríguez MD PhD DrSc, Cuba

Argelia Londoño Vélez PhD, Colombia

Estefanía López Pardo PhD, Colombia

Orestes R. López Piloto MD, Cuba

Carlos Lovesio Cataldo MD, Argentina
Nahuel A. Luengo PhD, Argentina

Roberto Mainieri Caropreso MD, Panama

Antonio Marrero Figueroa MD, Cuba

Cristóbal L. Martínez Gómez MD PhD, Cuba

Evelyn Martínez Cruz MD MS, Cuba

Isabel Martínez Motas MD PhD, Cuba

Silvia Martínez Calvo MD PhD, Cuba

Zulema Menéndez Díaz MS, Cuba

Leydis Miranda Benítez MD MS, Colombia

Minerva Montero Díaz, Cuba

Francisco L. Moreno Martínez MD, Cuba

Edgar Muñoz MD, USA

Vladimir Muñoz Rodríguez MD MS, Colombia

Nirosha J. Murugan PhD, USA

Daysi Navarro Despaigne MD PhD, Cuba

Porfirio Nordet MD MS PhD, Switzerland

Ramona Núñez Camarena MS MPH, Dominican Republic

Sumaila A.J. Obansa MD, Nigeria

Rolando Ochoa Azze MD PhD, Cuba

Manuel Olivares Grohnert MD, Chile

José G. Ortiz PhD, Puerto Rico

Liset Padilla Ledesma MD MS, Cuba

Ramón E. Paniagua Suárez MPH, Colombia

Julia S. Pérez Piñero PhD, Cuba

Nancy Pérez Rodríguez PhD, Cuba

Néstor M. Pérez Lache MD PhD DrSc, Cuba

Rolando Pérez Rodríguez PhD, Cuba

Tirso Pons Hernández PhD, Spain

Juan Prohías Martínez MD FACC FASE, Cuba

Alejandra Rabadán MD, Argentina

José F. Ramírez Pérez PhD, Cuba

Mayra Ramos Suzarte MD PhD, Cuba

Juan F. Rivera Medina MD, Peru

Miguel Angel Rodríguez Allende MD PhD, Cuba

Joan O. Rojas Fuentes MD, Cuba

Zenaida Sáez MD, Cuba

Belinda Sánchez Ramírez PhD, Cuba

Jesús E. Sánchez García PhD, Cuba

Yovannys Sánchez Corales MS, USA

Antonio Sanhueza PhD, Chile

Dámaso Sanz Guajardo MD, Spain

Armando Seuc Jo MS PhD, Cuba

Teddy O. Tamargo Barbeito MD MS PhD, Cuba

Omaida F. Torres Herrera MD, Cuba

Rafael de Jesús Tuesca Molina MD MPH PhD, Colombia

Juan Ramón Vázquez Cangas MS, Cuba

Linda Venczel MD PhD, USA

Carlos Villegas Valverde MD, Cuba

Angela O. Yanza Montalvan MS, Ecuador

We also thank the following colleagues for their valuable review of research methodology and statistical data in manuscripts submitted to MEDICC Review during 2017:

Iván Cuevas Valdespino MD MS MPH, epidemiologist Silvio Soler Cárdenas MS, biostatistician 


\section{Science at the Service of Public Health: Rafael Pérez Cristiá MD PhD General Director, Center for State Control of Medicines and Medical Devices}

\begin{abstract}
Conner Gorry MA
Cuba's nascent biotechnology sector began making scientific breakthroughs in the 1980s, including the isolation of human leukocyte interferon alpha (1981) and the development of the world's first safe, effective meningitis $B C$ vaccine (1989). With positive results in hand and a growing R\&D pipeline, the island nation established a national regulatory authority (NRA) to implement and oversee best practices for all pharmaceuticals and medical devices, domestically produced and imported, used in the country's universal health system. Founded in 1989, Cuba's Center for State Control of Medicines and Medical Devices (CECMED) is the entity charged with regulating all phases of scientific innovation for health, from clinical trial design to postmarketing surveillance.
\end{abstract}

Dr Rafael Pérez Cristiá, Distinguished Member of the Cuban Academy of Sciences, has been Director General of CECMED since 2000, overseeing regulation and control of unique and innovative biotechnology products and the concomitant evolution of the nation's regulatory authority. Under his guidance, CECMED has regulated unique therapies, vaccines, and pharmaceutical products-some unavailable anywhere else in the

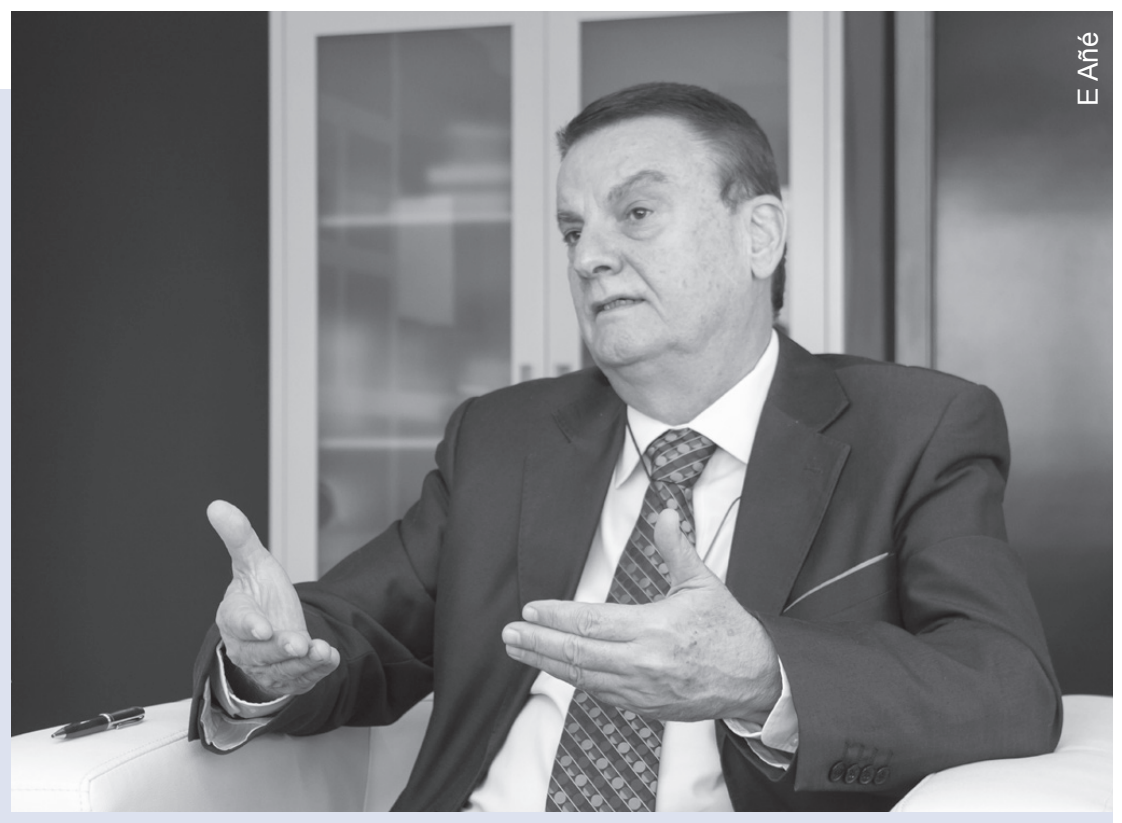

world-aimed at improving population health both at home and abroad. Recognized internationally as one of the top 20 countries with a safe and reliable biotechnology industry and regulatory authority, Cuba is having a measurable impact on public health. In this exclusive interview, Dr Pérez Cristiá, explains how a small, resource-scarce country has rocketed into the global biotech elite-and how it intends to stay there.

\section{MEDICC Review: Can you discuss the origins and evolution of CECMED?}

Rafael Pérez Cristiá: Our biotechnology industry was born of necessity: in the early 1980s, Cuba experienced a hemorrhagic dengue epidemic followed by an outbreak of meningococcal disease, both of which led to spikes in infant mortality. Pediatric intensive care units were established in hospitals across the country to treat these diseases, but the US embargo then-as now-kept us from easily accessing medicine and technology from the USA. So it became apparent that to diagnose, treat and control disease and other health problems, we were going to have to forge our own solutions. As a result, resources were marshalled to establish scientific R\&D capacities and a regulatory authority to oversee development, manufacture and distribution of vaccines and other biotechnology products. Our earliest success was VA-MENGOC-BC, the world's first vaccine against meningitis $B$ and $C$, which was awarded a World Intellectual Property Organization Gold Medal in 1986. This was a milestone for us, since it was then we realized the potential of Cuban biotechnology and the impact it could have on health. But we also realized that to properly support research and development of vaccines, pharmaceuticals and therapeutics, we needed a regulatory authority as sophisticated and trustworthy as our biotechnology industry and the products it was creating. This led to the founding of CECMED.

We reached out to international experts for training, advice and specialized know-how, launching an intense collaboration aimed at creating and designing an NRA. Although our team was small and worked from cobbled-together offices, we realized we were breaking new ground: Cuba was one of the first Latin American countries to create an autonomous regulatory authority, under the auspices of the Ministry of Public Health.

In 1992, CECMED moved to new headquarters, allowing us to expand our team and establish laboratories for independent analysis of scientific results submitted by the biotech sector. We pushed full steam ahead, instituting international standards for clinical trial design, research, development, manufacturing and surveillance, while training the necessary specialists. In 1999, our efforts paid off with another significant breakthrough: a safe and effective recombinant hepatitis B vaccine. In 2001, this vaccine received prequalification status for inclusion in the WHO's Global Alliance for Vaccine and Immunization Program (GAVI) — the first Cuban product to do so. 
This was a major breakthrough for Cuban biotechnology because prequalification status requires WHO certification that the vaccine is not only safe and effective, but that it was developed, produced, tested and distributed according to international best practices. Importantly, the WHO prequalification process for a vaccine also evaluates whether the national regulatory framework meets established criteria. CECMED is re-evaluated by independent, international specialists every two years to maintain this status, which we've done since 2000. Cuba is a country with many limitations and few resources-and we haven't always made proper use of them-but our government showed the political will to create, develop and fund an internationally recognized national regulatory authority, a great source of motivation for me and others at CECMED.

\section{MEDICC Review: Can you talk a bit more about how CECMED conceives its role?}

Rafael Pérez Cristiá: The concept of Cuba's biotechnology industry is based on the principle that science should be at the service of public health-research and development of any medicine, vaccine, therapy or technology must have potential tangible benefits for improving population health. Our industry wasn't designed for profit; it was designed to resolve health problems. Guaranteeing universal access to safe, effective medicines and medical technologies-especially for the most vulnerable-is one of the most important public health strategies, recognized as such when the Millennium Development Goals were first formulated and embedded in WHO strategic plans. Through various modalities, including prioritization of R\&D targeting neglected diseases, technology and knowledge transfer, and providing lower cost alternatives, Cuban biotechnology is moving closer to these goals.

All medicines used in our health system are heavily subsidized by government to guarantee access: medicines used in hospitals are dispensed free and those distributed via the national pharmacy network have extraordinarily low prices. This is a defining characteristic of our approach; I don't know of any other country with such a favorable national pricing policy for pharmaceuticals.

\section{MEDICC Review: Can you walk us through what CECMED does and its precise functions?}

Rafael Pérez Cristiá: The short answer is that CECMED, as Cuba's NRA, guarantees the safety and effectiveness of all medicines and devices used in the national health system. This includes the entire cycle of domestically manufactured products, from clinical trial design and implementation, to manufacturing, distribution, storage, and clinical application, including postmarketing surveillance of adverse events, quality control problems and the like. CECMED is also responsible for guaranteeing the safety and effectiveness of all imported medicines and technology. Independent analyses are conducted on all products, domestic and imported, at laboratories in our Havana headquarters.

CECMED must certify that all products for use in the health system conform to international best practices, which requires a large, team of inspectors, experts in various fields. In the case of clinical trials, for example, CECMED specialists evaluate and authorize trial design and protocols, provide evaluation during the four trial phases, inspect and certify trial sites, and evaluate and certify results. All these steps must conform to both scientific and ethical international best practices before receiving CECMED certification.

Then there's the manufacturing, distribution, storage and application of new medicines, which also must meet international best practice requirements; this also falls under CECMED's purview, as does the evaluation of all medical equipment, including installation and performance once certified for use in clinical settings. Even disposable medical supplies like gloves and sutures, condoms, and products like hospital disinfectants, are evaluated by CECMED and tested in our labs. All told, there are more than 1980 products used in our national health system that have received 5-year certification and another 1000 with temporary (2-year) certification from CECMED. We've spent extraordinary amounts of time and money training the specialists needed to ensure best practices are being met, particularly since we received $\mathrm{WHO}$ prequalification for inclusion in GAVI. Moving forward, our biotech industry continues to make new discoveries and innovations, and so CECMED has to keep pace.

Another of our responsibilities is regulation and control of all blood products, as well as the national network of blood banks and donations, plus organ transplants, and everything involving human tissues and cells-from production and storage to recertification and surveillance. These activities are related to the international regulatory standard known as 'independent lot release.' Any licensed biological product considered high-risk-including blood products and certain vaccines-is only released for use in the health system after each lot is analyzed and certified by CECMED. This involves evaluation of all the documentation and manufacturing conditions under which it was produced, including the manufacturer's summary protocols and release certificate from the corresponding foreign NRA if applicable. After individual lots receive certification, they're released for patient use, whereupon CECMED assumes a surveillance role of these lots. Given all the certifications needed for each product and process, and the international best practices to which they must conform, it's not surprising that it takes between 12 and 15 years for a new product to progress from idea to application.

\section{MEDICC Review: Cuba has a national program for integrative medicine. Are natural and traditional medicines evaluated by CECMED as well?}

Rafael Pérez Cristiá: Promoting proven natural and alternative treatments is part of our health system's long-term development and sustainability plan. We've collaborated closely with specialists from China, Vietnam and India to incorporate complementary therapies-even yoga-into clinical practice, and medicines as well. In addition to Cuba's Basic Drug List (essential medicines used in hospitals and distributed across the country in community pharmacies), we have a Natural Products Basic Drug List. Every product on this list (153 natural medicines), whether domestically produced or imported, is evaluated and certified by CECMED and passes through the same regulatory and control processes. Some natural and traditional medicines are produced on an industrial scale; those manufactured locally are tested at municipal and provincial laboratories that are inspected and certified by CECMEDagain applying all relevant international best practices-before they are sent to CECMED's lab for safety and effectiveness analysis. This certified network of local laboratories, staffed by specialists, means natural products-including, for example, cough 
syrups, propolis and other apiary-derived medicines-can be distributed to pharmacies and dispensed to the public safely and efficiently.

\section{MEDICC Review: You mention collaboration with several coun- tries. Can you elaborate on the international component of CECMED's work?}

Rafael Pérez Cristiá: In recent decades, and especially given the increasing global health burden of chronic disease, pharmaceutical and biotech industries have evolved exponentially. This has permitted the production and marketing of medicines that are safer and more effective thanks to advanced technology, manufacturing and other best practices, strict surveillance and controlled protocols. This has been fundamental in the fight against certain complex diseases, but the regulatory authority certifying these medicines must be fully integrated into the international arena if such medicines are going to reach the people who need them.

CECMED and our regulatory framework are designed to guarantee that products conform to established protocols and quality standards. Once products are certified for patient use, CECMED conducts regular surveillance to ensure they are safe and effective, and address the health problem for which they were designed and approved. Of the 761 medicines on Cuba's 2018 Basic Drug List, 273 are imported, as are $95 \%$ of all disposable and consumable medical supplies. All these products are subject to the same regulation and control for use in our health system.

We have strong, time-tested relationships with international and country NRAs, allowing us to play a dynamic role in providing access to these medicines to people around the world. Cuba currently exports pharmaceuticals and biologicals to over 50 countries, and has bilateral technology transfer agreements with many, including China, Russia and Brazil. In the latter case, technology transfer and training of local specialists allows Brazilian manufacturing facilities to produce Cuban products like recombinant human erythropoietin (developed by the Molecular Immunology Center, CIM) with the same quality, safety and effectiveness guarantee as if it were produced here, but at more affordable prices for Brazilians since it is manufactured domestically. Nevertheless, for this technology transfer to work, to assure all the necessary guarantees of safety and effectiveness, our separate NRAs needed to be on the same page, so to speak. So we developed a bilateral Regulatory Technical Committee-the first joint regulatory authority initiative of its kind in Latin America-to ensure biological standardization of Brazilian-manufactured erythropoietin.

CECMED is leaving its imprint on a global scale as well. In 2000, it was the first NRA in Latin America to receive WHO certification as qualified for vaccine regulation. This led to the aforementioned prequalification status for Cuban recombinant hepatitis $B$ vaccine for GAVI; there are two additional Cuban vaccines with prequalification status - a Haemophilus influenzae type $b$ (Hib) vaccine and the meningitis ACW-135 vaccine, developed collaboratively with Brazil. Furthermore, CECMED's Quality Management System has been certified by the Spanish Association for Standardization and Certification (AENOR), an IQnet member for the past 10 years, a certification recognized in 25 countries, including the USA and Canada; again, we were one of the first regulatory authorities in Latin America to receive this distinction.
In 2010, CECMED was certified as a PAHO Regional Reference Regulatory Authority for Medicines and Biologicals; we received Level 4 status, the highest certification. CECMED was recertified in 2016 at this level by international experts and will be re-evaluated in 2019. In 2016, CECMED also achieved observer status in the International Council for Harmonisation of Technical Requirements for Registration of Pharmaceuticals for Human Use; only two other countries in Latin America, Colombia and Mexico, share this status; Brazil is an active member. After three years in this observer role, CECMED is eligible to become an active member, requiring a rigorous review and evaluation process. Recognition by these organizations and entities-the gold standards of medicine and medical equipment regulation and control-places us in the global 'big leagues.' Several leading Cuban products are now generating considerable interest abroad, including Heberprot-P (for treatment of diabetic foot ulcer; Genetic Engineering and Biotechnology Center); CIMAvax-EGF (for non-small cell lung cancer; CIM); cancer-fighting monoclonal antibodies; and several biosimilars.

MEDICC Review: Being a small, developing country in the global 'big leagues' must come with its attendant problems. What is the biggest challenge for CECMED in the current international context?

Rafael Pérez Cristiá: One challenge we face is precisely because of our small size: with a population of just over 11 million people, it can be difficult to conduct large-scale clinical trials. Sometimes it's simply impossible to identify enough potential candidates. In these cases, we conduct multicenter trials or look for candidates outside of Cuba. These multicenter/international trials are subjected to all the necessary scientific and ethical norms, and several trials of this type are ongoing.

However, in my opinion, the greatest challenge to all NRAs not only CECMED, is where scientific innovation intersects with the administration of regulation and control. We need to change the paradigm. The speed and sophistication with which new discoveries are emerging-we're talking about a diversity of high-quality products with the potential to transform health-are outstripping the capacity of regulatory authorities to respond. Today, we're close to making major breakthroughs in the early stages of a product's development, alternatives that hold the possibility of benefitting patients, but the rigid, one-size-fits-all regulatory model means patients have to wait up to 15 years for a treatment to be approved. And of course, some can't wait. This poses the question of how to introduce flexibility without compromising rigor. To do this, the regulatory process has to be directly linked to regulatory science, with approval prerequisites and timelines taking into consideration each product's components, characteristics and possible health benefits.

This is only possible if regulatory scientists have the same level of scientific knowledge and application of best practices as the researchers making the discovery. If there isn't parity between the scientists making discoveries and the specialists evaluating and certifying their discoveries, there are going to be lengthy delays before product approval. Cuba's biotechnology portfolio and pipeline are robust, with many products and projects; as a regulatory authority, we can't be on the sidelines. To be able to respond to this demand, we have to be integrally and seamlessly inserted into the development process and policies, without compromising our integrity. $-1 /$ - 


\title{
Treatment of Basal Cell Carcinoma with Interferons Alpha-2b and Gamma in Primary Care
}

\author{
Meilyn Fernández-Martori MD MS, Iraldo Bello-Rivero MS PhD, Yaquelín Duncan-Roberts MD MS
}

\begin{abstract}
SUMMARY
INTRODUCTION Interferons have been used to treat basal cell carcinoma with positive results. Cuba's Genetic Engineering and Biotechnology Center developed HeberPAG, a combined formulation of interferons alpha- $2 b$ and gamma, for treatment of basal cell carcinoma of any size, subtype and location.

OBJECTIVE Evaluate the safety and effectiveness of using HeberPAG in primary care to treat basal cell carcinomas.

METHODS A descriptive observational study was conducted of basal cell carcinoma treated with HeberPAG. The sample comprised 21 tumors in 19 patients who met selection criteria. The dose was 3.5 million international units of antiviral activity administered by perilesional infiltration 3 times a week for 3 weeks. Clinical monitoring and laboratory testing of patients was conducted before treatment initiation and at 4, 8, 16 and 52 weeks. Variables recorded were: age, sex, skin phototype, clinical and histologic type, clinical response to treatment, changes in tumor diameters and adverse events. Four response categories were included: complete response, partial response, stable disease and progressive disease. Data were recorded in medical dossiers. Microsoft Excel and SAS were used for data management and calculation of measures of frequency, central tendency and dispersion.
\end{abstract}

RESULTS Of 19 patients studied, $63 \%$ were male, and $63 \%$ aged $61-80$ years. At 16 weeks, there was an objective response in $76 \%$ of tumors ( 8 complete and 8 partial responses). Fewer objective responses were seen in rodent ulcer, advanced invasive and sclerosing clinical types and in the sclerodermiform histologic type. Mean sum of diameters decreased from $36.9 \mathrm{~mm}$ (SD $4.1 \mathrm{~mm}$ ) to $10.3 \mathrm{~mm}$ (SD $18.3 \mathrm{~mm}$ ). One-year recurrence was $10 \%$. The most common adverse reaction was flu-like syndrome, consisting of fever, malaise, joint pain and muscle pain.

CONCLUSIONS Basal cell carcinoma can be successfully treated in primary care settings with a combination of interferons alpha- $2 \mathrm{~b}$ and gamma administered by trained personnel. At the dose employed in this study, the formulation produces a favorable response in basal cell carcinomas of low clinical and histologic risk, and is well tolerated, with only mild side effects.

KEYWORDS Basal cell carcinoma, interferons, interferon alpha- $2 b$, interferon gamma, primary care, Cuba

CONTRIBUTION OF THIS RESEARCH This study demonstrates the feasiblity of treating basal cell carcinoma in primary care settings with a combined formulation of interferons alpha- $2 b$ and gamma, enabling management in primary care of a cancer usually treated in hospital.

\section{INTRODUCTION}

Skin cancer morbidity has tripled worldwide in the last 20 years. [1] Its incidence in Cuba is increasing, with 10,432 cases in 2016, making it the most common cancer in Cuba, surpassing both prostate cancer in men and breast cancer in women.[2] The most common type is basal cell carcinoma (BCC),[3-5] a slow-growing cutaneous neoplasm with limited malignancy and low metastatic potential.[6] In 2010-2014, the Pathological Anatomy Registry at Mario Muñoz Monroy General Teaching Hospital, in the city of Colón, Matanzas Province, Cuba, received 822 pathology reports of skin cancer, of which $68.1 \%$ were BCC.

A broad range of BCC treatment options exists, although not all are available in every medical setting. Despite great efforts, it remains a challenge to find a single treatment that is ideal for every age, comorbidity, location, histologic type, tumor size and esthetic requirement, and that assures minimum recurrence. Surgery and radiotherapy are the most effective and have low recurrence rates of $3.5 \%-5 \% .[7,8]$ Traditional nonsurgical treatment modalities are 5-fluorouracil cream, cryosurgery, curettage, electrodessication, and combinations of two or more of these.[9-14] The above methods, except for radiotherapy and cryosurgery, are used in the dermatology department of the polyclinic where this study was conducted.

The Genetic Engineering and Biotechnology Center (CIGB) in Havana, Cuba developed a new formulation of interferons alpha$2 \mathrm{~b}$ and gamma called HeberPAG, for treatment of BCC of any size, subtype and location.[15-18] It was registered with Cuba's Center for State Control of Medicines, Equipment and Medical Devices on May 23, 2008 (B-08-040-L03).[19] The objective of this study is to evaluate HeberPAG's effectiveness and safety when used in routine medical practice in a primary care setting.

\section{METHODS}

Study design and population A descriptive observational study was conducted from February 1, 2013 through February 29, 2016 , of patients with histologically diagnosed BCC, treated at the provincial skin cancer clinic of the Carlos J. Finlay Polyclinic in Colón, Matanzas Province, Cuba. A dermatologist and a nurse with a degree in surgery in charge of these patients' care attended workshops on use of HeberPAG and handling of adverse events.

Included were patients aged $>18$ years, of any skin phototype, with confirmed clinical and histologic diagnosis of BCC (any clinical subtype, location, size), previously treated or not, primary or recurrent. The sample consisted of 19 participants with 21 tumors studied for one year.

Procedures and variables The study followed the Incarbacel IV clinical trial protocol,[15] which proposes a physician-selected dose of 3.5-10.5 MIU of antiviral activity. In this study, all tumors were treated with a mixture of $3.5 \mathrm{MIU}$ of interferon alpha-2b and interferon gamma. In one patient with a tumor larger than $4 \mathrm{~cm}$ (considered advanced BCC), the same dose was used, since higher doses could have compromised the patient's health. Each ampoule was diluted in one $\mathrm{mL}$ of water for injection and administered by perilesional infiltration three times a week for three weeks. Independent variables were participant age, sex, and skin phototype; and tumor clinical and histologic type. Dependent variables were clinical response to treatment 
(changes in size), laboratory results ( $\mathrm{CBC}$ and blood chemistry), tumor diameters, and adverse events at 0, 2, 3, 4, 8, 16 and 52 weeks from treatment initiation. For laboratory variables, descriptive analyses are based on the number of tumors and not on the number of patients, since recurrence implied new laboratory determinations.

To classify results, we adopted treatment response categories based on recommendations of the Response Evaluation Criteria in Solid Tumors Group.[20] The largest and smallest tumor diameters were measured and summed. Response categories were:

- complete response (CR)—total tumor disappearance,

- partial response (PR)— $\geq 30 \%$ decrease in sum of diameters,

- progressive disease $\geq 20 \%$ increase in sum of diameters,

- stable disease-insufficient decrease to qualify as partial response, or insufficient increase to qualify as progressive disease.

Two additional synthetic variables were created: objective response (CR plus $\mathrm{PR}$ ) and favorable response (CR or PR).

Any reappearance of a tumor once its disappearance had been reported by clinical observation was classified as a recurrence. Tumor evolution was assessed using clinical observation, dermatoscopy or histology.

Adverse event severity was classified as: grade 1, mild; grade 2, moderate; grade 3, hospitalization required or prolonged; grade 4, severe, with risk of disability or death; and grade 5 , death related to adverse event (from US National Cancer Institute's grading criteria for clinical and laboratory adverse events).[21] Anemia was assessed by measuring hematocrit (normal values in men: 0.40-0.50; in women, 0.37-0.45).[22]

Data management and analysis Data were compiled in a medical record and ledger created by CIGB. Microsoft Excel and SAS 9.0 were used for data storage and management, and to calculate statistical measures of frequency, central tendency and dispersion. Since a given patient could have more than one tumor, tumor number was used as the denominator for some analyses.

Ethics The study protocol was reviewed and approved by the ethics committees of the Dr Carlos J. Finlay Polyclinic and Medical University of Matanzas. The study complied with the principles of the Helsinki Declaration.[23] Written, informed consent was obtained from study participants, and study documents were stored on site at the polyclinic, along with evaluations by clinical trial monitors and sponsors.

\section{RESULTS}

Of the 19 patients studied, $12(63 \%)$ were male, and $12(63 \%)$ were aged $61-80$ years. All had white skin color, phototypes II or III. There were 21 tumors in all because 2 patients had second tumors (Table 1). Tumors were located on the head, face and neck in 16 (76\%). Among clinical types, 11 were nodular (52\%); histologically, 10 (48\%) were solid tumors (Table 1).

Figure 1 shows the distribution of mean sum of diameters in patients treated with HeberPAG, and its pattern over time. When calculating means, one outlier tumor was omitted. The minimum tumor sum
Table 1: Characteristics of patient BCCs treated with HeberPAG at Carlos Finlay Polyclinic, Colón, Matanzas, Cuba, 2013-2016

\begin{tabular}{|l|l} 
Variable & $n(\%)$
\end{tabular}

\section{Sex}

Female $\quad 7(37)$

Male

$12(63)$

Age (years) ${ }^{a}$

$<40$

41-60

$3(16)$

$61-80$

$12(63)$

$>80$

$3(16)$

Range

34-96

Mean (SD)

Skin phototype

II

III

Tumor clinical type ${ }^{b}$

Nodular

$11(52)$

Multiple superficial

Sclerosing

Rodent ulcer

Advanced invasive

Tumor histologic type

Solid

Superficial

Sclerodermiform

Unspecified

$a_{n}=19 \quad{ }^{b} n=21 \quad$ BCC: basal cell carcinoma

Figure 1: Changes in BCC size after treatment with HeberPAG $(\mathrm{n}=20)^{*}$
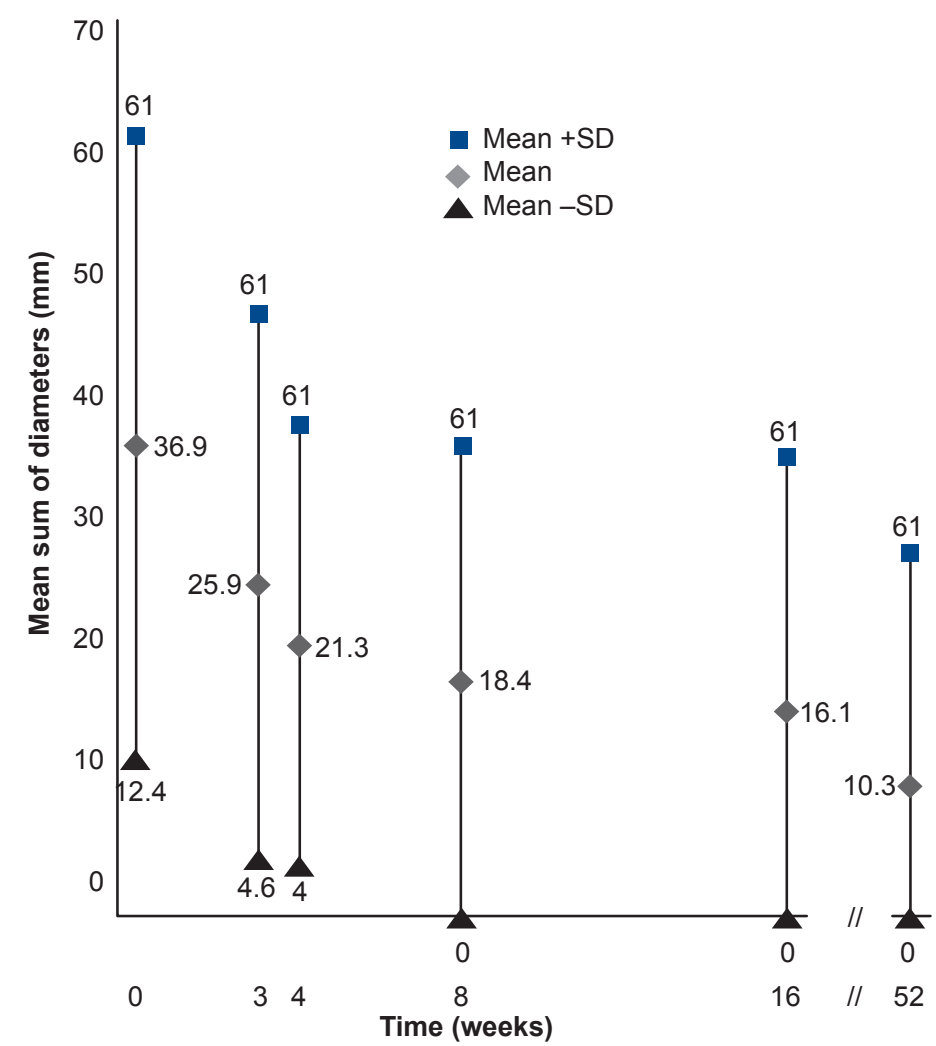

*One outlier omitted

BCC: basal cell carcinoma 
Table 2: BCC clinical response to HeberPAG at weeks 16 and 52 $(\mathrm{n}=\mathbf{2 1})$

\begin{tabular}{|l|r|r|}
\hline Response & $\begin{array}{r}\text { Week 16 } \\
\text { n (\%) }\end{array}$ & $\begin{array}{r}\text { Week 52 } \\
\text { n (\%) }\end{array}$ \\
\hline Objective (CR+PR) & $16(76)$ & $14(67)$ \\
Complete (CR) & $8(38)$ & $11(52)$ \\
\hline Partial (PR) & $8(38)$ & $3(14)$ \\
\hline Stable disease & $4(19)$ & $4(19)$ \\
Progressive disease & $1(5)$ & $1(5)$ \\
Recurrence within one year & - & $2(10)$
\end{tabular}

BCC: basal cell carcinoma

of diameters at treatment initiation was $6 \mathrm{~mm}$; maximum was 75 $\mathrm{mm}$ (the outlier measured $190 \mathrm{~mm}$ ). A decrease in mean sum of diameters was observed, from $36.9 \mathrm{~mm}$ (SD 24.1) at treatment initiation to $10.3 \mathrm{~mm}$ (SD 8.3) at week 52. Tumors disappeared in four patients, beginning in week 8 .

Table 2 shows tumor clinical response at weeks 16 and 52 after treatment initiation. Of 11 complete responses, 7 (64\%) were treated with HeberPAG alone, and 4 (36\%) also underwent surgery. Tumors classified as stable and progressive at week 16 remained in their respective categories at week 52 . Two tumors $(10 \%)$ recurred after complete clinical disappearance. One female patient with partial response at week 16 achieved complete response weeks later, and maintained that response at week 52. For patients without complete responses, we proposed a second round of the product or combining it with surgery. Four patients with partial responses decided to complete treatment with surgery. These patients were assessed one year later and had no recurrences; these were considered complete responses. The tumor classified as progressive at week 16 remained in progression at the one-year mark, and the patient died some time later. This was a recurrent, previously treated solid tumor that had first appeared over 10 years earlier; it was classified clinically as advanced invasive and had the largest sum of diameters (190 mm).

Figure 2 shows clinical response to treatment by clinical type. Nodular tumors had the greatest number of objective responses.

Figure 2: BCC response to HeberPAG at week 16 , by clinical type ( $n=21)$

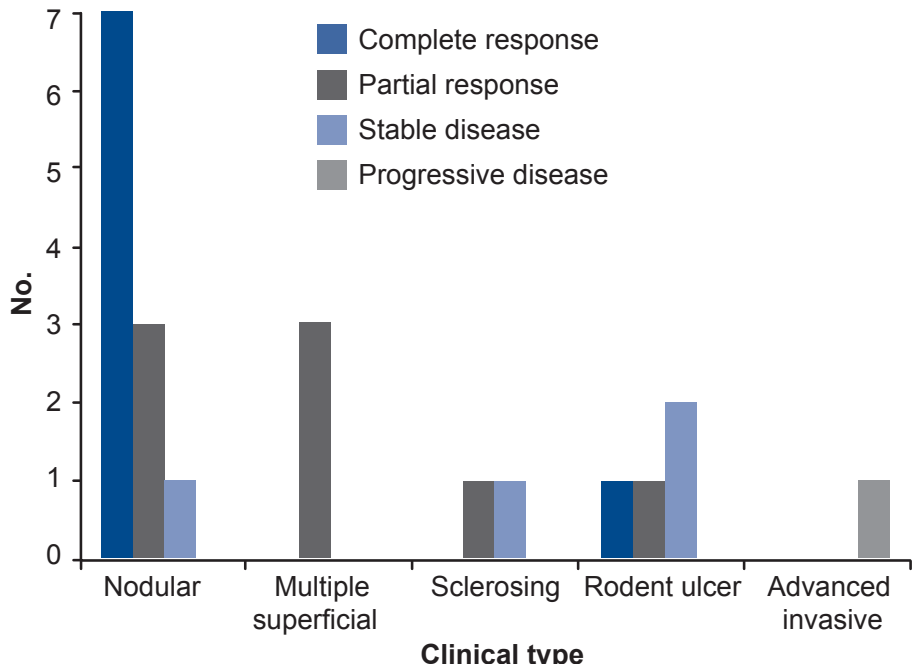

BCC: basal cell carcinoma
Figure 3: BCC response to HeberPAG at week 16, by histologic type $(n=17)^{*}$

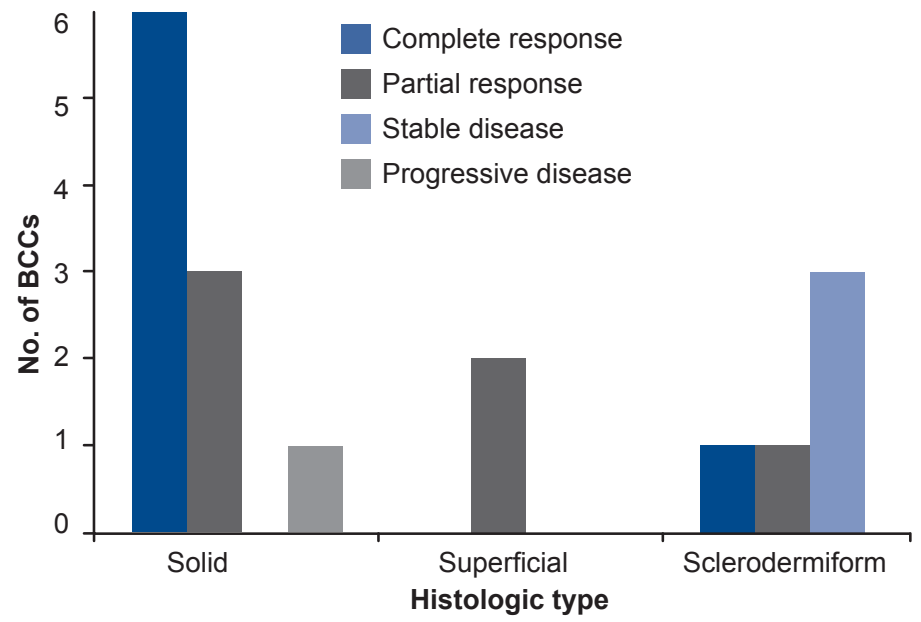

*Histologic type unspecified for 4 tumors

BCC: basal cell carcinoma

Multiple superficial BCCs responded favorably, and all tumors of this type showed partial response. Sclerosing and rodent ulcer tumors showed less response, and an advanced invasive BCC (the outlier) did not respond.

Figure 3 shows clinical response to treatment by histologic type. Solid and superficial BCCs showed mostly favorable responses. One solid tumor showed progression in a patient who had risk factors for poor prognosis. The sclerodermiform subtype remained stable in three of five tumors.

Figure 4: Adverse reactions to HeberPAG $(n=21)^{*}$

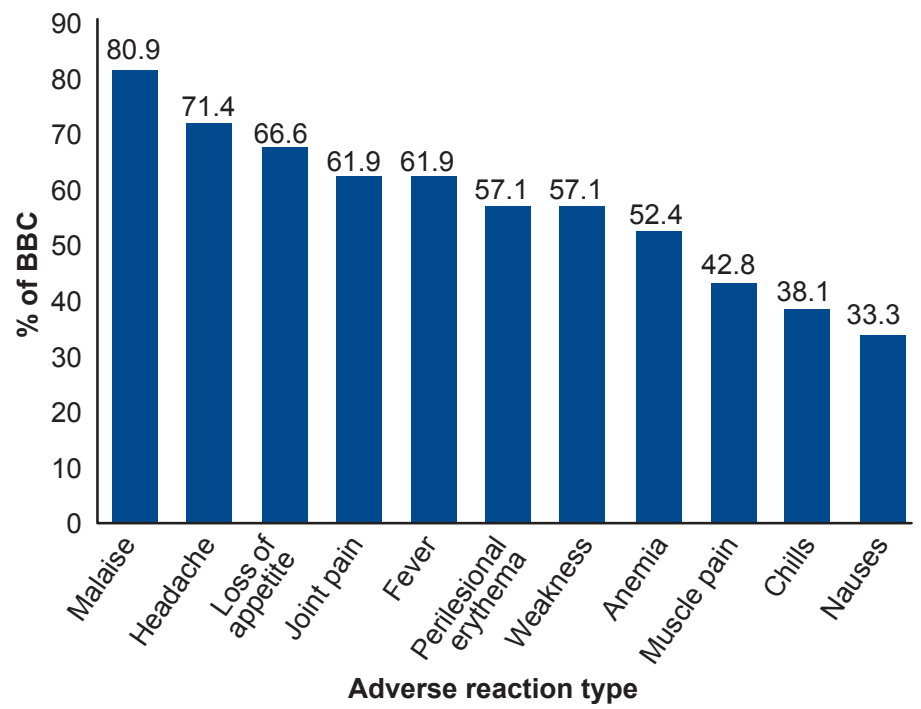

*21 tumors in 19 patients

Note: In addition, all treated patients had pain in the infiltration area.

Figure 4 shows adverse reactions to HeberPAG. Blood values were checked at each followup visit, up to week 52 . We observed below-normal hemoglobin figures in $52 \%$ of patients at week 4 , and in $43 \%$ at week 16 . Most adverse events were fleeting, appearing on day of treatment and improving within 24 hours. Once loss of appetite appeared, in most cases it persisted until one to two weeks after the last dose. All patients reported 
localized pain during infiltration. Muscle pain, chills and nausea were reported in fewer than half of patients, who were advised to take 2 dipyrone tablets and 1 diphenhydramine tablet every 12 hours while symptoms persisted.

Below-normal hematocrit values were detected in 7 patients before treatment began, with minimum values of 0.36 in women and 0.35 in men; these were cases of mild anemia, not cause for exclusion from treatment. The patient with hematocrit 0.35 was also included and received customary oral treatment with ferrous fumarate and vitamin C. After week 4 of treatment, mild anemia was found in 11 of 19 patients; in 2 patients, hematocrit could not be measured at week 4 . Of the 11 patients with mild anemia, 6 had below-normal levels before infiltration. After treatment, hematocrit values decreased in 5 patients whose initial values were normal. The lowest hematocrit measured at week 4 was 0.30 , in the same patient whose hematocrit was 0.35 before treatment. At week 16,9 patients had anemia, 8 of them mild cases, with a minimum hematocrit of 0.31 , while 1 had moderate anemia (hematocrit 0.25). Of these 9 patients, 4 had low levels before treatment, and 5 of the 11 with low levels at week 4 returned to normal values at week 16 . Of the 19 patients, 7 maintained normal hematocrit levels during the followup period, with 2 patients assessed twice (hematocrit testing was repeated in 2 patients when their second tumor was treated), for a total of 21 determinations.

\section{DISCUSSION}

Local treatment with interferon alpha-2b, an immune response modifier, has been used for low-risk BCCs. It is the most frequently used intralesionally acting molecule, with an optimal dose of $1.5 \mathrm{MIU}, 3$ times a week for 3 weeks, showing response in $80 \%-83 \%$ of small superficial and nodular BCCs. [24] It is effective in treatment of BCC and squamous cell carcinoma, with a response range of $60 \%-100 \%$ and low recurrence $(4 \%)$, although in our references, duration of response was not specified.[18,25] Feinsilber obtained $75 \%$ effective response in BCC using a 3 MIU dose of interferon alpha-2b for BCCs measuring $<2 \mathrm{~cm}$ and 5 MIU for larger tumors.[26] Since then, others have studied interferon as a BCC treatment option.[26,27]

In Cuba, use of interferon alpha-2b in BCC at a dose of 1.5 MIU 3 times a week for 3 weeks was examined in a quasiexperimental study conducted in 2012-2013 at Amalia Simoni Hospital in Camagüey province, with $70 \%$ complete response,[28] comparable to what we observed at 52 weeks.

The first results using the synergistic interferon formulation for advanced, recurrent and treatment-resistant basal cell and squamous cell carcinomas in Cuba at dosages of 3-21 MIU were published in 2009 by the National Oncology and Radiobiology Institute (INOR), Havana. Results were encouraging, with an objective response of $86.7 \%(46.7 \%$ complete and $40 \%$ partial). In patients whose tumors had infiltrated bone or other areas beyond reach of a needle, HeberPAG treatment was combined with chemotherapy.[16] These results had a clear impact, showing HeberPAG to be an excellent new adjunct treatment for BCC, with an average sustained clinical response of 38 months.[18]
HeberPAG was used in 2011-2012 in two primary care settings in rural Mayabeque Province: the Noelio Capote Polyclinic in Jaruco and the Luis Li Trejent Polyclinic in Güines.[18,25] Results from these sites are part of a retrospective study that also included patients treated at two Havana hospitals: INOR and Hermanos Ameijeiras Clinical-Surgical Teaching Hospital. All these patients had received a clinical and histologic diagnosis of periocular nonmelanoma skin tumor (BCC or squamous cell carcinoma). The study included several clinical trials administering doses from 0.875 to 27 MIU 3 times a week for 3 weeks.[18,25]

The InCarbacel II trial, a comparative clinical trial whose objective was to assess the safety and efficacy of a 1.75MIU dose of HeberPAG versus interferon alpha-2b, obtained 42.1\% CR with HeberPAG and 33.3\% CR with interferon alpha-2b. Patients treated with HeberPAG showed $C R$ one month earlier than patients treated with interferon alpha-2b alone.[15] CR was maintained for at least one year in all patients.[18] These results are similar to those of our study, which used the same treatment frequency but a higher dose.

In a patient with nodular periocular BCC diagnosed 3 years earlier, it was reported that clinical signs of the tumor disappeared after 12 weeks of treatment with HeberPAG (3.5 MIU). Dermatoscopy detected a $1-\mathrm{mm}$ remnant that was surgically excised. Investigators confirmed that HeberPAG is useful as a nonsurgical option for treatment of periocular tumors. In their opinion, this experience revealed a synergy that had not been previously observed, at a higher dose of interferon alpha-2b than proposed in the literature.[17] Rueda states that the optimal dose for treatment of superficial and small nodular BCCs is $1.5 \mathrm{MIU}$, with good cosmetic and therapeutic response of $80 \%-83 \%$,[24] although the authors of the case described above conclude that a higher dose may produce a better, faster and longer-lasting response.[17]

The InCarbacel III study, a dose-setting clinical trial of HeberPAG, reported objective responses of $93 \%$, with $60 \%$ CR for the 7-MIU dose arm, and $85 \%$ CR for the 10.5-MIU dose arm. Considering both trials, which were included in the same publication, the authors concluded that HeberPAG is useful in treating $B C C$, and that the dose eliciting the highest CR is 10.5 MIU.[15] These results of dose-setting studies were published after the product registration that guided our study, which prescribes a 3.5 -MIU dose for tumors measuring $\leq 4$ $\mathrm{cm}$ and a 10.5-MIU dose for tumors measuring $>4 \mathrm{~cm}$. $[15,18]$ In our study, we did not use a higher dose for the BCC that measured $>4 \mathrm{~cm}$, to avoid adverse reactions in that patient. At the 3.5-MIU dose, responses we obtained were similar to those observed in the InCarbacel II and III clinical trials.[18] Better responses might have been obtained had the sample been more homogeneous in tumor size and other risk factors (we treated a tumor with total sum of diameters of $190 \mathrm{~mm}$ at the same dose as tumors with total sums of diameters of 6 $\mathrm{mm}$ ). This aspect should be addressed in future studies.

The largest tumor assessed in this study demonstrates the importance of dosage. Every characteristic of the tumor indicated that it was a high-risk BCC. Its histologic type was solid, its clinical type advanced invasive (such tumors are 
known to be difficult to treat).[24] In addition to having first appeared 10 years earlier and recurring after radiotherapy, it progressed after treatment, and the patient died two years later. This type of $\mathrm{BCC}$ requires high doses of HeberPAG (10.5 MIU) in combination with an oral antineoplastic agent. It is important to assess all risk factors that may influence response to treatment. High-risk BCCs require multiple rounds of HeberPAG or larger doses, as high as $21 \mathrm{MIU} .[16,18]$

Various clinical factors have been identified in risk of recurrence. Tumor-related factors include size, location, time since appearance, clinical type, histopathologic factors (such as perineural invasion, reduced surgical margins and histologic pattern). Patient-related factors include age, sex, skin phototype, immune status and history of sun exposure). $[6,10,29]$

In our study, the two patients with recurrences had been surgically treated more than twice; their cases involved recurrent $B C C$ in high-risk locations (eyelid and nose), one with sclerodermiform histology and the other a mixed BCC with areas of squamous cell carcinoma.

These results suggest that this type of $B C C$ requires HeberPAG doses of $>3.5 \mathrm{MIU}$, and when choosing this dose, a risk factor assessment must be performed. However, one clinical trial on the product concluded that in patients with locally advanced tumors, doses of $\geq 10.5$ MIU should be used, which increase the number of objective responses, with a mean response duration of 38 months; only one patient with a CR relapsed, after 5 years of followup. These authors state that the risk of local recurrence is individual, and suggest that the low recurrence rate in patients treated with HeberPAG may be due to the potent antitumor effect of the new formulation of interferons,[16] which has synergistic antiproliferative properties.[18] Recurrence after Mohs surgery (a treatment of choice) is $6.5 \%$ after 5 years of followup, but due to its high cost, it is reserved for recurrent BCCs or high-risk facial BCCs. Vismodegib, approved for treatment of locally advanced BCCs, has a mean response duration of 7.6-9.5 months.[18,25]

It is important to assess each BCC clinical and histologic subtype to estimate its specific risk. In our study, nodular BCCs showed the best treatment response. The three superficial BCCs, which had lateral but shallow subclinical extension, showed partial response. In ulcerative or sclerosing BCCs (which have a poor prognosis and wide, deep subclinical extension) and advanced invasive BCC (especially aggressive tumors with rapid growth and invasion of deep layers) diameters showed little change, and more than half showed no favorable response. Similar patterns, dependent on the clinical nature of the tumor, have been observed in other studies.[24,30]

Nodular BCC has a good prognosis because it is the most circumscribed of all BCCs. Superficial BCCs do not invade deeper layers, but can have major subclinical lateral extension, although to a lesser extent than sclerosing BCCs. Micronodular, sclerosing and trabecular BCCs have an infiltrating growth pattern with subclinical lateral or deep extension. They are not circumscribed, and therefore have a poor prognosis.[24]
Studies published on the use of HeberPAG have not reported treatment response by clinical and histologic subtype, but there is evidence from studies conducted in Cuba using interferon alpha-2b on clinical variants. In subtypes with low clinical risk (superficial, nodular and pigmented), $70 \%$ showed objective responses (CR 60\%, PR 10\%), while in high-risk subtypes (ulcerative, infiltrative and sclerosing) only $10 \%$ showed CR.[28] These responses are similar in the histologic subtypes we have mentioned, which show the same behavior and level of aggression when assessed by clinical and histologic type.

Intralesional treatment has the advantage of achieving high local drug concentrations, with less drug entering the bloodstream than with systemic (oral or IV) therapy,[30-34] and fewer serious adverse events.[35] All adverse events reported in this study were mild, with no need to suspend treatment or lower the dose, consistent with descriptions of event type, severity and cause reported elsewhere.[16,25,28] Consistent with other authors' findings, our results indicate that the safety profile of HeberPAG is similar to that of other interferon formulations, and so can be employed in similar treatment plans and combined treatment regimens.[7,16,36,37] Premedication with dipyrone and diphenhydramine was also used in early studies of the product.[25]

In BCC, interferon alpha-2b induces an antitumor immune response that stimulates Th1 lymphocyte production and promotes formation of a peritumoral inflammatory infiltrate, mostly $\mathrm{CD} 4^{+} \mathrm{T}$ cells around tumor nests and, to a lesser extent, $\mathrm{CD}^{+} \mathrm{T}$ cells and some killer cells.[37] Interferon increases cell differentiation, has an antiproliferative effect, intensifies antitumor antigen expression, increases ICAM-1 expression, increases natural killer cell and macrophage activity, increases production of IL-1 and IL-2, lowers BCC production of IL-10, and induces tumor cell apoptosis, mediated by increased Fas receptor expression in BCC cells.[38] The combination of interferon alpha- $2 b$ and interferon gamma is intrinsically costimulating because it contains the main representatives of a Th1 response.[16,18,39] This mechanism explains why perilesional edema and erythema occur after the first infiltration and continue until the last dose; both reactions are indicators of the drug's effectiveness, and are not cause for treatment suspension.

Vismodegib and sonidegib, two of the systemic medications for advanced metastatic BCC, were approved by the US FDA in 2012 and 2015, respectively.[40,41] Both these drugs and HeberPAG are effective in treating advanced BCC; however, HeberPAG is safer because it has fewer and milder adverse effects. $[16,17]$ Severe reactions have been reported for the two systemic medications (muscle spasms, hepatotoxicity, alopecia, weight loss, fatigue and elevated creatinine).[41,42] Both systemic medications are used until tumor regression is achieved, and treatment is suspended if progression or severe toxicity is observed. Mean treatment duration for vismodegib is 7.6 months[18,41,43] and 13.9 to 18.1 months for sonidegib. $[33,40,42]$

Until recently, interferons alpha-2b and gamma were found in separate formulations. Their combined formulation is an innovative alternative. When interferon alpha- $2 b$ is given alone, 
it causes more serious adverse reactions than when combined with interferon gamma.[18]

Coadministration also improves the clinical effect of each interferon compared to separate administration, and the combined formulation has longer systemic retention and better pharmacokinetics and pharmacodynamics than interferon alpha-2b alone.[16,18,39,44]

HeberPAG is an option for tumors of any size. For large tumors, it needs to be combined with other topical or surgical treatments. It is also used for locations where surgery may compromise esthetics and function, for tumor reduction until surgical removal is possible, after surgery in patients with poor hemostasis (whether from anticoagulants or other causes) and for treatment of patients who refuse surgery.[16-18]
Small sample size was a limitation of this study. Nevertheless, it demonstrated successful treatment with HeberPAG in a primary care setting, with locally available resources and polyclinic staff trained to administer HeberPAG.

\section{CONCLUSIONS}

Basal cell carcinoma can be successfully treated in primary care settings using a synergistic combination of interferons alpha- $2 \mathrm{~b}$ and gamma administered by trained personnel. At the dose employed in this study, the formulation produces a favorable response in BCCs of low clinical and histologic risk, and is well tolerated, with only mild side effects.

\section{ACKNOWLEDGMENTS}

Our thanks to nurses Félix R. Marrero Ojito and Idania Pérez Peñalver of the Carlos J. Finlay Polyclinic in Colón, Matanzas Province, Cuba. -1 -

\section{REFERENCES}

1. Aceituno $P$, Buendía A, Arias $S$, Serrano $S$ Evolución de la incidencia del cáncer de pie en el período 1978-2002. Actas Dermosifiliogr [Internet]. 2010 [cited 2017 Dec 12];101(1):3946. Available from: https://www.ncbi.nlm.nih.gov/ pubmed/20109391. Spanish.

2. National Health Statistics and Medical Records Division (CU). Anuario Estadístico de Salud 2016 [Internet]. Havana: Ministry of Public Health (CU); 2017 [cited 2017 Apr 10]. 206 p. Available from http://files.sld.cu/dne/files/2017/05/Anuario_Esta d\%C3\%ADstico_de_Salud_e_2016_edici\% C3\%B3n 2017.pdf. Spanish.

3. Viñas García M, Algozaín Acosta Y, Álvarez Campos L, Quintana Díaz JC. Comportamiento del carcinoma basocelular facial en Artemisa durante la última década. Rev Cubana Estomato [Internet]. 2011 [cited 2016 Jan 31];48(2) Available from: http://www.bvs.sld.cu/revistas/ est/vol48_2 11/est04211.htm. Spanish.

4. Chinem VP, Miot HA. Epidemiology of basal cell carcinoma. An Bras Dermatol [Internet]. 2011 [cited 2012 Aug 1];86(2):292-305. Available from www.scielo.br/pdf/abd/v86n2/en_v86n2a13.pdf. Spanish.

5. Kyrgidis A, Vahtsevanos K, Tzellos TG, Xirou $\mathrm{P}$, Kitikidou K, Antoniades $\mathrm{K}$, et al. Clinical, histological and demographic predictors for recurrence and second primary tumours of head and neck basal cell carcinoma. A 1062 patientcohort study from a tertiary cancer referra hospital. Eur J Dermatol [Internet]. 2010 MayJun [cited 2016 Jan 31];20(3):276-82. Available from: http://www.john-libbey-eurotext.fr/medline .md?doi=10.1684/ejd.2010.0903

6. Negrín Díaz ML. Carcinoma basocelular. Dermatol Venezolana [Internet]. 2008 [cited 2016 Jan 31];46(1):4-16. Available from: http://revista svderma.org/index.php/ojs/article/view/75 Spanish.

7. Chren MM, Torres JS, Stuart SE, Bertenthal D, Labrador RJ, Boscardin WJ. Recurrence after treatment of nonmelanoma skin cancer: a prospective cohort study. Arch Dermatol [Internet]. 2011 May [cited 2016 Feb 10];147(5):540-6. Available from: https://www .ncbi.nlm.nih.gov/pmc/articles/pmid/21576572/

8. Chren MM, Linos E, Torres JS, Stuart SE, Parvataneni R, Boscardin WJ. Tumor recurrence 5 years after treatment of cutaneous basal cell carcinoma and squamous cell carcinoma. J Investigative Dermatol [Internet]. 2013 May [cited 2016 Feb 10];133(5):1188-96. Available from: https://www.ncbi.nlm.nih.gov/pmc/articles/ PMC3711403/
9. Conejo-Mir J, Conejo-Mir L. Nuevas dianas terapéuticas en carcinomas basocelulares. Med Cutan Iber Lat Am [Internet]. 2010 [cited 2015 Nov 11];38(3):105-8. Available from: www.medigraphic.com/pdfs/cutanea/mc-2010/ mc103a.pdf. Spanish.

10. Aguayo-Leiva IR, Ríos-Buceta L, JaénOlasolo P. Tratamiento quirúrgico vs. no quirúrgico en el carcinoma basocelular. Actas Dermosifiliogr [Internet]. 2010 Oct [cited 2016 Jan 31];101(8):683-92. Available from: http:// www.actasdermo.org/es/tratamiento-quirurgico -vs-no-quirurgico/articulo/S0001731010002796/. Spanish.

11. Bath-Hextall FJ, Perkins W, Bong J, Williams HC Interventions for basal cell carcinoma of the skin. Cochrane Database Syst Rev [Internet]. 2007 Jan 24 [cited 2013 Jul 19];(1):CD003412. Available from: https://dx.doi.org/10.1002/14651858.CD00 3412.pub2

12. Good LM, Miller MD, High WA. Intralesional agents in the management of cutaneous malignancy: a review. J Am Acad Dermatol [Internet]. 2011 Feb [cited 2017 Apr 23];64(2):413-22. Available from: https://linkinghub.elsevier.com/retrieve/pii// S0190-9622(09)02283-X

13. Silva Siwady JG. Principios prácticos de criocirugía. Dermatol Rev Mex [Internet]. 2013 Jan-Feb [cited 2017 Jan 25];57(1):73-7. Available from: http://www.medigraphic.com/ pdfs/derrevmex/rmd-2013/rmd131m.pdf. Spanish.

14. Gaitanis G, Alexopoulos E, Bassukas ID. Cryosurgery is more effective in the treatment of primary, non-superficial basal cell carcinomas when applied during and not prior to a five week imiquimod course: a randomized, prospective, open-label study. Eur J Dermatol [Internet]. 2011 [cited 2013 Jul 19];21(6):952-8. Available from: http://www.ncbi.nlm.nih.gov/pubmed/21926038

15. National Clinical Trials Coordination Center (CU). Registro Público Cubano de Ensayos Clínicos [Internet]. Havana: National Clinical Trials Coordination Center (CU); c2017. Combinación de los interferones en los carcinomas basocelulares (Estudio InCarbacel IV); [cited 2017 Jan 25]. Available from: http://registroclinico .sld.cu/ensayos/RPCEC00000164-Sp. Spanish.

16. Anasagasti-Angulo L, García-Vega Y, BarcelonaPérez S, López-Saura P, Bello-Rivero I. Treatment of advanced, recurrent, resistant to previous treatments basal and squamous cell skin carcinomas with a synergistic formulation of interferons. Open, prospective study. BMC Cancer [Internet]. $2009 \mathrm{Jul} 30$ [cited 2017 Apr
23];9:262. Available from: https://www.ncbi.nlm .nih.gov/pmc/articles/PMC2724551/

17. Jiménez Barbán $Y$, Vega Pupo $C$ Vila Pinillo D, Fernández Ychaso G, Arias Núñez V, Bello Rivero I. Uso de HeberPAG en carcinoma basocelular periocular. Rev Cubana Oftalmol [Internet]. 2014 Jul-Sep [cited 2017 Oct 6];27(3):482-9. Available from: http://scielo.sld .cu/scielo.php?script=sci_arttext\&pid=S0864-21 762014000300014\&Ing=es. Spanish.

18. Bello-Rivero I, García-Vega Y, Valenzuela-Silva C, Bello-Álvarez C, Vázquez-Blomquist D, LópezSaura $P$. Development of a new formulation of interferons (HEBERPAG) for BCC treatment. J Cancer Res Ther [Internet]. 2013 Dec [cited 2017 Oct 2];1(10):235-43. Available from: http:// www.nobleresearch.org/Doi/10.14312/2052-49 94.2013-36

19. Center for State Control of Medicines, Equipment and Medical Devices (CU) [Internet]. National Drug Formulary. Havana: Center for State Control of Medicines, Equipment and Medical Devices (CU); c2017 [cited 2017 Jan 27]. Available from: http://fnmedicamentos.sld.cu/ index.php?P=aplicacionAndroid. Spanish.

20. Eisenhauer EA, Therassse $P$, Bogaerts J, Schwartz LH, Sargent D, Ford R, et al. New response evaluative criteria in solid tumors. Revised RECIST guideline (versión 1.1). Eur J Cancer. 2009 Jan [cited 2017 Oct 6];45(2):22847. Available from: http://www.bioclinica.com/ assets/Uploads/recist response-evaluation.pdf

21. U.S. Department of Health and Human Resources. A Common Terminology Criteria for Adverse Events (CTCAE), Version 4.0 ( $v$ 4.03: June 14, 2010) [Internet]. Washington, D.C.: U.S. Department of Health and Human Resources; 2009 May 28 [cited 2017 Apr 23]. 194 p. Available from: https://evs.nci.nih .gov/ftp1/CTCAE/CTCAE_4.03_2010-06-14 QuickReference_5x7.pdf

22. Red Cubana de Patología Clínica [Internet]. Havana: National Medical Sciences Information Center (CU); c2017. Intervalos de Referencia, Hematología y Hemostasia Adultos; 2017 [cited 2017 Dec 18]. Available from: http://www.sld.cu/uvs/ patologiaclinica/temas. php?idv=14631. Spanish.

23. World Medical Association. Declaración de Helsinki de la AMM - Principios éticos para las investigaciones médicas en seres humanos [Internet]. 2013 [cited 2017 Apr 23]. Available from: http://www.unav.es/cdb/ammhelsinki2.html. Spanish

24. Rueda X, Acosta de Hart A, Aristizabal L, Fierro E. Guías de práctica clínica para 
el tratamiento del carcinoma basocelular. Rev Asoc Col Dermatol [Internet]. 2008 Jun [cited 2016 Jan 31];16(Suppl):102-15. Available from: http://www.imbiomed.com/1/1/ articulos.php? method=showDetail\&id_articu lo $=51979 \&$ id_seccion $=3262 \& i d \_$ejemplar $=5264$ \&id revista $=196$. Spanish.

25. García-Vega Y, Anasagasti-Angulo L, ValenzuelaSilva C, Navarro-Mestre M, Maribeth-Ordoñez $S$, Acosta-Medina D, et al. Retrospective study of periocular non melanoma skin cancer treated with the combination of IFN alfha2b and gamma (HeberPAG). J Clin Exp Ophthalmol [Internet]. 2015 Sep 26 [cited 2016 Jan 31];6(5):478. Available from: http://dx.doi.org/10.4172/2155-95 70.1000478

26. Feinsilber DG, Kogan NN, Schroh RG, Veira R. Interferón: tratamiento alternativo con infiltración intralesional en el carcinoma basocelular. Arch Argent Dermatol [Internet]. 2001 Mar-Apr [cited 2016 Feb 2];51(2):55-65. Available from: http:// pesquisa.bvsalud.org/portal/resource/es/lil -288889. Spanish.

27. Petrunin DD, Okovityı̆ SV, Kostalevskaia AV, Suchkov SV. [Approaches to immunotherapy in different immunophenotypes of cutaneous basal cell carcinoma].Vopr Onkol [Internet]. 2012 [cited 2016 Jan 31];58(3):406-12, 415. Available from: http://www.ncbi.nlm.nih.gov/pubmed/22888660. Russian.

28. Ballester Caballero $\mathrm{Y}$, Rodríguez JL, Campollo I, Cabrera M, Rojas A. Tratamiento con interferón alfa-2B recombinante en el carcinoma basocelular. Revista Electrónica de Portales Medicos.com [Internet]. 2015 [cited 2016 Feb 10];10(22):944. Available from: https://www .revista-portalesmedicos.com/revista-medica/ tratamiento-con-interferon-alfa-carcinoma-baso celular/. Spanish.

29. Ocanha JP, Dias JT, Miot HA, Stolf HO, Marques ME, Abbade LP. Relapses and recurrences of basal cell face carcinomas. An Bras Dermatol [Internet]. 2011 Mar-Apr [cited 2017 Apr 23];86(2):386-8. Available from: http://www.scielo.br/scielo.php?script=sci arttext\&pid=S0365-05962011000200032\&lng= en\&nrm=iso\&tlng=en. English, Portuguese.

30. Mosterd K, Arist AH, Thissen MR, KellenersSmeets NW. Histology-based treatment of basal cell carcinoma. Acta Derm Venereol [Internet]. 2009 [cited 2017 Apr 23];89(5):454-8. Available from: https://www.medicaljournals.se/acta/con tent/abstract/10.2340/00015555-0710

31. Danial C, Sarin KY, Oro AE, Chang AL. An investigator-initiated open-label trial of sonidegib in advanced basal cell carcinoma patients resistant to Vismodegib. Clin Cancer Res [Internet]. 2016 Mar 15 [cited 2017 Apr 23];22(6):1325-9. Available from: http:// clincancerres.aacrjournals.org/cgi/pmidlookup?vi ew=long \& pmid $=26546616$
32. Axelson M, Liu K, Jiang X, He K, Wang J, Zhao $\mathrm{H}$, et al. U.S. Food and Drug Administration approval: Vismodegib for recurrent, locally advanced, or metastatic basal cell carcinoma. Clin Cancer Res [Internet]. 2013 May 1 [cited 2017 Apr 23];19(9):2289-93. Available from: http://clincancerres.aacrjournals.org/cgi/pmidloo kup?view=long\&pmid=23515405

33. Burness CB, Scott LJ. Sonidegib: a review in locally advanced basal cell carcinoma. Target Oncol [Internet]. 2016 Apr [cited 2017 Apr 23];11(2):239-46. Available from: https://dx.doi .org/10.1007/s11523-016-0418-9

34. Keserü M, Green S, Dulz S. [Vismodegib Therapy for Periocular Basal Cell Carcinoma]. Klin Monbl Augenheilkd [Internet]. 2017 Jan [cited 2017 Apr 23];234(1):64-9. Available from: http://www.thieme-connect.com/DOI/DOI?10 .1055/s-0042-121606. German.

35. Allevato MA. Fármacos antineoplásicos cutáneos. Act Terap Dermatol [Internet]. 2008 [cited 2016 Jan 31];31:78-91. Available from: http://www.atdermae.com/pdfs/atd $31 \quad 0202$ .pdf. Spanish.

36. Silverman MK, Kopf AW, Grin CM, Bart RS, Levenstein MJ. Recurrence rates of treated basal cell carcinomas. Part 1: Overview. J Dermatol Surg Oncol [Internet].1991 Sep [cited 2016 Jan 31];17(9):713-8. Available from: https://www .ncbi.nlm.nih.gov/pubmed/?term=Recurrence+ra tes+of+treated+basal+cell+carcinomas.+Part+1 $\% 3 \mathrm{~A}+$ Overview

37. Vidal D, Matías-Guiu X, Alomar A. Open study of the efficacy and mechanism of action of topical imiquimod in basal cell carcinoma. Clin Exp Dermatol [Internet]. 2004 Sep [cited 2017 Apr 23];29(5):518-25. Available from: http:// onlinelibrary. wiley.com/resolve/openurl?genre=a rticle\&sid=nlm:pubmed\&issn=0307-6938\&date $=$ $2004 \&$ volume $=29 \&$ issue $=5 \&$ spage $=518$

38. Dai M, Wei H, Yip YY, Feng Q, He K, Popov $\mathrm{V}$, et al. Long-lasting complete regression of established mouse tumors by counteracting Th2 inflammation. J Immunother [Internet]. 2013 May [cited 2017 Apr 23];36(4):248-57. Available from: https://www.ncbi.nlm.nih.gov/pmc/articles/ $\mathrm{pmid} / 23603859 /$

39. García-Vega Y, García-García I, CollazoCaballero SE, Santely-Pravia EE, Cruz-Ramírez A, Tuero-Iglesias AD, et al. Pharmacokinetic and pharmacodynamic characterization of a new formulation containing synergistic proportions of interferons alpha-2b and gamma (HeberPAG) in patients with mycosis fungoides: an open-label trial. BMC Pharmacol Toxicol [Internet]. 2012 Dec 28 [cited 2017 Apr 23];13:20. Available from: https://www.ncbi.nlm.nih.gov/pmc/articles/ $\mathrm{pmid} / 23272809 /$

40. Jacobsen AA, Aldahan AS, Hughes OB, Shah VV, Strasswimmer J. Hedgehog pathway inhibitor therapy for locally advanced and metastatic basal cell carcinoma: a systematic review and pooled analysis of interventional studies. JAMA Dermatol [Internet]. 2016 Jul 1 [cited 2017 Apr 23];152(7):816-24. Available from: http:// jamanetwork.com/journals/jamadermatology/ fullarticle/2516221

41. Ruiz-Salas V, Alegre M, López-Ferrer A Garcés JR. Vismodegib: a review. Actas Dermosifiliogr [Internet]. 2014 Oct [cited 2017 Oct 2]:105(8):744-51. Available from: http://www .elsevier.es/en/linksolver/pdf/pii/S0001-7310 (13)00371-2. English, Spanish.

42. Kish T, Corry L. Sonidegib (Odomzo) for the systemic treatment of aults with recurrent, locally advanced basal cell skin cancer. P T [Internet]. 2016 May [cited 2017 Oct 2];41(5):322-5. Available from: https://www.ncbi.nlm.nih.gov/ pubmed/27162473

43. Edwards BJ, Raisch DW, Saraykar SS, Sun M Hammel JA, Tran HT, et al. Hepatotoxicity with Vismodegib: an MD Anderson Cancer Center and Research on Adverse Drug Events and Reports Project. Drugs R D [Internet]. 2017 [cited 2017 Oct 2];17(1):211-8. Available from: https://www .ncbi.nlm.nih.gov/pmc/articles/pmid/28063021/

44. Bello Rivero I. A synergistic immunotherapy for skin cancer [Internet]. Bristol: Scientia Global 2016 [cited 2017 Oct 2]. 3 p. Available from: http://www.scientiapublications.com/wp-content/ uploads/2016/08/Iraldo-Bello-Rivero.pdf

\section{THE AUTHORS}

Meilyn Fernández-Martori (Corresponding author: fmeilyn.mtz@infomed.sld.cu),dermatologist with a master's degree in infectious diseases. Assistant professor and adjunct researcher, Carlos J. Finlay University Polyclinic, Colón, Cuba.

Iraldo Bello-Rivero, chemist with a master's degree in chemical sciences and doctorate in biological sciences. Senior researcher, Clinical Trials Division, Genetic Engineering and Biotechnology Center (CIGB), Havana, Cuba.

Yaquelin Duncan-Roberts, physician specializing in laboratory medicine, with a master's degree in contemporary biotechnology. Adjunct researcher, Clinical Trials Division, CIGB, Havana, Cuba.

Submitted: January 18, 2017

Approved for publication: December 18, 2017 Disclosures: IBR and YDR are employees of CIGB, which developed HeberPAG, marketed as Heberferon. 


\title{
Brain Metastases in Havana Cancer Patients
}

\author{
Joel Caballero-García MD, Rosainerys Jiménez-Martínez MD, Adolfo M. Giol-Álvarez MD, \\ Mario de Jesús Caso-Cantero MD MS, Orlando Cruz-García MD PhD, Diana de los Ángeles García-López MD
}

\begin{abstract}
INTRODUCTION Cancer is a major public health problem worldwide and in Cuba. Approximately one third of cancer patients develop a brain metastasis. Despite this, epidemiological studies are scarce, internationally and in Cuba; published research is mainly limited to autopsy studies and hospital case series.
\end{abstract}

OBJECTIVE Characterize patients with brain metastases residing in Habana del Este Municipality, Havana, Cuba, with respect to demographics, metastasis location and primary tumor site.

METHODS A retrospective descriptive study was carried out with data for all patients with histologically confirmed cancer diagnosed in 2014 and registered in primary health care in Habana del Este Municipality. Diagnostic reports from computed tomography and/or magnetic resonance imaging were used to identify patients with brain metastases. Study variables were age, sex, skin color, number and location of brain metastases, control of primary tumor, and presence of extracranial metastases. Percentages were calculated and presented in tables.

RESULTS We identified 832 cancer patients in the Habana del Este population of 181,473 (prevalence 458.5 per 100,000 population)

\section{INTRODUCTION}

Cancer is a major public health problem worldwide,[1] with 17.5 million cases and 8.7 million deaths in 2015.[1,2] Approximately one third of cancer patients develop a brain metastasis (BM).[3,4] $\mathrm{BM}$ is 10 times more frequent than primary brain cancers.[5] It is the most frequent tumor of the central nervous system (CNS) and has a very poor prognosis in most cases.[5,6]

BM incidence has increased worldwide $2-5$ times in the past 40 years, despite scientific and medical advances.[5] This increase can be explained by the following: increased cancer patient survival, which gives more time for metastases to appear; $[7,8]$ improvements in diagnostic imaging with the advent of computed tomography (CT) and magnetic resonance imaging (MRI), allowing identification of increasingly smaller metastases;[9] increased lung cancer and melanoma incidence; $[6,10]$ general population aging; the fact that most systemic chemotherapeutic agents do not cross the blood-brain barrier; and finally, that some chemotherapeutics weaken this barrier, which facilitates entry of malignant cells into the CNS.[10]

According to official health statistics, cancer was the second cause of overall mortality in Cuba in 2016, with an incidence rate of 216.3 per 100,000 population,[11,12] thus a high burden of BM can be expected. Most Cuban research on the subject consists of autopsy studies and hospital case series, rather than population studies. [13-18] The most extensive study was carried out in 2014,[16] but only included patients admitted to selected hospitals, which did not permit determination of population prevalence or relative frequency of BM among cancers. After an exhaustive search of
Among patients with cancer, $27.6 \%$ (230/832) had brain tumors, among which $83 \%(191 / 230)$ were brain metastases and $17 \%$ (39/230) primary tumors, a ratio of $4.9: 1$. Brain metastases appeared in $23 \%(191 / 832)$ of cancer patients (prevalence 105.2 per 100,000 population). Among patients with brain metastases, $48.2 \%$ (92/191) were aged $41-60$ years and $61.3 \%(117 / 191)$ were female sex. The majority, $59.7 \%$ (114/191) had multiple metastases. The most frequent primary tumor location was the breast $(40.8 \%, 78 / 191)$, followed by the lung $(31.9 \% ; 61 / 191)$; $46.8 \%(211 / 451)$ of brain metastases were in the parietal lobe.

CONCLUSIONS Brain metastases are more prevalent in this Cuban municipality than reported in other countries, but they constitute a higher proportion of cancer cases than seen in other population-based studies. The study's results underline the importance of detecting brain metastasis early, to permit timely interventions to improve quality of life and survival.

KEYWORDS Cancer, neoplasm metastasis, tumor metastasis/brain, epidemiology, prevalence, Cuba

CONTRIBUTION OF THIS RESEARCH This is the first epidemiological study of brain metastases in Cuba and one of the few carried out internationally. national publications in PubMed and SciELO databases, as well as Cuba's National Cancer Registry,[12] using the search terms "brain metastasis/Cuba/epidemiology/incidence/prevalence," five articles were identified, two autopsy studies[14,15] and three hospital case series.[16-18] No population studies of BM were found.

Population studies only appear in the international literature, along with some mistakenly classified as such. For example, in 2002 an epidemiological study of BM based on hospital populations in Aragón and La Rioja, Spain, was published.[19] On the other hand, true population studies are scarce, among them Barnholtz-Sloan's 1973-2001 cohort study of 16,210 US cancer patients,[20] and Schouten's 1986-2005 cohort study in the Netherlands.[21] These two studies constitute our main external referents.

Due to the paucity of epidemiological studies on the subject, our study aimed to characterize patients with brain metastases residing in Habana del Este Municipality, in Havana, Cuba, with respect to demographic indicators, metastasis location and primary tumor.

\section{METHODS}

Study type and population A retrospective descriptive study was carried out based on data for patients residing in the municipality of Habana del Este in Havana, Cuba who were diagnosed with cancer in 2014. This municipality was selected to allow comparison with a previous study in the Luis Díaz Soto Hospital (serving a large part of the Municipality's population), which gathered the 
largest series of autopsies in Cuba.[15] In Cuba's National Health System (NHS), primary health care (PHC) is delivered in familydoctor-and-nurse offices (CMF), and multispecialty community polyclinics to which CMFs report.[22] Habana del Este has 24 polyclinics and 192 CMFs. In Cuba, cancer patients receive special diets through $\mathrm{PHC}$ and are continuously linked with CMFs in office and home visits, even while being treated in secondary or tertiary care.

Inclusion and exclusion criteria Patients with histologically confirmed cancer diagnoses, treated at any level in the NHS were included. Patients with primary hematopoietic neoplasms (leukemias, lymphomas) were excluded, since in such cases, infiltration of the leptomeninges causes BMs with different biological and pathological characteristics.

\section{Terminology}

- Patients with BM: those with imaging confirmation (CT or MRI)

- Supratentorial: located above the cerebellar tentorium

- Infratentorial: located below the tentorium

- Cortico-subcortical: located in the cerebral cortex or immediately adjacent

- Synchronous metastases: diagnosed at same time as primary tumor

- Metachronous metastases: occurring months or years after primary tumor diagnosis

\section{Variables}

- Age in years at time of BM diagnosis, grouped as categorical variable: $20-40,41-60,>60$

- Sex: male, female

- Skin color: white, black, mestizo

- Primary site: organ where primary tumor was located

- BM location: frontal, parietal, temporal, occipital lobes; cerebellum; brainstem

- Number of metastases: 1, 2-5, 6-10, >10

- Control of primary tumor: controlled, uncontrolled (with residual lesions)

- Extracranial metastases: present, absent

Data collection Initially, we visited the municipal Office of Food Supply Control (OFICODA), which distributes cancer patients' special diets, to obtain the number of patients receiving such diets, and the Municipal Health Department of Habana del Este, which maintains health statistics about its population. The number of patients with cancer was obtained from these sources, as well as data on demographics (age and sex), on diet requisitions, and the numbers of patient's CMFs and community polyclinics.

Thus, we were able to contact the corresponding CMFs by phone to obtain the remaining information needed. When this was not possible, we visited patient residences personally or contacted them by telephone. Patients with a history of BM were visited at home and clinical histories were reviewed at the clinical-surgical hospitals or the research and care institutions where they were diagnosed and treated.

From these records, information was obtained on imaging studies (CT and/or simple or contrast cranial MRI). A data collection form was used (Appendix) and data were then transferred to a Microsoft Excel 2010 table.
Analysis Cancer and BM prevalence was calculated as the number of patients diagnosed with each in 2014, over the population of Habana del Este Municipality obtained from the 2014 population and housing census $(181,473)$, multiplied by 100,000 . Relative frequency of BM for each site was calculated as the proportion of patients with BM among the total number of cancer patients for that site the same year. Data were organized in frequency distribution tables. Absolute and relative frequencies were used.

Ethics Patients with BM received all the necessary information about the study before been asked to provide written consent to participate. The study protocol was approved by the Habana del Este Municipal Health Department's Ethics Committee and authorization was obtained to access data from OFICODA. Data management procedures protected patient confidentiality.

\section{RESULTS}

There were 832 persons diagnosed with cancer in 2014, for a prevalence of 458.5 per 100,000 population; of these, $27.6 \%$ (230/832) had malignant brain neoplasms, 83\% (191/230) of which were BMs and $17 \%$ (39/230) primary, a ratio of 4.9:1. Relative frequency of BMs among all cancer patients was $23 \%$ (191/832), for a prevalence of 105.2 per 100,000 population. Melanoma had the highest relative frequency of BM, $77.4 \%$ (Table 1).

Table 1: Relative frequency of brain metastases by primary site, Habana del Este, 2014

\begin{tabular}{|l|r|}
\hline Primary cancer $(\mathbf{n})^{\mathrm{a}}$ & \multicolumn{1}{|c|}{$\begin{array}{c}\text { Brain metastasis } \\
\mathbf{n}^{\mathrm{a}} \text { (relative frequency \%) }^{\circ}\end{array}$} \\
\hline Lung (308) & $61(19.8)$ \\
\hline Breast (305) & $78(25.6)$ \\
\hline Colon (86) & $22(25.6)$ \\
\hline Other $^{\mathrm{b}}(61)$ & $3(4.9)$ \\
\hline Kidney (41) & $3(7.3)$ \\
\hline Melanoma (31) & $24(77.4)$ \\
\hline Total (832) & $191(23.0)$
\end{tabular}

apatients

Includes two patients with brain metastases from adenocarcinoma of the prostate and another from laryngeal adenocarcinoma.

The largest age group among BM patients was aged 41-60 years $(48.2 \%, 92 / 191)$; there were no patients aged $<20$ years with BM. Some $61.3 \%(117 / 191)$ of BM patients were female. Relative frequency was similar among white, black and mestizo patients (36.6\%, 29.8\% and 33.5\%, respectively). Breast and lung were the primary sites in $72.8 \%$ of BM patients, breast being the most frequent site in women $(66.7 \%, 78 / 117)$, and lung in men $(50 \%$, 37/74) (Table 2).

BMs from melanoma were more frequent in men than in women ( $28.4 \%$ vs. $2.6 \%)$. Of patients with other primary sites, two BMs originated in prostate adenocarcinoma and one in laryngeal adenocarcinoma. No association with primary site was found for age group and skin color (Table 2).

Almost half $(46.8 \%)$ of all BMs were in the parietal lobe. All BMs secondary to kidney cancer were in the cerebellum, but there was no association between location and primary site (Table 3 ). 
Table 2: Demographic characteristics of patients with brain metastases by primary site, Habana del Este, 2014

\begin{tabular}{|c|c|c|c|c|c|c|c|}
\hline \multirow{2}{*}{ Variable } & \multicolumn{6}{|c|}{ Primary site } & \multirow{2}{*}{ Total (\%) } \\
\hline & Breast & Lung & Melanoma & Colon & Kidney & Other* & \\
\hline \multicolumn{8}{|c|}{ Age group } \\
\hline $20-40$ & 3 & 12 & 17 & 0 & 0 & 0 & $32(16.7)$ \\
\hline $41-60$ & 36 & 27 & 7 & 17 & 3 & 2 & $92(48.2)$ \\
\hline$>60$ & 39 & 22 & 0 & 5 & 0 & 1 & $67(35.1)$ \\
\hline \multicolumn{8}{|l|}{ Sex } \\
\hline M & 0 & 37 & 21 & 10 & 3 & 3 & $74(38.7)$ \\
\hline $\mathrm{F}$ & 78 & 24 & 3 & 12 & 0 & 0 & 117 (61.3) \\
\hline \multicolumn{8}{|c|}{ Skin color } \\
\hline White & 30 & 18 & 10 & 9 & 2 & 1 & $70(36.6)$ \\
\hline Mestizo & 25 & 24 & 8 & 6 & 0 & 1 & $64(33.5)$ \\
\hline Black & 23 & 19 & 6 & 7 & 1 & 1 & $57(29.8)$ \\
\hline Total (\%) & $78(40.8)$ & 61 (31.9) & 24 (12.6) & $22(11.5)$ & $3(1.6)$ & $3(1.6)$ & $191(100.0)$ \\
\hline
\end{tabular}

*Includes two patients with brain metastases from adenocarcinoma of the prostate and another from laryngeal adenocarcinoma

Table 3: Location of intracranial brain metastases by primary site, Habana del Este, $2014(n=451)^{a}$

\begin{tabular}{|c|c|c|c|c|c|c|c|}
\hline \multirow[b]{2}{*}{ Location } & \multicolumn{6}{|c|}{ Primary site } & \multirow{2}{*}{$\begin{array}{c}\text { Distribution } \\
\text { by location } \\
\mathbf{n}(\%)\end{array}$} \\
\hline & $\begin{array}{c}\text { Breast } \\
n=202\end{array}$ & $\begin{array}{c}\text { Lung } \\
n=107\end{array}$ & $\begin{array}{c}\text { Melanoma } \\
n=114\end{array}$ & $\begin{array}{l}\text { Colon } \\
n=22\end{array}$ & $\begin{array}{c}\text { Kidney } \\
n=3\end{array}$ & $\begin{array}{l}\text { Otherb }^{b} \\
n=3\end{array}$ & \\
\hline \multicolumn{8}{|c|}{ Supratentorial } \\
\hline Frontal & $39(19.3)$ & $6(5.6)$ & $47(41.2)$ & 0 & 0 & 0 & $92(20.4)$ \\
\hline Parietal & $88(43.6)$ & $51(47.7)$ & 50 (43.9) & $19(86.4)$ & 0 & $3(100.0)$ & 211 (46.8) \\
\hline Temporal & $27(13.7)$ & $5(4.7)$ & $16(14.0)$ & 0 & 0 & 0 & 48 (10.6) \\
\hline Occipital & $32(15.8)$ & $34(81.8)$ & $1(0.9)$ & 0 & 0 & 0 & $67(14.9)$ \\
\hline \multicolumn{8}{|c|}{ Infratentorial } \\
\hline Cerebellum & $14(6.9)$ & $9(8.4)$ & 0 & $3(13.7)$ & $3(100.0)$ & 0 & $29(6.4)$ \\
\hline Brainstem & $2(1.0$ & $2(1.9)$ & 0 & 0 & 0 & 0 & $4(0.9)$ \\
\hline
\end{tabular}

aSome patients had $>1$ metastasis

bIncludes two patients with brain metastases from adenocarcinoma of the prostate and another from laryngea adenocarcinoma.

Table 4: Number of patients with brain metastases by primary site, $2014(n=191)$

\begin{tabular}{|c|c|c|c|c|c|c|c|}
\hline \multirow{2}{*}{$\begin{array}{l}\text { Metastasis } \\
\text { n }\end{array}$} & \multicolumn{6}{|c|}{ Primary site (\%) } & \multirow[b]{2}{*}{ Total (\%) } \\
\hline & $\begin{array}{l}\text { Breast } \\
n=78\end{array}$ & $\begin{array}{l}\text { Lung } \\
n=61\end{array}$ & $\begin{array}{c}\text { Melanoma } \\
n=24\end{array}$ & $\begin{array}{l}\text { Colon } \\
n=22\end{array}$ & $\begin{array}{c}\text { Kidney } \\
n=3\end{array}$ & $\begin{array}{l}\text { Other* } \\
n=3\end{array}$ & \\
\hline 1 & $18(23.1)$ & $28(45.9)$ & $3(12.5)$ & $22(100.0)$ & $3(100.0)$ & $3(100.0)$ & $77(40.3)$ \\
\hline $2-5$ & $55(70.5)$ & $22(36.1)$ & 21 (87.5) & 0 & 0 & 0 & $98(51.3)$ \\
\hline $6-10$ & $4(5.1)$ & $10(16.4)$ & 0 & 0 & 0 & 0 & $14(7.3)$ \\
\hline$>10$ & $1(1.3)$ & $1(1.6)$ & 0 & 0 & 0 & 0 & $2(1.0)$ \\
\hline
\end{tabular}

*Includes two patients with brain metastasis from adenocarcinoma of the prostate and another from laryngeal adenocarcinoma.

In $59.6 \%$ of BM patients there were multiple lesions, the majority $(91.6 \%)$ having $<6$. All BMs of colon, kidney and "other" sites were solitary (Table 4).

Residual lesions in the primary site were observed in 98 patients $(51.3 \%)$, despite cancer treatment, while 87 (45.5\%) had extracranial metastases.

\section{DISCUSSION}

True BM prevalence is difficult to determine in clinical and hospital series, since many metastases are not diagnosed during life and autopsy studies have selection biases; hospitalized patients are not necessarily representative of the population. Not all patients diagnosed with BM are admitted to a hospital or brought to autopsy.
That motivated our population-wide study, which is more reliable, has fewer biases and is more representative of the population. The data source, OFICODA, is highly reliable, because virtually all cancer patients receive the special diets it distributes. Data capture methods employed cannot guarantee $100 \%$ coverage or biasfree information, but data are more complete than would be obtained in hospital or autopsy-based studies. Furthermore, the retrospective design allowed us to obtain and process selected variable data in a relatively brief time.

The relative frequency of $\mathrm{BM}$ in cancer patients $(23 \%)$ is in the range found by Grossman (10\%-40\%),[3] but higher than in epidemiological studies by Barnholtz-Sloan and Schouten, in which prevalence for all primary sites combined was 9.6\%[20] and $8.5 \%,[21]$ respectively. However, these two studies included only certain cancers (lung, breast, melanoma, colorectal and kidney). In most cancer patients, routine imaging studies are not performed, and many metastases may remain asymptomatic; therefore, theoretically the true prevalence of BM is greater than that found in epidemiological studies.

Of the two epidemiological studies we retrieved, Schouten did not examine skin color,[21] while Barnholtz-Sloan observed significantly higher incidence proportions in African Americans compared with white patients for lung, melanoma and breast cancer; similar for colon cancer; and lower for renal cancer.[20] We were unable to stratify all cancer patients by skin color and calculate comparative BM risk from relative frequency, which excludes any reliable inference about an association between skin color and BM risk. However, skin color distribution in $\mathrm{BM}$ cases is not suggestive of an association.

BM constitutes a high proportion of CNS neoplasms in autopsy studies, surpassing primary brain neoplasms by $10: 1,[5,6]$ double what we observed. This could be explained by differences, discussed earlier, between population studies and hospital case series and autopsy studies. In Cuba (as elsewhere), underdiagnosis or underregistration of metastases may reduce numbers seen in population studies, while autopsy studies may be able to detect even micrometastases.

BM patients are usually older, with peak incidence between ages 50 and 60 years,[5] in keeping with the higher frequency of cancer 
in these age groups. Thus, the predominance of age $>40$ years in our study is not surprising.

BM incidence tends to be similar for men and women, with slight predominance in men, (except for breast cancer, which is very rare in men).[6] The predominance of women in the BM group we studied reflects the high numbers of breast cancers and small numbers of cancers that are more frequent in men, such as prostate and colon cancers.

Some neoplasms tend to develop brain metastases more than others. The "seed and soil" hypothesis describes one possible biological mechanism, that some neoplasms tend to develop metastases in certain target organs through molecular mediators and membrane receptors.[23-26] Testicular cancer, melanoma, lung cancer and renal cell carcinoma display the greatest propensity for BM, in order of frequency.[15] On the other hand, other lesions such as prostate and stomach cancer rarely metastasize to the brain.[14,15] The high relative frequency of BM we observed for melanoma is consistent with reports from other authors.[20,21]

The lung is the most common primary site for BM in most hospital and pathology series[14,15,17] and in epidemiological studies. $[20,21]$ This is reflective of its higher incidence as primary tumor as well as its propensity to metastasize. In two autopsy studies of Cuban adults, the most frequent origins of BM were lung cancer $(50 \%-60 \%)$, breast cancer $(15 \%-20 \%)$, skin cancer $(5 \%-10 \%)$ and cancers of the GI tract $(4 \%-6 \%)$. $[14,15]$

However, in our study, breast was the predominant site for BM, followed closely by lung cancer. This phenomenon could be explained by the high proportion of breast cancer patients with BM found in the study population, perhaps related to the current low survival of patients with lung cancer compared with those of breast cancer, who experience longer survival thanks to advances in early diagnosis and current therapies that increase time available for metastasis to occur.[26,27] Interestingly, there were only 3 more cases of lung cancer than there were of breast cancer in our series; in 2013, there were 5722 new cases of lung cancer and $<4000$ new cases of breast cancer in Cuba.[11] This difference could also reflect lower lung cancer survival, since our series examined prevalent cases.

Our findings regarding BM location are consistent with observations elsewhere that most BMs are supratentorial. Between $60 \%$ and $80 \%$ of intracranial metastases are supratentorial, with $20 \%-40 \%$ infratentorial $(15 \%$ cerebellum and $5 \%$ brainstem).[6] Cortico-subcortical location in the frontal, parietal and temporal lobes has been explained by vascular and molecular factors, since it is the distribution area of the middle cerebral artery, which has the largest caliber of terminal branches of the internal carotid artery. Thus, tumor emboli are more likely to be directed to this artery.[6,25]

Adenocarcinoma of the breast and colon, renal cell carcinoma and thyroid carcinoma are known to produce single BMs, while melanoma and lung cancer tend to produce multiple BMs.[6] In Cuban autopsy studies, more than half of cancer patients have single metastases.[14,15] While single BMs were frequent in our study, most frequent were patients with 2-5 lesions. International research reports frequent multiple BMs in breast cancer, partly because longer survival provides more time for patients to accumulate risk of new metastases.[26] Also, the brain is a propitious location for breast cancer cells, since BMs are not affected by chemotherapeutic agents and monoclonal antibodies, principally because of the blood-brain barrier. Patients with HER2 positive and triple-negative breast cancer (negative for estrogen, progesterone and HER2 receptors) have increased BM risk.[28,29]

Treatment with trastuzumab has been shown to act on extracranial metastases, but not on intracranial ones, thereby "unmasking" the latter.[30,31] Our retrospective design and limited available data prevented us from obtaining insights on this point.

In our series, multiple breast metastases predominated, more than half of breast cancer patients having oligometastasis. Oligometastasis may have a better prognosis than a larger number of lesions, if the primary lesion is controlled and metastases treated focally.[8,30,32] Some authors arbitrarily use the term "extensive metastases" to refer to presence of $\geq 10$ metastases.[25,27,28] In our series, only two patients, having primary breast and lung cancer, respectively, were found with $\geq 10$ lesions.

Just over half of patients had uncontrolled primary cancer and almost half had extracranial metastasis, something that has not been reported in previous Cuban studies.[14,15] This substantially worsens their prognosis, because an uncontrolled primary lesion limits options for specific BM treatment.[29] In Nieder's study, $32 \%$ of patients had uncontrolled primary disease (consistent with our study) and $77 \%$ had extracranial metastasis,[6] a higher percentage than we found.

Our results are useful as a starting point to approach BM as a health problem. However, they should be interpreted cautiously, because of some study limitations. In the first place, this was a descriptive retrospective study, without control of relevant variables that can be assessed in prospective studies, such as overall survival, local control and disease-free survival. In addition, because the study was based on administrative data, it could not have the rigorous data standardization of a clinical research study. For example, when contrast media were not available, imaging results could have been subject to bias, if some metastases were missed.

Furthermore, data on disease states at the municipal level might not be representative of the national situation. Presence of asymptomatic metastases can lead to underestimates of true prevalence in population studies, while at the same time, there can be false positives because of concomitant nonmetastatic lesions. Nonetheless, the advantage goes to population-based studies over autopsy series or hospital studies, for the reasons enumerated earlier.

A highly developed PHC system in Cuba, based on CMFs reporting to community polyclinics, ensures that medical attention and services are accessible to the entire population. There have been advances in complementary detection methods with increasingly higher sensitivity and specificity and increasingly targeted therapies (such as radiosurgery). Deployment of BM imaging studies in cancer patients on an epidemiological scale has 
an unacceptably high cost-benefit ratio.[5] Together these factors tend to reduce the role of $\mathrm{PHC}$ in early detection of metastases.

Nevertheless, early neurological BM signs might be detectable in $\mathrm{PHC}$ if physicians maintain a sufficiently high index of suspicion. Such timely detection could lead to earlier referral to other care levels for confirmation and interventions to improve quality of life and survival.

\section{CONCLUSIONS}

Brain metastases are more prevalent in this Cuban municipality than reported in other countries, but they constitute a higher proportion of cancer cases than seen in other population-based studies. The study's results underline the importance of detecting brain metastasis early, to permit timely interventions to improve quality of life and survival. -1 .

\section{APPENDIX: DATA COLLECTION FORM}

General information
Name_al history
Clinical
Age__
Sex
Pkin color
Primary tumor
Organ/site
Histological type
Number of extracranial metastases_
Control: Controlled__ Not controlled

Brain metastasis

Number of metastases

Location
M1
M2
M3
M4
M5
M6
M7
M8
M9
M10

\section{REFERENCES}

1. Horton S, Gauvreau CL. Cancer in Low- and Middle-Income Countries: An Economic Overview. In: Gelband H, Jha P, Sankaranarayanan R, Horton S, editors. Cancer: Disease Control Priorities. Vol 3. 3rd ed. Washington, D.C.: The International Bank for Reconstruction and Development / The World Bank; 2015 Nov 1 [updated 2016 Jul 31; cited 2017 Feb 1]. Available from: http://www .ncbi.nlm.nih.gov/books/NBK343620/

2. GBD 2015 Mortality and Causes of Death Collaborators. Global, regional, and national life expectancy, all-cause mortality, and causespecific mortality for 249 causes of death, 1980-2015: a systematic analysis for the Global Burden of Disease Study 2015. Lancet. 2016 Oct 8;388(10053):1459-544.

3. Grossman R, Mukherjee D, Chang DC, Purtell $\mathrm{M}$, Lim M, Brem $\mathrm{H}$, et al. Predictors of inpatient death and complications among postoperative elderly patients with metastatic brain tumors. Ann Surg Oncol. 2011 Feb;18(2):521-8.

4. Stanford J, Gardner S, Schwartz M, Davey P. Does the surgical resection of a brain metastasis alter the planning and subsequent local control achieved with radiosurgery prescribed for recurrence at the operated site? Br J Neurosurg. 2011 Aug:25(4):488-91.

5. Tabouret E, Bauchet L, Carpentier AF. Brain metastases epidemiology and biology. Bull Cancer. 2013;100(1):57-62.

6. Nieder C, Spanne O, Mehta MP, Grosu AL, Geinitz $H$. Presentation, patterns of care and survival in patients with brain metastases: what has changed in the last 20 years? Cancer. 2011 Jun 1;117(11):2505-12

7. Platta CS, Khuntia D, Mehta MP, Suh JH. Current treatment strategies for brain metastasis and complications from therapeutic techniques: a review of current literature. Am J Clin Oncol. 2010 Aug;33(4):398-407.

8. Niibe Y, Chang JY. Novel Insights of Oligometastases and Oligo-Recurrence and Review of the Literature. Pulmonary Med [Internet]. 2012 Jul [cited 2014 Dec 21];2012(Art 261096):1-5. Available from: http://www.hindawi.com/journals/ pm/2012/261096/cta/
9. Kienast $\mathrm{Y}$, von Baumgarten L, Fuhrmann M, Klinkert WE, Goldbrunner R, Herms J, et al. Real-time imaging reveals the single steps of brain metastasis formation. Nat Med. 2010 Jan;16(1):116-22.

10. Davies MA, Liu P, McIntyre S, Kim KB, Papadopoulos N, Hwu WJ, et al. Prognostic factors for survival in melanoma patients with brain metastases. Cancer. 2011 Apr 15;117(8):1687-96.

11. National Health Statistics and Medical Records Division (CU). Anuario Estadístico de Salud 2016 [Internet]. Havana: Ministry of Public Health (CU); 2017 [cited 2017 May 20]. 206 p. Available from: http://files.sld.cu/dne/files/2017/05/Anuario Estad\%C3\%ADstico_de_Salud_e_2016_edici \%C3\%B3n_2017.pdf. Spanish.

12. Ministry of Public Health (CU). Registro Nacional del Cáncer [Internet]. Havana: National Medical Sciences Information Center (CU); c19992017 [updated 2016 Apr 2; cited 2017 May 2]. Available from: http://instituciones.sld.cu/sicc/ registro-nacional-del-cancer/. Spanish.

13. Cruz García O, Caballero García J, Salas Rubio JH. Para cambiar la percepción ante las metástasis encefálicas en Cuba. Rev Cubana Neurol Neurocir. 2014;4(2):103-4. Spanish.

14. Caballero García J, Felipe Morán A, Toledo Valdés $\mathrm{C}$, Pérez La O P, Morales Pérez I. Consideraciones anatomopatológicas y demográficas de la metástasis intracraneal. Rev Cubana Neurol Neurocir. 2012;2(1):23-7. Spanish.

15. Caballero García J, de Mendoza Amat JH, Cruz García O, Montero González TJ, Felipe Morán A. Características de la metástasis intracraneal en 14321 autopsias realizadas en el Hospital "Dr. Luis Díaz Soto", La Habana (1962-2011). Rev Cubana Neurol Neurocir. 2013 JulDec;3(2):132-8. Spanish.

16. Chi Ramírez D, Forteza Sáez M, Galán Álvarez Y, Chon Rivas I, Ortiz Reyes RM, Caballero García J. Mortalidad por metástasis encefálica (La Habana, 2006-2008). Rev Cubana Neurol Neurocir. 2014 Jul-Dec;4(2):109-16. Spanish.

17. Caballero García J, Cruz García $O$, Morales Pérez I, Pérez La O P, Hernández Díaz Z, Salazar Rodríguez S. Características clínicas y de neuroimagen de las metástasis cerebrales. Rev
Cubana Neurol Neurocir. 2015 Jan-Jun;5(1):512. Spanish

18. Lacerda Gallardo AJ, Borroto Pacheco R. Metástasis cerebral: estudio clínico-quirúrgico y anatomopatológico. Rev Cubana Cir. 2000 Aug [cited 2015 Jan 22];39(2):103-7. Available from: http://neuroc99.sld.cu/text/metastasis.htm\#up. Spanish.

19. Pascual Piazuelo MC, Bestué M, Serrano Ponz M, Montori-Lasilla M. Estudio epidemiológico de las metástasis cerebrales en Aragón y La Rioja. Rev Neurol. 2002 May 1-15;34(9):897-8.

20. Barnholtz-Sloan JS, Sloan AE, Davis FG, Vigneau FD, Lai P, Sawaya RE. Incidence proportions of brain metastases in patients diagnosed (1973 to 2001) in the Metropolitan Detroit Cancer Surveillance System. J Clin Oncol. 2004 Jul 15;22(14):2865-72.

21. Schouten LJ, Rutten J, Huveneers HA, Twijnstra A. Incidence of brain metastases in a cohort of patients with carcinoma of the breast, colon, kidney, and lung and melanoma. Cancer. 2002 May 15;94(10):2698-705.

22. Sánchez Jacas I. La planeación estratégica en el Sistema Nacional de Salud cubano. MEDISAN. 2017 May;21(5):635-41. Spanish.

23. Jackson JE, Burmeister BH, Burmeister EA, Foote MC, Thomas JM, Meakin JA, et al. Melanoma brain metastases: the impact of nodal disease. Clin Exp Metastasis. 2014 Jan;31(1):81-5.

24. Hauswald H, Dittmar JO, Habermehl D, Rieken S, Sterzing F, Debus J, et al. Efficacy and toxicity of whole brain radiotherapy in patients with multiple cerebral metastases from malignant melanoma. Radiat Oncol. 2012 Aug 2;7:130.

25. Vermeulen L, de Sousa e Melo F, Richel DJ, Medema JP. The developing cancer stem-cell model: clinical challenges and opportunities. Lancet Oncol. 2012 Feb;13(2):e83-9.

26. Kondziolka D, Kalkanis SN, Mehta MP, Ahluwalia M, Loeffler JS. It is time to reevaluate the management of patients with brain metastases. Neurosurgery. 2014 Jul;75(1):1-9.

27. Dziggel L, Segedin B, Podvrsnik NH, Oblak I, Schild SE, Rades D. A survival score for 
patients with brain metastases from less radiosensitive tumors treated with wholebrain radiotherapy alone. Strahlentherap und Onkolog. 2014 Jan;190(1):54-8.

28. Murrell DH, Foster PJ, Chambers AF. Brain metastases from breast cancer: lessons from experimental magnetic resonance imaging studies and clinical implications. J Mol Med. 2014 Jan;92(1):5-12.

29. Jenkinson MD, Haylock B, Shenoy A, Husband D, Javadpour M. Management of cerebral metastasis: Evidence-based approach for surgery, stereotactic radiosurgery and radiotherapy. Eur J Cancer. 2011 Mar:47(5):649-55.

30. Carlson JA, Nooruddin Z, Rusthoven C, Elias A, Borges VF, Diamond JR, et al. Trastuzumab emtansine and stereotactic radiosurgery: an unexpected increase in clinically significant brain edema. Neuro Oncol. 2014 Jul;16(7):1006-9.

31. Senkus E, Cardoso F, Pagani O. Time for more optimism in metastatic breast cancer? Cancer Treat Rev. 2014 Mar;40(2):220-8.
32. Marchetti M, Milanesi I, Falcone C, De Santis $M$, Fumagalli L, Brait L, et al. Hypofractionated stereotactic radiotherapy for oligometastases in the brain: a single-institution experience. Neurol Sci. 2011 Jun;32(3):393-9.

\section{THE AUTHORS}

Joel Caballero-García (Corresponding author: joelcg@infomed.sld.cu), physician with dual specialties in family medicine and neurosurgery, National Oncology and Radiobiology Institute (INOR), Havana, Cuba.

Rosainerys Jiménez-Martínez, family medicine resident, Wilfredo Santana Rivas Polyclinic, Habana del Este, Havana, Cuba.

Adolfo M. Giol-Álvarez, physician with dual specialties in family medicine and neurosurgery, Juan Manuel Márquez Pediatric Teaching Hospital, Havana, Cuba.
Mario de Jesús Caso-Cantero, internist with a master's degree in infectious diseases. Assistant professor, Gregorio Valdés Cruz Polyclinic, Habana del Este, Havana, Cuba.

Orlando Cruz-García, neurosurgeon with a doctorate in medical sciences. Full professor and senior researcher, INOR, Havana, Cuba.

Diana de los Ángeles García-López, physician specializing in anesthesiology and resuscitation, Ramón González Coro University Maternity Hospital, Havana, Cuba.

Submitted: January 18, 2017

Approved for publication: October 30, 2017 Disclosures: None

\title{
Science, Nature and Tradition for Life
}

\author{
International Congress on Natural and Traditional Medicine \\ September 3-7, 2018 \\ Havana's International Convention Center
}

Topics include acupuncture, ethnomedicine, homeopathy, flower therapy, traditional exercise therapy and more.

Sessions will explore scientific, regulatory, marketing and health system aspects.

Sponsor: Cuban Society of Natural and Bioenergetic Medicine

Languages: Spanish, English

Information: evelyna@infomed.sld.cu 


\title{
Liver Stiffness Reference Values for Healthy Cuban Adults
}

\author{
Ángela Elvírez-Gutiérrez MD MS, Marlén I. Castellanos-Fernández MD, Wendy Santillán-López MD, \\ Zaily Dorta-Guridi MD PhD, Enrique Galbán-García MD PhD, Enrique Arús-Soler MD PhD
}

\begin{abstract}
INTRODUCTION Reference values for liver stiffness for healthy individuals vary worldwide. Different optimal cutoff values correspond to the stages of fibrosis in chronic liver disease.

OBJECTIVES Characterize the distribution of liver stiffness in Cuban adults without liver disease and its association with age, serum uric acid and body mass index.

METHODS A cross-sectional study was performed of 110 plasma donors recruited from the Havana Province Blood Bank January 2016 through February 2017. Measurements of liver stiffness were performed using a FibroScan elastography device on the same day of laboratory analyses and abdominal ultrasound. The Pearson coefficient was used to assess correlations, and the reference range was calculated using the mean and its $95 \%$ confidence interval.
\end{abstract}

RESULTS Liver stiffness values observed ranged from $2.2-6.3 \mathrm{kPa}$ The reference range $(95 \% \mathrm{Cl})$ for the 110 subjects without known liver disease was 4.2-4.6 kPa (mean 4.4). A positive correlation was observed between liver stiffness measurements and body mass index $(r=0.255, p<0.01)$ and serum uric acid $(r=0.266, p<0.01)$. There was no correlation between liver stiffness and age. Liver stiffness in women was similar to that of men, $4.3(2.4-6.1)$ and $4.5(2.2-6.3) \mathrm{kPa}$, respectively $(p=0.086)$.

CONCLUSIONS Liver stiffness in Cuban adults without liver disease ranges from $2.2-6.3 \mathrm{kPa}$. The reference range is $4.2-4.6 \mathrm{kPa}$. Body mass index and serum uric acid levels are positively associated with liver stiffness.

KEYWORDS Liver disease, liver fibrosis, hepatic cirrhosis, hepatic fibrosis, diagnostic imaging, elastography, sonoelastography, elasticity imaging techniques, tissue elasticity imaging, technology assessment, Cuba

CONTRIBUTION OF THIS RESEARCH This is the first Cuban study using FibroScan to measure liver stiffness; its results will enable better assessment of liver disease in clinical practice.

\section{INTRODUCTION}

Chronic liver disease is an important health problem globally, with worldwide distribution independent of age, sex, region or race. Cirrhosis is the end result of a variety of liver diseases characterized by fibrosis and architectural distortion of the liver with formation of regenerative nodules. It has varying clinical manifestations and complications.

Globally, deaths from liver cirrhosis increased from about 676,000 in 1980 to more than $1,000,000$ in 2010 ,[1] and by $10.3 \%$ between 2005 and 2015.[2] A systematic analysis from the 2015 Global Burden of Disease study estimated deaths from liver cancer and liver cirrhosis in four etiologic categories: hepatitis $B$ virus (HBV) infection, hepatitis $\mathrm{C}$ virus $(\mathrm{HCV})$ infection, alcohol and "other." Viral hepatitis accounts for $53 \%$ of liver cirrhosis and $54 \%$ of liver cancers.

In Cuba, liver cirrhosis and other chronic liver diseases have been increasing. In 2016 they were the ninth cause of death, with a rate of 8.8 per 100,000 inhabitants, 3.6 times higher for men than for women.[3]

Fibrosis represents the histologically apparent final result of a liver healing response, to repair tissue damaged by chronic injury. The degree of fibrosis indicates the severity of liver disease. Different causes of chronic liver injury share similar fibrogenic mechanisms; the morphological pattern of fibrosis is related to the underlying disease because it reflects the topographic distribution of liver damage.[4]

The gold standard for diagnosing liver damage, including fibrosis, is liver biopsy. Histology is fundamental to assessment and management of patients with liver disease, and has long been considered an integral component of clinical diagnosis. However, it has little acceptance among patients because it is painful and invasive, and involves risk of complications such as bleeding and even death. Liver biopsy technique requires specific training to ensure collection of appropriately sized samples and the lowest possible complication rate. Sample variability is one of the main limitations of liver biopsy and it is not useful for performing periodic repeated followup assessments.[5-7]

Although histological findings are important for assessing prognosis and adapting treatment, noninvasive techniques may replace liver histology for these purposes, especially for assessing fibrosis severity. Measurement of liver stiffness (LS) using transient elastography has become one of the most feasible noninvasive methods for assessing liver fibrosis.[8,9]

Vibration-controlled transient elastography (VTE) is recommended for clinical management of liver disease patients. VTE with FibroScan (Echosens, France) offers several advantages over liver biopsy: it is relatively noninvasive, has fewer risks, covers larger areas of damaged tissue, is reproducible, has precision and accuracy comparable to those of liver biopsy, and results are instantly available. It can be repeated periodically and is substantially less expensive.[10] VTE can thus inform decisions regarding patient discharge after treatment for viral hepatitis. $[9,10]$

The FibroScan device measures shear wave velocity. In this technique, a $50 \mathrm{MHz}$ wave passes through the liver from a small transducer at the end of an ultrasound probe. The probe also has an end transducer that can measure shear wave speed (in meters per second) as the sound wave passes through the liver. The technology measures sound wave speed and converts it into a measurement of LS in kilopascals $(\mathrm{kPa})$. The entire process is commonly known as liver ultrasound elastography.[11] 
LS is proportional to severity of hepatic fibrosis, with reference cutoff points corresponding to stage of hepatic fibrosis in patients with chronic liver disease. These reference values are specific to underlying liver disease and to a given population. Most research is based on Western populations. In both European and Asian studies, LS in healthy adults is in the range of $2.5-7.5 \mathrm{kPa}$, with an average of $5.5 \mathrm{kPa}$. Globally, no ideal LS cutoff values have yet been established for healthy individuals.[12-17]

FibroScan was introduced in Cuba in 2014, through a collaborative agreement with the Spanish Development Cooperation Agency. As a result, Cubans needing assessment of damage from hepatic disease were assured universal and equitable access to this cutting-edge technology. Characterizing local or regional reference LS values for healthy individuals would enable appropriate interpretation and comparison of LS results. Hence, the purpose of this study was to measure LS in Cuban adults without liver disease and study its association with age, serum uric acid and body mass index (BMI).

\section{METHODS}

A cross-sectional study was conducted at the Institute of Gastroenterology (IGE) in Havana between January 2016 and February 2017. Of 263 plasma donors admitted to the Havana Province Blood Bank during that period, 150 volunteered to participate in the study and gave written informed consent. Volunteers were excluded if screening tests routinely performed in the donor program indicated that they were infected with hepatitis $B$, hepatitis $C$, or HIV. Other exclusion criteria were pregnancy, more than occasional or social consumption of alcohol, use of potentially hepatotoxic drugs, cancer, ischemic liver diseases, obesity (BMI $>30 \mathrm{~kg} / \mathrm{m}^{2}$ ), use of pacemakers or other electronic devices and ascites. Of the 150 volunteers, 110 met inclusion criteria: age $\geq 19$ years (range 19-75), chest circumference $>75$ $\mathrm{cm}$ and $<110 \mathrm{~cm}$, skin-liver capsule distance $<2.5 \mathrm{~cm}$.

Laboratory analyses followed principles of good clinical practice for clinical trials, which are externally quality controlled by the national regulatory authority, the Center for State Control of Medicines, Equipment and Medical Devices. Data on participants were obtained by an interviewer-administered questionnaire covering medical history, current status, and use of medications, alcohol or other potential toxins (herbs, drugs). All participants were assessed according to the FibroScan Use protocol of IGE's Department of Hepatology.

Variables LS Measurement These were performed on the same day as blood extraction, after laboratory tests and abdominal ultrasound. An experienced technician, who did not know the participants' clinical information, performed all LS measurements. The FibroScan operator placed the $\mathrm{M}$ probe ( $3.5 \mathrm{MHz}$ frequency) in the right hepatic lobe (this localization allows in-depth assessment of hepatic parenchyma volume comparable to that of a cylinder $10 \mathrm{~mm}$ $x 40 \mathrm{~mm}, 25-65 \mathrm{~mm}$ below the skin surface) through the intercostal spaces, with participants in dorsal decubitus with the right arm in maximal abduction: then the probe button was pressed to obtain the measurement,[18] expressed in $\mathrm{kPa}$. Results were considered useful once 10 valid measurements were completed (computer generated), with a success rate of $>60 \%$ and an interquartile range (IQR) over median—variation of valid measurements with respect to their median value - of <0.3.[19-21]
Demographics These were sex (male, female), age (in years, continuous and grouped by $<50$ and $\geq 50$ )

Physical measures These were weight $(\mathrm{kg})$ and height $(\mathrm{cm})$, body mass index (BMI) grouped as normal weight $\left(18.5-24.9 \mathrm{~kg} / \mathrm{m}^{2}\right.$ ) and overweight: $25-29.9 \mathrm{~kg} / \mathrm{m}^{2}$, thoracic perimeter $(\mathrm{cm})$.

Abdominal ultrasound This was performed by two experienced radiologists, with very good interobserver agreement (kappa index >0.7) using Toshiba Aplio 300 Ultrasound (Toshiba Medical Systems Europe, The Netherlands). Skin capsule distance was calculated. Liver size, capsular contour, parenchymal echogenicity, vascularity, biliary tree and presence of masses or abscesses were also assessed.

Virology Confirmatory hepatitis serology was performed in IGE's molecular biology laboratory by ELISA for hepatitis $B$ virus surface antigen ( $\mathrm{HBsAg}$ ), hepatitis B virus core antibody (anti-HBc) and antibody to hepatitis C virus (HCVAb) using SUMA technology (Immunoassay Center, TecnoSuma Internacional, SA, Cuba). Reverse PCR for hepatitis $B$ and hepatitis $C$ viruses was performed using commercially available kits (Cobas Amplicor version 2.0 for hepatitis B and C virus; Roche Diagnostics, Germany). In addition, confirmatory HIV serology was performed by ELISA.

Laboratory tests Blood parameters were bilirubin, gamma-glutamyl transferase, alanine aminotransferase, aspartate aminotransferase, alkaline phosphatase, albumin, total proteins, glycemia, creatinine, triglycerides, amylase, total cholesterol, uric acid, urea and serum iron. These were measured in IGE's clinical laboratory using routinely validated methods for the Cobas C311 clinical chemistry analyzer (Roche Diagnostics, Germany), with technical support from the manufacturer. Immunoglobulin $\mathrm{G}$ and $\mathrm{M}$ concentrations (reference values: IgG, 6.80-14 $45 \mathrm{~g} / \mathrm{L}$; IgM, 0.14-0.91 g/L for men and $0.40-0.95 \mathrm{~g} / \mathrm{L}$ for women) were determined by turbidimetry. Prothrombin time was measured ( $<15$ seconds) using the ST4 Coagulation Analyzer (Diagnostica Stago, France), with technical support from the manufacturer.

Analyses Variables were recorded and processed in a database using SPSS Windows 21 (IBM-SPSS Inc., USA). Means, standard deviations, medians, ranges and frequencies were calculated. We also calculated the Pearson correlation coefficient for LS with BMI and laboratory tests. The $95 \% \mathrm{Cl}$ for the mean was calculated to obtain a reference range for $L S$.

Ethics Study participants gave written informed consent and patient confidentiality was assured. Those who did not meet all selection criteria were informed of the reasons for their exclusion and those with pathological conditions were referred for followup and control by IGE specialists. In such cases, the patients benefited from clinical and imaging tests to establish their diagnosis. The study was reviewed and approved by the IGE Research Ethics Committee. Diagnostic methods were selected based on maximum benefit, the ethical principle of doing no harm, established international and national guidelines, and resource availability.[22]

\section{RESULTS}

The 150 volunteers selected were negative for HBV, HCV and HIV infection. Forty were excluded for the following reasons: 2 had $\mathrm{BMI}>30 \mathrm{~kg} / \mathrm{m}^{2}, 15$ had chest circumference $<75 \mathrm{~cm}$, 
7 had fatty liver by abdominal ultrasound and 16 had abnormal laboratory tests ( 6 individuals with elevated transaminases, 2 with elevated gamma-glutamyltransferase, 1 with high bilirubin, 4 with hyperamylasemia and 3 with hypercholesterolemia and hypertriglyceridemia). The remaining 110 participants had a valid LS examination and were included in the final analysis. Patient flow is described in Figure 1.

Baseline characteristics Demographic data and laboratory values are summarized in Table 1 . All participants had normal liver enzymes and hepatic parenchyma (by ultrasound), and were free of chronic medical conditions or significant alcohol consumption. All had normal BMI.

The results of the LS measurements regarding reliability standards are summarized in Table 2, which shows an average success rate higher than $95 \%$ and an IQR/median of $<0.3$, the normal threshold.

Table 1: Descriptive statistics of age, body mass index and laboratory variables, baseline values by sex

\begin{tabular}{|c|c|c|c|}
\hline \multirow[b]{2}{*}{ Variable } & \multicolumn{3}{|c|}{ Mean (SD) } \\
\hline & $\begin{array}{c}\text { Total } \\
n=110\end{array}$ & $\begin{array}{c}\text { Men } \\
n=53\end{array}$ & $\begin{array}{c}\text { Women } \\
n=57\end{array}$ \\
\hline $\begin{array}{l}\text { Age (years) } \\
\text { (median/range) }\end{array}$ & $47.5(19-73)$ & $47(23-72)$ & $48(19-73)$ \\
\hline Body mass index $\left(\mathrm{kg} / \mathrm{m}^{2}\right)$ & $24.5(2.6)$ & $25.1(2.1)$ & $23.9(2.9)$ \\
\hline $\begin{array}{l}\text { Alanine aminotransferase } \\
(\mathrm{U} / \mathrm{L})\end{array}$ & $20.5(7.8)$ & $22.4(7.4)$ & $18.6(7.8)$ \\
\hline $\begin{array}{l}\text { Aspartate } \\
\text { aminotransferase (U/L) }\end{array}$ & $19.6(5.6)$ & $20.7(4.8)$ & $18.7(6.1)$ \\
\hline Alkaline phosphatase (U/L) & $89.5(25.1)$ & $86.1(22.1)$ & $92.6(27.5)$ \\
\hline $\begin{array}{l}\text { Gamma-glutamyltransferase } \\
\text { (U/L) }\end{array}$ & $26.8(12.0)$ & $29.1(13.0)$ & $24.7(10.6)$ \\
\hline Total bilirubin $(\mu \mathrm{mol} / \mathrm{L})$ & $8.7(3.3)$ & $9.1(3.1)$ & $8.4(3.4)$ \\
\hline Total proteins ( $\mathrm{g} / \mathrm{L})$ & $72.7(4.7)$ & $71.5(4.7)$ & $73.8(4.5)$ \\
\hline Albumin (g/L) & $45.2(2.2)$ & $45.2(2.1)$ & $45.2(2.3)$ \\
\hline Glycemia $(\mu \mathrm{mol} / \mathrm{L})$ & $5.0(0.5)$ & $5.0(0.5)$ & $5.0(0.4)$ \\
\hline Creatinine $(\mu \mathrm{mol} / \mathrm{L})$ & $73.6(13.7)$ & $80.8(10.7)$ & $66.8(12.9)$ \\
\hline Total cholesterol $(\mu \mathrm{mol} / \mathrm{L})$ & $4.4(0.7)$ & $4.3(0.7)$ & $4.5(0.7)$ \\
\hline Triglycerides $(\mu \mathrm{mol} / \mathrm{L})$ & $0.96(0.3)$ & $1.04(0.3)$ & $0.89(0.3)$ \\
\hline Amylase (U/L) & $59.7(18.0)$ & $60.1(18.1)$ & $59.4(18.0)$ \\
\hline Uric acid $(\mu \mathrm{mol} / \mathrm{L})$ & $295.4(73.6)$ & $336.0(62.8)$ & $257.6(62.3)$ \\
\hline Urea $(\mu \mathrm{mol} / \mathrm{L})$ & $4.3(0.9)$ & $4.4(0.9)$ & $4.3(0.8)$ \\
\hline Serum iron $(\mu \mathrm{mol} / \mathrm{L})$ & $13.5(2.7)$ & $13.9(2.3)$ & $13.1(2.9)$ \\
\hline Prothrombin time (sec) & $12.4(0.6)$ & $12.5(0.7)$ & $12.3(0.5)$ \\
\hline
\end{tabular}

Table 2: Study-generated standardization criteria for liver elastography

\begin{tabular}{|c|c|c|}
\hline Parameter & $\begin{array}{l}\text { Point estimate } \\
\text { (range) }\end{array}$ & $\begin{array}{c}\text { Externally reported } \\
\text { normal range }\end{array}$ \\
\hline $\begin{array}{l}\text { Liver stiffness }(\mathrm{kPa}) \\
\text { Median (range) }\end{array}$ & $\begin{array}{r}4.4 \\
(2.2-6.3)\end{array}$ & $2.5-7.5$ \\
\hline $\begin{array}{l}\text { Interquartile range/median } \\
\text { Median (range) }\end{array}$ & $\begin{array}{r}0.13 \\
(0.03-0.33)\end{array}$ & $<0.30$ \\
\hline $\begin{array}{r}\text { Success rate }(\%) \\
\text { Median (range) }\end{array}$ & $\begin{array}{r}100 \\
(65-100)\end{array}$ & $>60$ \\
\hline $\begin{array}{l}\text { Exam duration (sec) } \\
\text { Median (range) }\end{array}$ & $\begin{array}{r}128.5 \\
(48-1048)\end{array}$ & $300-600$ \\
\hline $\begin{array}{l}\text { Number of measures ( } n \text { ) } \\
\text { Median (range) }\end{array}$ & $\begin{array}{r}10 \\
(10-20)\end{array}$ & . \\
\hline
\end{tabular}

amean $4.4 \mathrm{kPa}, 95 \%$ confidence interval 4.2-4.6 breferences 19-21
Figure 1: Flow of healthy plasma donors, Havana Province Blood Bank, 2016-2017

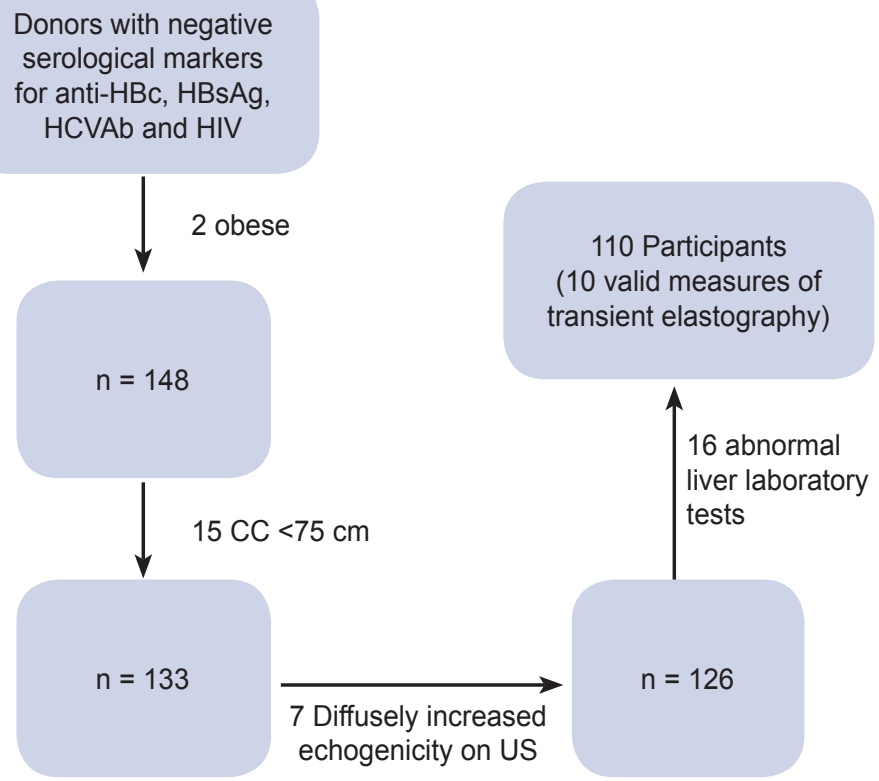

anti-HBc: antibody to hepatitis B core antigen $\quad$ CC: chest circumference HBsAg: hepatitis B surface antigen HCVAb: hepatitis C antibodies US: ultrasound

LS measurement by age, sex and BMI There was no correlation between age and LS measurements $(r=-0.092, p=0.338)$. The median (range) of LS measurements for subjects aged $<50$ years was 4.5 (2.4-6.1) and for subjects aged $\geq 50$ years. $4.3(2.2-6.3)$ $\mathrm{kPa}$ respectively $(p=0.102)$. Median LS was similar between women and men: $4.1(2.4-6.1)$ and $4.5(2.2-6.1) \mathrm{kPa}$, respectively $(p=0.086)$.

A positive correlation was found between LS and BMI $(r=0.255$, $\mathrm{p}<0.01)$.

Correlation of LS measurements with laboratory parameters Among laboratory parameters, only serum uric acid had a positive and significant correlation with LS measurements $(r=0.266$, $\mathrm{p}<0.01$ ). Median uric acid in all participants was $298.6 \mu \mathrm{mol} / \mathrm{L}$ (range 155.2-428.0), 337.1 (155.2-428) for men and 242.4 (159.2-426.9) $\mu \mathrm{mol} / \mathrm{L}$ for women. Overall uric acid levels in the study were normal. However, six women had a level of uric acid slightly above normal.

Reference range The LS reference range $(95 \% \mathrm{Cl})$ for the 110 subjects with no known liver disease was 4.2-4.6 kPa (mean 4.4) with distribution shown in Figure 2. The total range for this variable was $2.2-6.3 \mathrm{kPa}$.

\section{DISCUSSION}

LS is ethnically and anthropometrically diverse, and should be assessed in healthy subjects to obtain an appropriate reference range. Due to a lack of large population studies in healthy subjects, reference values for LS are not available. The present study was performed with participants with no apparent liver disease and is the first attempt to obtain approximate LS reference values in Cuban adults. These values should be compared to well-established cutoff points for various stages of fibrosis obtained in patients with specific liver disease. There 
Figure 2: Liver stiffness in healthy plasma donors, Havana Province Blood Bank, 2016-2017 ( $\mathrm{n}=110)$

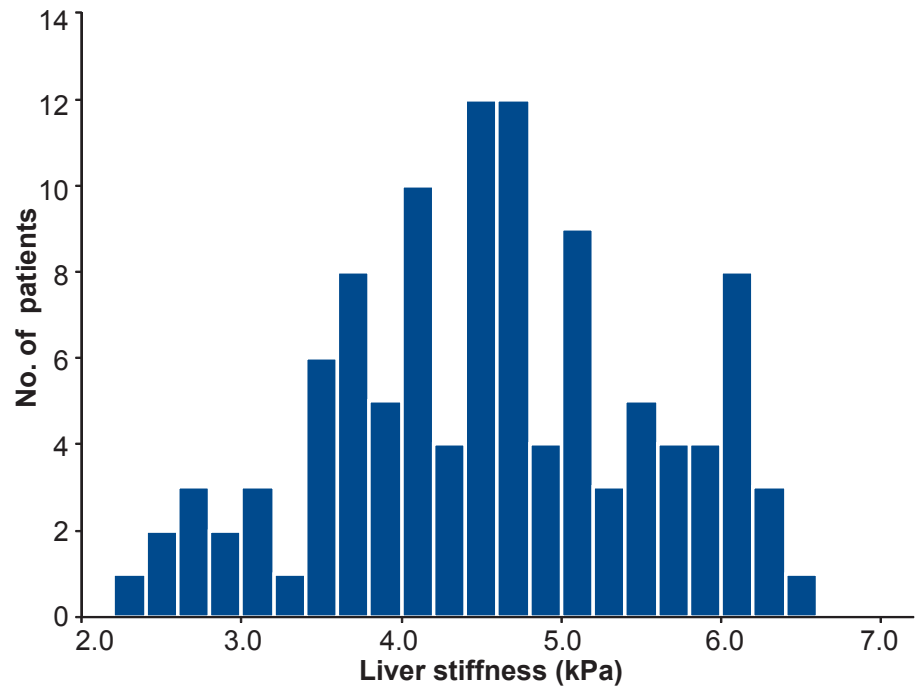

is growing interest in estimating the elasticity of liver tissues because focal and diffuse diseases are often related to changes in tissue elasticity.[23,24]

In the study, LS values were not significantly different between men and women, coinciding with what Kim[25] and Alsebaey describe. [26] However, they contrast with results from other authors, who report higher values in men than in women.[15,27-29] Female sex appears to be a protective factor in fibrosis progression in chronic liver diseases, because estrogens have a fibrosuppressive effect. $[30,31]$ However, it is still unknown whether extracellular matrix density in the liver differs between healthy men and women.[28] Factors other than sex appear to be more influential, making sexspecific reference ranges of little use.

The groups aged $<50$ and $\geq 50$ years had similar LS means, concistent with results obtained by Colombo,[16] Kumar[32] and Das.[17] However, Fung found lower LS values in healthy Chinese older adults.[27]

One important finding is that LS is significantly associated with $\mathrm{BMI}$, which has been described as an independent predictor of LS. Hu explored LS in healthy Chinese adults using real-time tissue elastography and found it unaffected by age and sex but positively correlated with BMI.[33]

Das found that LS values were higher at the extremes of BMI distribution, i.e., in obese and underweight individuals.[17] Cellular components and the Glisson capsule are probably more important in explaining BMl's effect on LS measurement in a healthy liver.[34,35] Geographic location and ethnicity influence nutritional status, which could indirectly help explain differences in results.

To date, research to identify ideal cutoff values in healthy individuals shows variable results, due to diverse methods used, as well as geographic and social environments. These differences reveal the influence of context on LS, and therefore the need to identify national or regional reference values according to the different environmental factors, and the habits and lifestyles of each region.
A prospective study in Gambia assessed the impact of food intake on LS measurement values in subjects with chronic hepatitis $B$ and healthy controls. The results suggested that food intake (an 850 Kcal breakfast) significantly increased LS (and IQR), compared to fasting values.[36] Other factors may also increase LS, such as liver infiltration with tumor cells, mastocytosis, inflammatory cells (all forms of hepatitis), and amyloidosis. In addition, LS correlates directly with venous pressure and increases during mechanical cholestasis. Therefore, LS should always be interpreted in the context of clinical and laboratory findings and imaging studies.[37]

One of the most important findings of this study was the influence of uric acid on LS. This is an inert metabolic end product of purine metabolism, which has recently been assigned a causal role in hypertension, metabolic syndrome, diabetes, nonalcoholic fatty liver disease and chronic kidney disease.[38] The purine group varies significantly with dietary animal protein content and with final metabolism of endogenous purines derived from liver, intestines and other tissues such as muscles, kidneys and vascular endothelium.[39]

Normal values of serum uric acid in the general population are controversial; evidence suggests that silent deposition of monosodium urate crystals as a result of hyperuricemia can lead to early destructive skeletal changes. Moreover, this may play a pathophysiological role in many cardiovascular, renal and metabolic disorders. Desideri recommended carefully reconsidering the concept of "asymptomatic" hyperuricemia.[40] In view of new scientific knowledge about the pathophysiological role of uric acid in human disease, a threshold value of $<6.0 \mathrm{mg} / \mathrm{dL}(<360 \mu \mathrm{mol} / \mathrm{L})$ seems to better identify truely healthy subjects and should be reasonably considered for all individuals.

Hyperuricemia is a common symptom of metabolic syndrome, together with hypertriglyceridemia and abnormal accumulation of liver fat, either as simple steatosis (nonalcoholic fatty liver) or nonalcoholic steatohepatitis, which is usually accompanied by fibrosis with subsequent progression to cirrhosis.[41]

Our findings suggest that LS is influenced by uric acid levels, something only detectable by transient elastography, even before changes in parenchymal echogenicity are observed in abdominal ultrasound. Further research is needed to clarify the effects of uric acid on liver elasticity in healthy people.

One study limitation is that our sample was relatively small and perhaps not representative of the Cuban population, which suggests cautious use of results. To address the difficulty of finding healthy adults to define LS cutoff values, we selected plasma donors because they are routinely screened for viral hepatitis, HIV, and other chronic diseases. A second study limitation is the lack of liver biopsies to confirm absence of fibrosis in participants.

This is the first Cuban study using FibroScan to measuring LS (there is no other such device in the country), and its results will enable better assessment of liver disease in clinical practice.

\section{CONCLUSIONS}

LS in Cuban adults without liver disease ranges from 2.2-6.3 kPa. The normal reference range is $4.2-4.6 \mathrm{kPa}$. Body mass index and serum uric acid levels are positively associated with LS; there is no association with sex and age. - $1 /$ - 


\section{REFERENCES}

1. Mokdad AA, López AD, Shahraz S, Lozano R, Mokdad AH, Stanaway J, et al. Liver cirrhosis mortality in 187 countries between 1980 and 2010: a systematic analysis. BMC Med [Internet] 2014 Sep 18 [cited 2017 May 5];12:145. Available from: https://bmcmedicine.biomedcentral com/articles/10.1186/s12916-014-0145-y

2. GBD 2015 Mortality and Causes of Death Collaborators. Global, regional, and national life expectancy, all-cause mortality, and causespecific mortality for 249 causes of death, 1980-2015: a systematic analysis for the Global Burden of Disease Study 2015. Lancet. 2016 Oct 8;388(10053):1459-544.

3. National Health Statistics and Medical Records Division (CU). Anuario Estadístico de Salud 2016. Havana: Ministry of Public Health (CU); 2017 [cited 2017 Jun 12]. 206 p. Available from: http://files.sld.cu/dne/files/2017/05/Anuario _Estad\%C3\%ADstico_de_Salud_e_2016 edici\%C3\%B3n 2017.pdf. Spanish.

4. Lee UE, Friedman SL. Mechanisms of hepatic fibrogenesis. Best Pract Res Clin Gastroenterol. 2011 Apr;25(2):195-206.

5. Rockey DC, Caldwell SH, Goodman ZD, Nelson RC, Smith AD; American Association for the Study of Liver Diseases. Liver biopsy. Hepatology. 2009 Mar;49(3):1017-44.

6. European Association for the Study of Liver, Asociación Latinoamericana para el Estudio del Hígado. EASL-ALEH Clinical Practice Guidelines: Non-invasive tests for evaluation of liver disease severity and prognosis. J Hepatol. 2015 Jul;63(1):237-64.

7. Cohen EB, Afdhal NH. Ultrasound-based hepatic elastography: origins, limitations, and applications. J Clin Gastroenterol. 2010 Oct:44(9):637-45.

8. Tapper EB, Afdhal NH. Vibration-controlled transient elastography: a practical approach to the noninvasive assessment of liver fibrosis. Curr Opin Gastroenterol. 2015 May;31(3):192-8.

9. Tapper EB, Castera L, Afdhal NH. FibroScan (vibration-controlled transient elastography): where does it stand in the United States practice. Clin Gastroenterol Hepatol. 2015 Jan;13(1):27-36.

10. van Katwyk S, Coyle D, Cooper C, Pussegoda $\mathrm{K}$, Cameron C, Skidmore B, et al. Transient elastography for the diagnosis of liver fibrosis: a systematic review of economic evaluations. Liver Int [Internet]. 2017 Jun [cited 2017 Jun 12];37(6):851-61. Available from: http://dx.doi .org/10.1111/liv.13260

11. Frulio $\mathrm{N}$, Trillaud $\mathrm{H}$. Ultrasound elastography in liver. Diagn Interv Imaging. 2013 May;94(5):51534.

12. Chin JL, Chan G, Ryan JD. Noninvasive assessment of liver fibrosis and cirrhosis with ultrasound-based elastography in alcoholrelated liver disease. Gastroenterology. 2016 May;150(5):1251-2.

13. Obara N, Ueno Y, Fukushima K, Nakagome Y, Kakazu E, Kimura O, et al. Transient elastography for measurement of liver stiffness measurement can detect early significant hepatic fibrosis in Japanese patients with viral and nonviral liver diseases. J Gastroenterol [Internet]. 2008 [cited 2017 May 14];43(9):720-8. Available from: https://dx.doi.org/10.1007/s00535-008-2225-2

14. Jung MK, Cho HJ, Lee HC, Park KS, Seo EH, Jeon SW, et al. [Comparison of transient elastography and hepatic fibrosis assessed by histology in chronic liver disease]. Korean J Gastroenterol. 2008 Apr;51(4):241-7. Korean.

15. Roulot $D$, Czernichow $S$, Le Clésiau $H$, Costes $\mathrm{JL}$, Vergnaud AC, Beaugrand M. Liver stiffness values in apparently healthy subjects: influence of gender and metabolic syndrome. J Hepatol. 2008 Apr;48(4):606-13.
16. Colombo S, Belloli L, Zaccanelli M, Badia E, Jamoletti C, Buonocore $\mathrm{M}$, et al. Normal liver stiffness and its determinants in healthy blood donors. Dig Liver Dis. 2011 Mar;43(3):231-6.

17. Das K, Sarkar R, Ahmed SM, Mridha AR, Mukherjee PS, Das K, et al. "Normal" liver stiffness measure (LSM) values are higher in both lean and obese individuals: a population-based study from a developing country. Hepatology. 2012 Feb;55(2):584-93.

18. Kucharczyk MC, Solari J, Gadano A, García Mónaco R. Elastografía transicional (Fibroscan $®$ ): nuevo método para la evaluación no invasiva de la fibrosis hepática. Rev Hosp Ital B Aires. 2011 Dec;31(4):150-4. Spanish.

19. Carrión JA. Utilidad del Fibroscan para evaluar la fibrosis hepática. Gastroenterol Hepatol. 2009 Jun-Jul;32(6):415-23. Spanish.

20. Sandrin L, Fourquet B, Hasquenoph JM, Yon S, Fournier C, Mal F, et al. Transient elastography: A new noninvasive method for assessment of hepatic fibrosis. Ultrasound Med Biol. 2003 Dec;29(12):1705-13.

21. Lucidarme D, Foucher J, Le Bail B, Costera L, Villars S, Forzy G, et al. The ratio interquartile range/median value of liver stiffness measurement is a key factor of accuracy of transient elastography (Fibroscans) for the diagnosis of liver fibrosis. Hepatology. 2007 Oct;46:318A

22. World Medical Association [Internet]. FerneyVoltaire (FR): World Medical Association; c2017. Declaración de Helsinki. Principios éticos para la investigación en seres humanos; 2013 Oct 19 [cited 2017 Jan 25]; [about 6 screens]. Available from: https://www.wma.net/es/policies-post/ declaracion-de-helsinki-de-la-amm-principios -eticos-para-las-investigaciones-medicas-en -seres-humanos/. Spanish.

23. Zhao J, Zhai F, Cheng J, He Q, Luo J, Yang X, et al. Evaluating the significance of viscoelasticity in diagnosing early-stage liver fibrosis with transient elastography. PLoS One. 2017 Jan 20;12(1):e0170073.

24. Wong GL, Chan HL, Choi PC, Chan AW, Lo $A O$, Chim AM, et al. Association between anthropometric parameters and measurements of liver stiffness by transient elastography. Clin Gastroenterol Hepatol [Internet]. 2013 Mar [cited 2017 May 14];11(3):295-302. Available from: https://linkinghub.elsevier.com/retrieve/pii/S1542 -3565(12)01140-8

25. Kim SU, Choi GH, Han WK, Kim BK, Park JY, Kim DY, et al. What are 'true normal' liver stiffness values using FibroScan®?: a prospective study in healthy living liver and kidney donors in South Korea. Liver Int. 2010 Feb;30(2):268-74.

26. Alsebaey A, Allam N, Alswat K, Waked I. Normal liver stiffness: A study in living donors with normal liver histology. World J Hepatol. 2015 May 18;7(8):1149-53.

27. Fung J, Lee CK, Chan M, Seto WK, Wong DK, Lai $\mathrm{CL}$, et al. Defining normal liver stiffness range in a normal healthy Chinese population without liver disease. PLoS One. 2013 Dec 26;8(12):e85067.

28. Corpechot C, El Naggar A, Poupon R. Gender and liver: is the liver stiffness weaker in weaker sex? Hepatology. 2006 Aug;44(2):513-4.

29. Sirli R, Sporea I, Tudora A, Deleanu A, Popescu A. Transient elastographic evaluation of subjects without known hepatic pathology: does age change the liver stiffness. J Gastrointestin Liver Dis. 2009 Mar; 18(1):57-60

30. Poynard T, Ratziu V, Charlotte F, Goodman Z, McHutchison J, Albrecht J. Rates and risk factors of liver fibrosis progression in patients with chronic hepatitis C. J Hepatol. 2001 May;34(5):730-9.

31. Di Martino V, Lebray P, Myers RP, Pannier E, Paradis V, Charlotte F, et al. Progression of liver fibrosis in women infected with hepatitis C: longterm benefit of estrogen exposure. Hepatology. 2004 Dec;40(6):1426-33.

32. Kumar M, Sharma P, Garg H, Kumar R, Bhatia V, Sarin SK. Transient elastographic evaluation in adult subjects without overt liver disease: influence of alanine aminotransferase levels. J Gastroenterol Hepatol. 2011 Aug:26(8):1318-25.

33. Hu Y, Gong HY, Lin HJ. Real-time tissue elastography for assessment of liver stiffness in adults without known liver disease. J Ultrasound Med. 2015 Oct;34(10):1895-900.

34. Orescanin M, Qayyum MA, Toohey KS, Insana MF. Dispersion and shear modulus measurements of porcine liver. Ultrason Imaging. 2010 Oct;32(4):255-66.

35. Roan $E$. The effect of Glisson's capsule on the superficial elasticity measurements of the liver. $J$ Biomech Eng. 2010 Oct;132(10):104504.

36. Lemoine M, Shimakawa $Y$, Njie R, Njai HF, Nayagam S, Khalil M, et al. Food intake increases liver stiffness measurements and hampers reliable values in patients with chronic hepatitis B and healthy controls: the PROLIFICA experience in The Gambia. Aliment Pharmacol Ther. 2014 Jan;39(2):188-96.

37. Mueller S, Sandrin L. Liver stiffness: a novel parameter for the diagnosis of liver disease. Hepat Med. 2010 May 25;2:49-67.

38. Kanbay M, Jensen T, Solak Y, Le M, RoncalJiménez $C$, Rivard $C$, et al. Uric acid in metabolic syndrome: from an innocent bystander to a central player. Eur J Intern Med. 2016 Apr;29:3-8.

39. Chaudhary K, Malhotra K, Sowers J, Aroor A. Uric acid-key ingredient in the recipe for cardiorenal metabolic syndrome. Cardiorenal Med. 2013 Oct;3(3):208-20.

40. Desideri G, Castaldo G, Lombardi A, Mussap M, Testa A, Pontremoli R, et al. Is it time to revise the normal range of serum uric acid levels? Eur Rev Med Pharmacol Sci. 2014;18(9):1295-306.

41. Metrakos P, Nilsson T. Non-alcoholic fatty liver disease-a chronic disease of the 21st century. J Biomed Res. 2017 May 26

\section{THE AUTHORS}

Ángela Elvírez-Gutiérrez (Corresponding author: aelvirez@infomed.sld.cu),radiologist with a master's degree in diagnostic imaging. Assistant professor, Gastroenterology Institute (IGE), Havana, Cuba.

Marlén I. Castellanos-Fernández, gastroenterologist. Full professor, IGE, Havana, Cuba.

Wendy Santillán-López, physician. Third-year gastroenterology resident, IGE, Havana, Cuba.

Zaily Dorta-Guridi, epidemiologist with a doctorate in health sciences. Associate researcher, IGE, Havana, Cuba.

Enrique Galbán-García, physician specializing in epidemiology with a doctorate in health sciences. Senior researcher, IGE, Havana, Cuba.

Enrique Arús-Soler, gastroenterologist with a doctorate in medical sciences. Full professor, IGE, Havana, Cuba.

Submitted: September 7, 2017

Approved for publication: October 17, 2017 Disclosures: None 


\title{
Systemic Ozone Therapy by Rectal Insufflation for Immunoglobulin A Deficiency
}

\author{
Jacqueline Díaz-Luis MD MS, Silvia Menéndez-Cepero PhD, Consuelo Macías-Abraham MD PhD, Lucía Fariñas-Rodríguez MS
}

\begin{abstract}
SUMMARY
INTRODUCTION IgA deficiency is a primary immunodeficiency predominantly due to an antibody defect, for which there is no replacement therapy. Treatment consists of prevention and treatment of infections and other associated conditions. Given the immunomodulatory and regulatory properties of the redox balance of ozone therapy in infectious and inflammatory conditions, evaluation of its effect on IgA deficiency is of interest.
\end{abstract}

OBJECTIVE Assess the benefits and possible adverse effects of ozone treatment in patients with IgA deficiency.

METHODS A monocentric randomized controlled phase 2 clinical trial (RPCEC 00000236) was carried out, after approval by the Institutional Ethics Committee of the Roberto Rodríguez Fernández Provincial General Teaching Hospital in Morón, Ciego de Ávila Province, Cuba. Included were 40 patients aged 5-50 years, distributed in 2 groups of 20 , after agreeing to participate and signing informed consent. The experimental group received 2 cycles of ozone by rectal insufflation for 20 days ( 5 times a week for 4 weeks each cycle) with a 3-month interval between cycles, for a total of 40 doses, with age-adjusted dose ranges. The control group was treated with leukocyte transfer factor (Hebertrans), $1 \mathrm{U}$ per $\mathrm{m}^{2}$ of body surface area subcutaneously, once weekly for 12 weeks. Frequency of appearance and severity of clinical symptoms and signs of associated diseases, serum immunoglobulin concentrations and balance of pro-oxidant and antioxidant biomarkers

\section{INTRODUCTION}

Primary or inherited immunodeficiencies (PIDD) are infrequent. Their prevalence varies by type of genetic defect; while selective IgA deficiency is relatively common, more serious defects such as severe combined immunodeficiency are rare. New immunodeficiencies are continually being discovered, so the exact prevalence is unknown, although considered to be low.[1] In Cuba these diseases are underreported because of lack of specific diagnosis, among other causes.[2] The global incidence of IgA deficiency varies by ethnic origin. In the USA, estimated PIDD frequency varies between 1:1000 and 1:223 in the general population, and is much lower, between $1: 18,000$ and 1:2600 in those of Asian origin.[3]

According to criteria of the Pan American Immunodeficiency Group and the European Immunodeficiency Society, two clinical forms of $\lg \mathrm{A}$ deficiency-complete and partial deficits-are included as PIDDs "predominantly due to antibody defect" and may be associated with failure in formation of antibodies against polysaccharide antigens or deficiencies of IgG2. When secretory $\lg \mathrm{A}$ is lacking, patients may remain asymptomatic $(70 \%$ of those affected) or develop florid clinical presentations in which infectious, allergic and autoimmune diseases predominate.[3,4]

IgA deficiency was the most frequent PIDD among patients with suspected immunodeficiencies seen at the Ciego de Ávila provincial Immunology Service during the six years of this study (1 of every 101). Thus, PIDD is considered an important health were recorded at treatment initiation and one month after treatment completion. Therapeutic response was defined as complete, partial, stable disease or progressive disease. Descriptive statistics and significance were calculated to compare groups and assess effect size.

RESULTS One month after treatment completion, $70 \%$ of patients in the experimental group experienced significant increases in IgG $(p=0.000)$ and $\operatorname{lgM}(p=0.033)$. The experimental group also displayed decreased pro-oxidation biomarkers, glutathione modulation and increased antioxidant enzymes, with reduced oxidative stress; none of these occurred in the control group. Complete therapeutic response was achieved in $85 \%$ of patients in the experimental group and only $45 \%$ in the control group. Mild, transient adverse events were reported in both groups.

CONCLUSIONS Ozone therapy by rectal insufflation is a suitable therapeutic option for treating IgA deficiency because it produces antioxidant and immunomodulatory effects and is feasible, safe and minimally invasive.

KEYWORDS Ozone therapy, IgA deficiency, primary immunodeficiency, oxidative stress, antioxidants, pro-oxidants, Cuba

CONTRIBUTION OF THIS RESEARCH This paper introduces in Cuba a new treatment a for IgA deficiency, with immunomodulatory and antioxidant effects offering substantial clinical benefits to patients with this immunodeficiency. problem for immunology and allergology services in the province. Other PIDDs were less frequent, 1 of every 509 seen (administrative data, Immunology Service, Roberto Rodríguez Fernández Provincial General Teaching Hospital).

Recurrent bacterial respiratory infections are the most common health problem in patients with IgA deficiency; some can also develop gastrointestinal parasitic infections, such as giardiasis, and allergic and autoimmune disorders. An association between IgA deficiency and bronchial asthma is also reported.[3-6]

IgA deficiency has no specific or replacement treatment. Infections are treated with antimicrobials depending on the sensitivity of the causal agent. Some patients need prolonged antibiotic prophylaxis against infections to avoid complications. When allergic and autoimmune diseases coincide with $\lg \mathrm{A}$ deficiency, specific treatment for each disease is used. A therapeutic alternative could be replacement or supply of external sources of $\operatorname{lgA}$, but blood products that contain it (human immunoglobulin preparations) are not recommended, due to risk of anaphylactic reactions in patients with anti-lgA antibodies.[7,8] These treatment limitations led to a search for effective and noninvasive options to improve patients' immune response, particularly against infections.

The normal immune response involves cellular receptors, costimulatory signals, cytokines and regulation by oxidation- 
reduction (redox) processes.[9] In recurrent infections, as well as allergic and autoimmune diseases, the balance between free oxygen radical production and antioxidant systems is tilted in favor of the former, causing oxidative damage to proteins, lipids, DNA, organs and systems. Reversing the effects of free radicals and regulating the redox state requires safe and effective therapeutic interventions; ozone has been suggested as an appropriate treatment.[10,11]

Ozone's immune system effects have been described by Bocci and Larini.[10,12] Ozone is a prodrug with oxidizing properties, which produces biological effects in the body with a biphasic dose response (hormesis). Therapy is based on reversion of chronic oxidative stress at the cellular level and modulating effects on immune system function.[10]

In Cuba, ozone has had beneficial effects in management of various secondary humoral and cellular immune deficiencies, including HIVIAIDS, autoimmune diseases such as rheumatoid arthritis, and phagocytic immunodeficiencies.[13-15] Several studies show the immunomodulatory, antioxidant and antiinflammatory effects of ozone therapy.[13-16]

IgA-deficient patients in Cuba may benefit from the demonstrated utility of ozone therapy for treatment of various conditions, its safety and well-understood main mechanisms, if used under internationally recommended good practice standards.[17] This therapy may successfully treat conditions caused by the underlying disorder and accompanying diseases, both infectious and due to immune system deregulation. We therefore proposed evaluating the potential benefits and adverse effects of ozone treatment in such patients.

\section{METHODS}

A monocentric, randomized, controlled, phase 2, open-label clinical trial (RPCEC 00000236) was carried out. Participation criteria were defined: inclusion (age 5-50 years, either sex, complete or partial IgA deficiency, selective or with deficient response of specific antibodies, isolated or associated with allergic or autoimmune diseases); exclusion (blood transfusions three months before or during the trial, any immunomodulatory treatment within the previous 6 months); and withdrawal (serious adverse reactions; treatment noncompliance or abandonment). Needed statistical power was calculated, considering prevalence variability and acceptable type 1 error.

The study population comprised 40 patients, aged 5-50 years, of both sexes, seen in the Immunology Service from January 18, 2010 through September 12, 2016. There were no withdrawals. Adults provided written informed consent to participate in the trial; parents gave written concent for participating children.

Patients were assigned by systematic random sampling to two groups, experimental (EG) and control (CG), 20 cases each. Members of both groups received specific treatment for their allergic disorder or autoimmune disease.

Treatment The EG received two cycles of ozone therapy by rectal insufflation. Each cycle consisted of 20 sessions ( 5 per week), with a 3-month interval between cycles. Ozone was produced by an ozone generator (OZOMED plus, Havana, Cuba). Recommended age-specific doses were applied according to the following schedule.[18]

- 5-10 years: $1.25-3 \mathrm{mg} \mathrm{(25} \mathrm{mg/L} \mathrm{concentration} \mathrm{in} 50 \mathrm{~mL}$ to 30 $\mathrm{mg} / \mathrm{L}$ in $100 \mathrm{~mL}$ )

- $11-15$ years: $2.25-4.2 \mathrm{mg}$ (30 mg/L in $75 \mathrm{~mL}$ to $35 \mathrm{mg} / \mathrm{L}$ in 120 $\mathrm{mL})$

- >15-50 years: $2-8 \mathrm{mg} \mathrm{(20} \mathrm{mg/L} \mathrm{in} 100 \mathrm{~mL}$ to $40 \mathrm{mg} / \mathrm{L}$ in 200 $\mathrm{mL})$

The CG received Hebertrans transference factor (Genetic Engineering and Biotechnology Center, Cuba). Dosage was one unit per $\mathrm{m}^{2}$ of body surface subcutaneously, once weekly for 12 weeks.[19]

Variables Therapeutic response was assessed as complete, partial, stable disease and progressive disease.

- Complete: satisfactory clinical status (absence of infectious diseases characteristic of these patients), increased IgM or lgG; normalization of all pro-oxidant parameters and increase of $\geq 2$ antioxidant parameters

- Partial: satisfactory or acceptable clinical status (absence or decrease in severity and frequency of infectious diseases characteristic of these patients), increased IgM or IgG, normalization of $\geq 1$ pro-oxidant parameter and increase of $\geq 1$ antioxidant parameter

- Stable disease: presenting one or two of the following-clinical status the same as at onset, no increased IgM or IgG, no normalization of pro-oxidant parameters, and no activation of antioxidant parameters

- Progressive disease: with three or four of the followingworsening clinical condition, no increased $\lg M$ or $\operatorname{lgG}$, no normalization of pro-oxidant parameters and no activation of antioxidant parameter

Serum was obtained by centrifugation and decantation after clot retraction, and simple radial immunodiffusion was used for immunoglobulin quantification, results expressed in $\mathrm{mg} / \mathrm{mL}$. Specific antibodies against tetanus and diphtheria toxoids were determined by ELISA, results expressed in $\mathrm{IU} / \mathrm{mL}$. Absolute values of lymphoid populations were estimated by flow cytometry. $[20,21]$

Plasma was obtained to assess redox state biomarkers, using EDTA as anticoagulant and erythrocyte lysate.

Pro-oxidation biomarkers: Concentration of malondialdehyde (MDA), a lipid peroxidation marker, was determined in plasma by the method described in LPO-586TM of the BIOXYTECH assay (OXIS Indague, USA), values expressed in $\mu \mathrm{mol} / \mathrm{L}$.[22] Advanced oxidation protein products (AOPP) were evaluated by Witko's spectrophotometric technique, values expressed in $\mu \mathrm{mol} / \mathrm{L}$.[23] A colorimetric method was used for total peroxide quantification, based on oxidation of ferrous to ferric ions mediated by hydrogen peroxide $\left(\mathrm{H}_{2} \mathrm{O}_{2}\right)$ under acidic conditions, results expressed in $\mu \mathrm{mol} / \mathrm{L} .[24]$

Biomarkers of antioxidant defense: Superoxide dismutase activity was determined by Marklund's indirect kinetic method,[25] results expressed in percentage inhibition/minute/mL of enzyme $(\mathrm{U} / \mathrm{mL})$. Erythrocyte catalase activity was determined by a direct kinetic method using $\mathrm{H}_{2} \mathrm{O}_{2}$ as substrate, results expressed in $\mathrm{mmol}$ 
$\mathrm{H}_{2} \mathrm{O}_{2} / \mathrm{t} / \mathrm{min} / \mathrm{mL}$.[26] Cellular glutathione peroxidase activity was determined by Paglia and Valentine's technique, units of enzymatic activity expressed in $\mathrm{mU} / \mathrm{mL}$.[27] Plasma concentration of protein thiols, referred to as reduced glutathione, was determined by Sedlak and Lindsay's technique, results expressed in $\mu \mathrm{mol} / \mathrm{L}$. [28] Total antioxidant capacity of plasma was measured by the ferric-reducing plasma ability assay, an indicator of antioxidant power and plasma ability to reduce ferric ions to ferrous, results expressed in $\mathrm{mM} \mathrm{Fe}^{2+} / \mathrm{L}$.[29]

Data collection and management Information was collected in patient registers and data collection notebooks.

Analysis Simple descriptive statistics demonstrated group homogeneity of demographic, clinical and immunological factors. The dependent-samples $T$ test was used to compare groups with respect to response variables, comparing before and after treatment values in each group, and changes between groups by the double difference method. SPSS version 15.0 was used for analysis. The threshold specified for statistical significance was $p \leq 0.05$.

Ethics Safety-related variables were analyzed as stipulated by the National Drug and Medical Equipment Quality Control Center (CECMED) in Regulation No. 45-2007 for notification and reporting of serious or unexpected adverse events in clinical trials.[30] Adult participants and children's parents or legal guardians were given a detailed explanation of the trial, treatments used, and informed that they would receive one of two therapeutic options, both of which were expected to provide benefits by improving or temporarily eliminating some clinical manifestations of disease; $[10,12-19]$ that allocation would be randomized, to avoid subjectivity; and that participants could abandon the trial at will, without prejudice to care. The trial was approved by the Research Ethics Committee of the Roberto Rodríguez Fernández Provincial General Teaching Hospital (main sponsor) and complied with the principles of the Helsinki Declaration.[31]

\section{RESULTS}

At trial onset, the groups were homogeneous with respect to demographic, clinical and immunological factors. Most patients were aged $5-10$ years (14 cases in the EG and 16 in the CG) and male sex predominated (Table 1). Susceptibility to infection was evidenced by history of recurrent bacterial respiratory infections (3 events in one year and inadequate response to antibiotics) in 33 cases (18 in the EG and 15 in the CG) $(82.5 \%$ of total) and by infectious parasitic diseases such as giardiasis in 17 patients (42.5\% of total, 8 in the CG and 9 in the EG). Among concurrent diseases, allergy ranked first (32 cases, $80 \%$ ) and of these, bronchial asthma was the most frequent with 25 cases $(62.5 \%$ of total, 14 in the EG and 11 in the CG). Autoimmune diseases were diagnosed in 2 patients, one with rheumatoid arthritis (EG) and another with vitiligo (CG).

Immunological alterations were detected at trial onset, including decreased antibodies against protein antigens of tetanus and diphtheria toxoids in 2 patients, with values lower than those considered protective for these diseases $(>0.1 \mathrm{IU} / \mathrm{mL})$ and below-normal CD19+ $\mathrm{B}$ cell levels (>1\%) in 10 cases. According to these results for immunological parameters, 95\% (38/40) of cases showed selective IgA deficiency and 5\% (2/40) $\lg A$ deficiency associated with functional response deficit (Table 1).
At treatment completion, complete $\lg \mathrm{A}$ deficiency (IgA values below $0.07 \mathrm{~g} / \mathrm{L})$ was found in 10 cases $(25 \%)$ and partial $(\lg A$ values at least 2 standard deviations below normal values for age) in $30(75 \%)$; IgM and IgG were normal in these cases at onset. After two cycles of ozone therapy, significant differences were observed between the EG and CG in $\operatorname{IgG}(p=0.000)$ and $\operatorname{Ig} M$ $(p=0.033)$ (Table 2).

The results of the oxidative stress study (Table 3), showed imbalances in the redox system with respect to normal reference values, since AOPP and MDA were elevated at study onset in both groups, indicating that patients with IgA deficiency had a prooxidant redox state. Reduced glutathione was elevated in $80 \%$ of patients and glutathione peroxidase was $60 \%$ below reference values for healthy individuals.

After two cycles of ozone therapy, AOPP $(p=0.003)$ and MDA $(p=0.001)$ decreased. Levels of total peroxides did not vary, and reduced glutathione was normalized $(p=0.032)$. Redox

Table 1: Demographic and clinical characteristics of IgA-deficient individuals

\begin{tabular}{|c|c|c|c|}
\hline \multicolumn{2}{|c|}{ Characteristics } & $\begin{array}{c}\text { Experimental } \\
\text { group } \\
n=20 \\
n(\%)\end{array}$ & $\begin{array}{c}\text { Control } \\
\text { group } \\
n=20 \\
n(\%)\end{array}$ \\
\hline \multirow{2}{*}{ Age } & $5-10$ & $14(70)$ & $16(80)$ \\
\hline & $11-15$ & $6(30)$ & $4(20)$ \\
\hline \multirow{2}{*}{ Sex } & Female & $7(35)$ & $8(40)$ \\
\hline & Male & $13(65)$ & $12(60)$ \\
\hline \multirow{2}{*}{$\begin{array}{l}\text { Clinical } \\
\text { presentation }\end{array}$} & $\begin{array}{l}\text { Recurrent respiratory } \\
\text { infection }\end{array}$ & $18(90)$ & $15(75)$ \\
\hline & Giardiasis & $8(40)$ & $9(45)$ \\
\hline \multirow{4}{*}{$\begin{array}{l}\text { Associated } \\
\text { diseases }\end{array}$} & Bronchial asthma & $14(70)$ & $11(55)$ \\
\hline & Atopic dermatitis & $2(10)$ & $3(15)$ \\
\hline & Allergic rhinitis & $1(5)$ & $1(5)$ \\
\hline & Autoimmune disease & $1(5)$ & $1(5)$ \\
\hline \multirow{3}{*}{$\begin{array}{l}\text { Immunological } \\
\text { abnormalities }\end{array}$} & Selective IgAD & $14(70)$ & $16(80)$ \\
\hline & $\begin{array}{l}\text { IgAD with decreased } \\
\text { CD19+ a }\end{array}$ & $6(30)$ & $4(20)$ \\
\hline & $\begin{array}{l}\text { Anti-TT and -TD } \\
\text { decreased }^{b}\end{array}$ & $1(5)$ & $1(5)$ \\
\hline
\end{tabular}

${ }^{a}$ normal $>1 \% \quad{ }^{b}$ normal $>0.1 \mathrm{IU} / \mathrm{mL}$

CD19+: B-lymphocyte positive for CD19 antigen IgAD: IgA deficiency anti-TD: diphtheria toxoid antibody anti-TT: tetanus toxoid antibody

Table 2: Immunoglobulin levels in IgA-deficient individuals treated with ozone or Hebertrans

\begin{tabular}{|c|c|c|c|c|c|}
\hline & \multicolumn{2}{|c|}{$\begin{array}{c}\text { Experimental group } \\
\text { (ozone therapy) } \\
n=20 \\
\text { mean (SD) }\end{array}$} & \multicolumn{2}{|c|}{$\begin{array}{c}\text { Control group } \\
\text { (Hebertrans) } \\
n=20 \\
\text { mean (SD) }\end{array}$} & \multirow[t]{2}{*}{ p Value ${ }^{a}$} \\
\hline & Initial & After 1 month & Initial & After 1 month & \\
\hline $\lg G(g / L)$ & $\begin{array}{r}8.2 \\
(1.1)\end{array}$ & $\begin{array}{r}12.0 \\
(0.8)^{b}\end{array}$ & $\begin{array}{r}9.2 \\
(0.80)\end{array}$ & $\begin{array}{r}9.1 \\
(0.98)^{b}\end{array}$ & 0.000 \\
\hline $\lg A(g / L)$ & $\begin{array}{r}0.07 \\
(0.01)\end{array}$ & $\begin{array}{r}0.12 \\
(0.02)\end{array}$ & $\begin{array}{r}0.08 \\
(0.01)\end{array}$ & $\begin{array}{r}0.09 \\
(0.02)\end{array}$ & NS \\
\hline $\lg M(g / L)$ & $\begin{array}{r}1.2 \\
(0.2)\end{array}$ & $\begin{array}{r}1.9 \\
(0.39)^{\mathrm{b}}\end{array}$ & $\begin{array}{r}1.5 \\
(1.10)\end{array}$ & $\begin{array}{r}1.6 \\
(0.32)^{b}\end{array}$ & 0.033 \\
\hline
\end{tabular}

aassociated with double difference

bsignificant differences between values before and after treatment NS: not significant 
Table 3: Pro-oxidant and antioxidant biomarkers in IgA-deficient individuals before and after treatment

\begin{tabular}{|c|c|c|c|c|c|}
\hline \multirow[t]{2}{*}{ Biomarkers } & \multicolumn{2}{|c|}{$\begin{array}{c}\text { Experimental group } \\
n=20 \\
\text { mean (SD) }\end{array}$} & \multicolumn{2}{|c|}{$\begin{array}{c}\text { Control group } \\
n=20 \\
\text { mean (SD) } \\
\end{array}$} & \multirow[t]{2}{*}{$\begin{array}{c}\mathbf{p} \\
\text { value }^{a}\end{array}$} \\
\hline & Initial & Final & Initial & Final & \\
\hline MDA ( & $\begin{array}{r}1.98 \\
(1.70)\end{array}$ & $\begin{array}{r}0.7 \\
(0.11\end{array}$ & $\begin{array}{r}1.86 \\
(1.41)\end{array}$ & $\begin{array}{r}1.20 \\
(0.27)^{\mathrm{b}}\end{array}$ & 0.00 \\
\hline OF & $\begin{array}{l}55.88 \\
(1.36)\end{array}$ & 41 & $\begin{array}{l}53.90 \\
(1.29)\end{array}$ & $\begin{array}{r}50.48 \\
(0.55)^{\mathrm{b}}\end{array}$ & 0.003 \\
\hline FOX & $<1$ & 1.1 & $<1$ & $<1$ & NS \\
\hline $\mathrm{OO}$ & $\begin{array}{l}154.23 \\
(10.02)\end{array}$ & & $\begin{array}{r}158.59 \\
(9.10)\end{array}$ & $\begin{array}{l}159.09 \\
(2.12)^{b}\end{array}$ & 0.001 \\
\hline CAT & $\begin{array}{l}70.88 \\
(4.20)\end{array}$ & 78 & $\begin{array}{l}67.61 \\
(3.10)\end{array}$ & $\begin{array}{l}78.58 \\
(1.40)\end{array}$ & NS \\
\hline $\mathrm{SH}$ & $\begin{array}{l}42.12 \\
(1.14)\end{array}$ & $\begin{array}{r}35.02 \\
(1.12)^{b}\end{array}$ & $\begin{array}{l}40.06 \\
(2.02)\end{array}$ & $\begin{array}{r}40.09 \\
(1.02)^{b}\end{array}$ & 0.032 \\
\hline GPx ( & $\begin{array}{r}28,436.43 \\
(346.65)\end{array}$ & $\begin{array}{r}33,874.40 \\
(134.08)^{b}\end{array}$ & $\begin{array}{r}27,913.09 \\
(450.12)\end{array}$ & $\begin{array}{r}27,073.34 \\
(250.12)^{b}\end{array}$ & 0.012 \\
\hline FRAP (mM F & $\begin{array}{r}0.16 \\
(0.03)\end{array}$ & $\begin{array}{r}0.27 \\
(0.09)^{b}\end{array}$ & $\begin{array}{r}0.18 \\
(0.02)\end{array}$ & $\begin{array}{r}0.19 \\
(0.03)^{b}\end{array}$ & 0.001 \\
\hline
\end{tabular}

aassociated with double difference

${ }^{\text {b}}$ significant differences between values before and after treatment

AOPP: advanced oxidation protein products CAT: catalase

FOX: total peroxides FRAP: ferric reducing antioxidant power

GSH: reduced glutathione GPx: glutathione peroxidase

MDA: malondialdehyde SOD: superoxide dismutase

NS: not significant

balance was favored in the EG, since significant increases were found in several antioxidant defense markers, such as superoxide dismutase $(p=0.001)$, cellular glutathione peroxidase $(p=0.012)$ and ferric reducing ability of plasma $(p=0.001)$ (Table $3)$. Increased antioxidants and decreased pro-oxidants were not found in the CG.

Therapeutic response was complete in $85 \%(17 / 20)$ of the EG, and partial in 15\% (3/20). Complete response was found in $45 \%$ $(9 / 20)$ of the CG, partial in $35 \%$ (7/20); disease was stable in $20 \%$ $(4 / 20)$. Adverse events in the EG were mild and transient, and included tympanites immediately after rectal insufflation in two patients and abdominal pain in one. In the CG, erythema and pain at the injection site were reported by 8 patients $(40 \%)$.

\section{DISCUSSION}

Some authors consider that IgA deficiency can be diagnosed in young children, since the majority of patients, who have IgA below $0.07 \mathrm{~g} / \mathrm{L}$ at age 3 years $(77 \%)$ are still IgA deficient at age 7 years. $[4,8]$ However, since it could be confused with transient immunodeficiency of childhood, which occurs in young children due to delay in immune system development after birth,[3] we hold that age is an essential criterion for diagnosis, and that diagnosis of IgA deficiency should be made after the age of possible confusion with transient immunodeficiency of childhood; hence the lower limit in our study population.

The presence of recurrent respiratory and digestive infectious diseases is consistent with that reported by Domínguez in a chart review of 330 patients with IgA deficiency[32] and De Oliveira in a review of 39 patient files.[33] IgA deficiency manifests more frequently as digestive and respiratory system infections, as in the study cases, because IgA is predominant in mucosal secretions. IgA has an important biological function in mucous tissues, since it can neutralize viruses, bind to toxins, agglutinate bacteria, prevent bacteria from binding to epithelial cells and inhibit absorption of food antigens, thus preventing their entry into the bloodstream. These functions explain why IgA deficiency leads to a more aggressive bacterial microbiota and predisposes to local inflammatory processes. It has been suggested that low serum IgA levels cause less IgA transport to mucosal surfaces.[9] As in other studies, we found partial IgA deficiency was more frequent than complete deficiency.[32,33]

$\lg$ A deficiency is associated with a high prevalence of allergies, as found in our study, in which $80 \%$ of patients had clinical manifestations of these diseases. The literature reports that allergic disorders may be the initial clinical manifestation.[33,34] This may be because lack or insufficient concentrations of $\lg A$ causes partial loss of ability to block allergen entry through the mucosa, which induces sensitization and predisposes to development of allergies. Although the mechanism for association between bronchial asthma and IgA deficiency is unknown, some genetic defects, such as TNFRSF3B variants, may increase risk of this disease.[34]

Basal serum concentrations of specific antibodies prevaccination may be protective and are therefore valuable for studying humoral immunocompetence in IgA deficiency, since the humoral component of the immune response is compromised. The decreased $B$ lymphocyte population in 10 patients is consistent with the findings of a Brazilian study.[35] Some studies show decreased $\mathrm{CD}^{+} \mathrm{T}$ lymphocytes in IgA-deficient patients.[36,37] Existence of an associated immune defect indicates that patients require more effective monitoring. It is important to study cell markers and activation in these patients, since IgA deficiency can progress to a common variable immunodeficiency.

Due to lack of specific treatment for IgA deficiency in Cuba, it is treated with Hebertrans because of its favorable clinical effects and immunomodulatory actions (expressed by an antigen-dependent and specific late cutaneous hypersensitivity reaction, in addition to other effects related to cell-mediated immunity).[38,39] Taking into account published evidence of these effects, Hebertrans was administered to the control group to comply with the ethical imperative of using the best available product comparable to the one being tested.

According to Viebahn-Hänsler, ozone requires systemic application to achieve good immunomodulation results. Rectal insufflation has been reported to have a systemic effect similar to major autohemotherapy in $90 \%$ of patients and it is the route of choice in children, older adults and patients who cannot tolerate intravenous therapies.[18] The biological effect of rectal ozone insufflation pathway has been demonstrated in preclinical models and clinical research.[40]

The significant increases in $\lg G$ and $\lg M$ after two cycles of ozone therapy show the effect of ozone on these immunological parameters, favorably impacting clinical status of patients who had good therapeutic response by decreasing infection recurrence. This result is based on the role of immunoglobulins in the humoral response of adaptive immunity; their functional integrity is essential to maintain immune system homeostasis. Various studies demonstrate the immunomodulatory effect of ozone therapy on antibody response and other immunological parameters.[15,41-43] 
The fact that in this series of patients, AOPP and MDA were high in the initial assessment reveals the predominance of prooxidant damage. This is probably a consequence of intense and sustained activation of oxidative enzymes during recurrent infections and inflammatory processes, causing an excess of free radicals surpassing the capacity of endogenous antioxidant systems, with subsequent damage to proteins and lipids. The effect of free radicals on lipids is known as lipid peroxidation, and leads to destruction of the original lipid and loss of membrane integrity. MDA is a marker of this process. The effect on proteins causes amino acid oxidation, cross-linking of peptide chains and formation of carbonyl groups, evidenced by AOPP elevation.[44] From these results presence of inflammatory type oxidative stress can be inferred, caused by excessive activation of the natural mechanisms that generate reactive species and are associated with greater activation of the enzyme NADPH oxidase involved in chronic inflammation.[44]

The increase in pro-oxidant parameters and consequent oxidative stress is highly relevant to health-disease mechanisms, since it is associated with various pathological processes; in immunodeficiencies, it causes immune system dysfunction, which worsens existing deficits.[44-46] Immune system functioning is strongly influenced by redox balance, particularly in cells that have cytotoxic and phagocytic functions, which, due to their microbicidal activity are connected to free radical generation and deteriorate under oxidative stress. In IgA deficiency, other associated conditions, such as allergies and autoimmunity, worsen redox balance, resulting in tissue damage by free radicals. The pathophysiological repercussions of oxidation in IgA-deficient patients with allergies or autoimmunity are further immune dysfunction and lower response to immunomodulatory treatments.[15,47]

The significant increase in antioxidant parameters and decrease in pro-oxidants after two cycles of ozone therapy in the EG compared to the $C G$ is a consequence of oxidative preconditioning, which ensures that a cycle of 20 ozone treatments is enough to maintain the positive effect for approximately 3 months, depending on the disease and patient response.[40]

The importance of this result is that the increase in antioxidant enzymes prevents free radicals from damaging vital structures and halts production of new oxidant molecules. As cells shift from an oxidizing to a reducing environment, they maintain membrain integrity and retain their specific functions, which, in the case of immune system cells, is defense against pathogenic microorganisms.[48]

The mechanism of ozone therapy's antioxidant action at controlled doses is based on its ability to act as a hormetic stressor, which activates the related erythroid nuclear factor 2 , Nrf2, in cytoplasm. When released from the adapter protein Keap1, this transcription factor binds to the DNA regions that regulate antioxidant response, increasing expression of genes involved in this defense. In an in vitro assay, Bocci identified several transcription factors in peripheral blood cells activated by ozone, such as: Nrf2, NFAT, AP-1 protein, and NF-Kappa B. Activation of Nrf2 could be a common denominator among cellular hormetic activators.[49] The importance of these transcription factors in the immune response is based on their participation in intracellular signaling pathways for activation of T lymphocytes,[9] whose adequate function is essential for defense against infection.

Ozone therapy is well tolerated and safe, with very few adverse events, since the rectal route is relatively noninvasive and painless and does not require use of needles or syringes.[40] This investigation shows similar safety and reactogenicity results to a 20-year followup study where ozone therapy was applied in patients with retinitis pigmentosa.[50] More intense and longlasting adverse events were identified In the CG, such as pain at the injection site, but these were predominantly local and less severe than previously described for Hebertrans.[51] Distension and reddening are caused by local inflammation and recruitment of inflammatory cells after several applications.

The study's monocentric nature is a limitation, since it prevents generalization of these findings as guidelines for other hospitals.

\section{CONCLUSIONS}

Our research results support ozone therapy as a suitable therapeutic option in treatment of IgA deficiency, because it produces antioxidant and immunomodulatory effects and is feasible, safe and minimally invasive.

\section{ACKNOWLEDGMENTS}

We thank Dr Maikel Roque Morgado, biostatistician for his support with data analysis. -1 -

\section{REFERENCES}

1. Raje N, Dinakar C. Overview of immunodeficiency disorders. Immunol Allergy Clin North Am [Internet]. 2015 Nov [cited 2017 Feb 21];35(4):599-623. Available from: https://www ncbi.nlm.nih.gov/pmc/articles/PMC4600970/

2. Macías $C$, Sánchez M, Insua C, García MC, Hernández G, Arce A, et al. Tratamiento con inmunoglobulina $G$ subcutánea en enfermos con inmunodeficiencias primarias: resultados preliminares del estudio multicéntrico cubano. Rev Cubana Hematol Inmunol Hemoterapia [Internet]. 2016 [cited 2017 Feb 20];32(3):1-10. Available from: http://revhematologia.sld.cu/index.php/hih/ article/view/449/251. Spanish.

3. Kobrynski L, Waltenburg Powell R, Bowen S. Prevalence and morbidity of primary immunodeficiency diseases, United States 2001-2007.
J Clin Immunol [Internet]. 2014 [cited 2016 Mar 3];34(8):954-61. Available from: https://www .ncbi.nlm.nih.gov/pmc/articles/PMC4820073/

4. European Society for Immunodeficiencies [Internet]. Geneva: European Society for Immunodeficiencies; c2017. Registry. Diagnosis Criteria. New clinical diagnosis criteria for the ESID Registry; 2014 Mar [cited 2017 Feb 21]; [about 1 screen]. Available from: http://esid.org/Working -Parties/Registry/Diagnosis-criteria

5. Özcan C, Metin A, Erkoçoglu M, Kocabas CN Bronchial hyperreactivity in children with antibody deficiencies. Allergol Immunopathol (Madr). 2015 Jan-Feb;43(1):57-61.

6. Singh K, Chang C, Gershwin ME. IgA deficiency and autoimmunity. Autoimmun Rev [Internet]. 2014 Feb [cited 2017 Jan 20];13(2):163-77.
Available from: http://linkinghub.elsevier.com/ retrieve/pii/S1568-9972(13)00180-8

7. Grupo de Trabajo de Inmunología Pediátrica. Guías de manejo: medidas generales de prevención de infecciones y quimioprofilaxis en las inmunodeficiencias primarias. Arch Argent Pediatr [Internet]. 2011 [cited 2016 Mar 3];109(3):26773. Available from: http://www.scielo.org.ar/pdf/ aap/v109n3/v109n3a19.pdf. Spanish.

8. García Martínez JM, Santos-Díez L, Dopazo L. Diagnóstico de las inmunodeficiencias primarias. Protoc Diagn Ter Pediatr [Internet]. 2013 [cited 2016 Feb 24];1:81-92. Available from: http:// www.aeped.es/sites/default/files/documentos/ 7-inmunodeficiencias primarias 0.pdf. Spanish.

9. Abbas AK, Lichtman AH, Pillai S. Propiedades generales de las respuestas inmunitarias. In: 


\section{Original Research}

Abbas AK, Lichtman AH, editors. Inmunología celular y molecular. 8th ed [Internet]. Barcelona: Elsevier; 2015 [cited 2017 Feb 21]. Available from: http://booksmedicos.me/inmunologia-celu lar-y-molecular-abbas-8a-edicion/. Spanish.

10. Bocci V. Does ozone therapy normalize the cellular redox balance? Implications for therapy of human immunodeficiency virus infection and several other diseases. Med Hypotheses [Internet]. 1996 Feb [cited 2017 Feb 21];46(2) Available from: http://www.ncbi.nlm.nih.gov/pub med/8692040

11. Martínez-Sánchez G. La ozonoterapia gana evidencia científica en el campo clínico. Rev Cubana Farm [Internet]. 2013 Apr 9 [cited 2016 Feb 24];47(1):1-4. Available from: http://bvs.sld.cu/ revistas/far/vol47 1 13/far01113.htm. Spanish.

12. Larini A, Bocci V. Effects of ozone on isolated peripheral blood mononuclear cells. Toxicol In Vitro [Internet]. 2005 Feb [cited 2016 Mar 3];19(1):5561. Available from: http://www.ozonoterapiafran cia.com.mx/_downloads/Publicaciones_Ozono/ Bocci\%202.pdf

13. Nazarina I, Menéndez S, Rivero J. Ozonoterapia en SIDA. Rev Cubana Invest Biomed [Internet] 2005 Jan-Mar [cited 2017 Feb 21];24(1):69-71. Available from: http://bvs.sld.cu/revistas/ibi/ vol24_1_05/ibi09105.pdf. Spanish.

14. León Fernández OS, Viebahn-Haensler R, Cabreja GL, Espinosa IS, Matos YH, Roche LD, et al. Medical ozone increases methotrexate clinical response and improves cellular redox balance in patients with rheumatoid arthritis. Eur J Pharmacol [Internet]. 2016 Oct 15 [cited 2017 Feb 21];789:313-8. Available from: http://linkinghub .elsevier.com/retrieve/pii/S0014-2999(16)30471-X

15. Díaz Luis J, Padrón Sardiñas G, Menéndez Cepero S, Macías Abraham C. [Immunomodulator effect of ozone therapy in children with deficiency in immunity mediated by phagocytes]. Mediciego [Internet]. 2012 [cited 2016 Jan 4];18(1). Available from: http://bvs.sld.cu/revistas/mciego/ vol18_01_2012/pdf/T9.pdf. Spanish.

16. Gazin IK, Istomin N. [Disturbed immune status and immunocorrective effect of ozone-assisted therapy in comparison with traditional treatment of patients with diabetes mellitus complicated by pyonecrotic lesions of the lower extremities]. Immunologiya. 2009;(1):60-1. Russian.

17. Asociación Española de Profesionales Médicos en Ozonoterapia (AEPROMO). Declaración de Madrid sobre ozonoterapia [Internet]. Madrid AEPROMO; 2012 [cited 2014 Nov 20]. Available from: http://files.sld.cu/rehabilitacion-fis/ files/2012/06/declaracion-de-madrid-actualiza da-30-julio-castellano-20102.pdf. Spanish.

18. Viebahn-Hänsler R, León Fernández OS, Fahmy Z. Ozone in medicine: the low-dose ozone concept-guidelines and treatment strategies. Ozone Sci Engineering. 2012;34(6):408-24.

19. Formulario Nacional de Medicamentos. Factor de Transferencia [Internet]. Havana: Centro para el Desarrollo de la Farmacoepidemiología (CU); 2017 [cited 2017 Dec 12]; [about 2 screens]. Available from: http://fnmedicamentos.sld.cu/index .php?P=FullRecord\&ID=380. Spanish.

20. Ruiz Contreras J, González Granado LI. Pruebas de laboratorio en el diagnóstico de inmunodeficiencias primarias. An Pediatr Cont [Internet]. 2013 [cited 2016 Feb 24];11(5):282-90. Available from: https://www.clinicalkey.es/\#!/content/ journal/1-s2.0-S1696281813701495. Spanish.

21. Rozman C, Cardellach López F. Farreras Rozsman. Medicina Interna [Internet]. Barcelona: Elsevier; c2016 [cited 2017 Feb 21]. Chapter 338 Pruebas inmunológicas de interés diagnóstico; p. 2534-49. Available from: https://www.clinica key.es/\#!/content/book/3-s2.0-B978848086896 9003381. Spanish.
22. BIOPROCESS Online [Internet]. Pittsburg: BIOPREOCESS Online; c1996-2017. Product/ Service. Bioxytech LPO-586. Colorimetric assay for lipid peroxidation markers. Catalogue No. 941012. OXIS International, 1997; [cited 2016 Mar 3]; [about 1 screen]. Available from: https:// www.bioprocessonline.com/doc/bioxytech-lpo -586-colorimetric-assay-for-lipi-0001

23. Witko-Sarsat V, Friendlander M, Nguyen-Khoa T, Capeillère-Blandin C, Nguyen AT, Canteloup $S$, et al. Advanced oxidation protein products as novel mediators of inflammation and monocytes activation in chronic renal failure. J Immunol. 1998 Sep 1;161(5):2524-32.

24. Jiang ZY, Woollard AC, Wolff SP. Lipid hydroperoxide measurement by oxidation of $\mathrm{Fe} 2+$ in the presence of xylenol orange. Comparison with the TBA assay and an iodometric method. Lipids. 1991 Oct;26(10):853-6.

25. Marklund S, Marklund $G$. Involvement of the superoxide anion radical in the autoxidation of pyrogallol and a convenient assay for superoxide dismutase. Eur J Biochem. 1974 Sep 16;47(3):469-74

26. Aebi H. Catalase in vitro. Methods Enzymol. 1984;105:121-6.

27. Paglia DE, Valentine WN. Studies on the quantitative and qualitative characterization of erythrocyte glutathione peroxidase. J Lab Clin Med. 1967 Jul;70(1):158-69.

28. Sedlak J, Lindasy RH. Estimation of total protein bound and non-protein sulfhydryl group in tissue with Ellman's reagent. Anal Biochem. 1968 Oct 24;25(1):192-205

29. Benzie IF, Strain JJ. The ferric reducing ability of plasma (FRAP) as a measure of antioxidant power: the FRAP assay. Anal Biochem. $1996 \mathrm{Jul}$ 15;239(1):70-6.

30. Ministry of Public Health (CU); Center for State Control of Medicines, Equipment and Medical Devices (CU). Regulación No. 45-2007. Requerimientos para la notificación y el reporte de eventos adversos graves e inesperados en los ensayos clínicos 2007 [Internet]. Havana: National Quality Control Center for Drugs, Medical Equipment and Devices (CU); 2007 [cited 2011 Jan]. 18 p. Available from: http:// www.cecmed.cu/sites/default/files/adjuntos/ Reglamentacion/reg_45-07_requerimientos para_la_notificacion_y_el_reporte_de_eventos _adversos_graves_e_inesperados_en_los_en sayos_clinicos.pdf. Spanish.

31. World Medical Association. Declaración de Helsinki de la Asociación Médica Mundial. Principios éticos para las investigaciones médicas en seres humanos. Junio 1964 [Internet]. FerneyVoltaire: World Medical Association; 2017 Mar 21 [cited 2011 Jan 10]; [about 5 screens]. Available from: https://www.wma.net/es/policies-post/ declaracion-de-helsinki-de-la-amm-principios -eticos-para-las-investigaciones-medicas-en -seres-humanos/. Spanish.

32. Domínguez O, Giner MT, Alsina L, Martín MA, Lozano J, Plaza AM. Fenotipos clínicos asociados a la deficiencia selectiva de IgA: revisión de 330 casos y propuesta de un protocolo de seguimiento. An Pediatr [Internet]. 2012 [cited 2016 Feb 24];76(5):261-7. Available from: http://www.analesdepediatria.org/es/fenotipos -clinicos-asociados-deficiencia-selectiva/articulo/ S1695403311005522/. Spanish.

33. De Oliveira-Serra FA, Mosca T, Santos de Menezes MC, Carvalho-Neves Forte W. Manifestaciones clínicas de la deficiencia de IgA. Rev Alerg Mex [Internet]. 2017 [cited 2017 Feb 24];64(1):34-9. Available from: http://revistaalergia.mx/ojs/index .php/ram/article/view/216/436. Spanish.

34. Urm SH, Yun HD, Fenta YA, Yoo KH, Abraham RS, Hagan J, et al. Asthma and risk of celective IgA deficiency or common variable immunodeficiency: a population-based casecontrol study. Mayo Clin Proc [Internet]. 2013 Aug [cited 2016 Jun 20];88(8):813-21. Available from: https://www.ncbi.nlm.nih.gov/pmc/articles/ pmid/23910409/

35. Rivas JJ, Brocardo GA, Kokron C, Rizzo LV, Kalil J, Barros MT. Caracterização imunofenotípica de linfócitos $B$ de memória na deficiência de $\operatorname{lgA}$ e imunodeficiência comum variável. Rev Bras Alergia Imunopatol [Internet]. 2010 Jan-Feb [cited 2016 Jun 20];33(1):23-31. Available from: http:// pesquisa.bvsalud.org/bvsecuador/resource/pt/ lil-563501. Portuguese.

36. Soheili H, Abolhassani $\mathrm{H}$, Arandi N, Khazaei HA, Shahinpour S, Hirbod-Mobarakeh A, et al. Evaluation of natural regulatory $T$ cells in subjects with selective IgA deficiency: from senior idea to novel opportunities. Int Arch Allergy Immunol. 2013;160(2):208-14

37. Bezrodnik L, Di Giovanni D, Ginaca A, Krasovec S, Menard D, Carabajal $P$, et al. Evaluación clínica e inmunológica de 90 pacientes con deficiencia selectiva de inmunoglobulina A. Arch Argent Pediatr [Internet]. 2003 Sep-Oct [cited 2016 Mar 3];101(5):375-81. Available from: http://www.imbiomed.com/1/1/articulos.php?me thod=showDetail\&id_articulo $=44150 \&$ id_seccion $=2737 \& i d$ ejemplar=4481\&id_revista $=165$. Spanish.

38. Cruz Barrios MA, Rodríguez Montiel BN, Furones Mourelle JA, Martín de la Riva AD, Guerra Suárez LM, Páez Pérez AT. Patrones de prescripción del factor de transferencia en 11 hospitales de Ciudad de La Habana. Rev Cubana Salud Pública [Internet]. 2005 Dec [cited 2016 Mar 3];31(4):291-5. Available from: http://www .redalyc. org/articulo. oa? id=21418845004\&idp=1 \&cid $=34574$. Spanish

39. Inclán G. Respuesta clínica e inmunológica en pacientes con déficit de lgA después del tratamiento con factor de transferencia. Rev Cub Hematol Inmunol Hemoterapia. 1994;10:80-1. Spanish.

40. Martínez Sánchez G, Re L. Rectal administration and its application in ozone therapy. Intl J Ozone Therapy. 2012 Apr;11:41-9.

41. Mandzhgaladze NR, Kharebava ER, Didia TsG, Ardzhevanishvili MD, Gudzhabidze MV, Chigiashvili TsN. [Influence of intravenous ozone treatment on the level of different specificity antibodies]. Georgian Med News [Internet]. 2006 Sep [cited 2017 Feb 21];(138):93-5. Available from: https://www.ncbi.nlm.nih.gov/ pubmed/17057311

42. Díaz Luis J, Macías Abraham C, Menéndez Cepero S. Efecto modulador de la ozonoterapia sobre la actividad del sistema inmune. Rev $\mathrm{Cu}$ bana Hematol Inmunol Hemoterapia [Internet]. 2013 [cited 2017 Feb 21];29(2). Available from: http://www.revhematologia.sld.cu/index.php/hih/ article/view/27. Spanish.

43. Smith AJ, Oertle J, Warren D, Prato D. Ozone Therapy: a critical physiological and diverse clinical evaluation with regard to immune modulation, anti-infectious properties, anti-cancer potential, and impact on anti-oxidant enzymes. Open $\mathrm{J}$ Molecular Integr Physiol. 2015 Aug:5(3):37-48.

44. Sánchez Valle V, Méndez Sánchez N. Estrés oxidativo, antioxidantes y enfermedad. Rev Invest Med Sur Mex [Internet]. 2013 Jul-Sep [cited 2016 Jul 24];20(3):161-8. Available from: http:// medicasur.org.mx/pdf-revista/RMS133-AR01 -PROTEGIDO.pdf. Spanish.

45. Elejalde Guerra Jl. Estrés oxidativo, enfermedades y tratamientos antioxidantes. An Med Interna [Internet]. 2001 Jun [cited 2017 Jan 5];18(6):326-35. Available from: http://scielo.isciii .es/scielo.php?script=sci_arttext\&pid=S0212 -71992001000600010. Spanish. 
46. Pomier Suárez O, Gil del Valle L, Rodríguez Delgado $F$, Huetes L, Alerm González A, Bermúdez Alfonso $\mathrm{Y}$, et al. Indicadores de estrés oxidativo en pacientes afectados por $\mathrm{VIH} /$ sida con manifestaciones reumatológicas. Rev Cubana Farm. 2012 Jul-Sep;46(3):329-42. Spanish.

47. Hernández Rosales FA, Calunga Fernández JL, Turrent Figueras J, Menéndez Cepero S, Montenegro Perdomo A. Ozone therapy effects on biomarkers and lung function in asthma. Arch Med Res. 2005 Sep-Oct:36(5):549-54.

48. Corcho I, Hernández F, Reyes N, Carballo AL, Peña $\mathrm{O}$, Reyes $\mathrm{T}$, et al. [Changes in the immune system in inflammatory processes during the application of ozone therapy]. Rev CENIC Cienc Biol [Internet]. 1998 [cited 2017 Feb 21];29(3):203-5. Available from: http://amozon.org.mx/index.php/ blog/63-alergia-e-inmunologia/1171-changes-in -the-immune-system-in-inflammatory-processes -during-the-application-of-ozone-therapy. Spanish.

49. Bocci V, Valacchi G. Nrf2 activation as target to implement therapeutic treatments. Front Chem [Internet]. 2015 Feb 2 [cited 2016 Mar 3];3:4 Available from: https://www.ncbi.nlm.nih.gov/ pmc/articles/pmid/25699252/

50. Copello M, Menéndez S, Hernández F. Ozone therapy in retinitis pigmentosa patients: clinical evolution and oxidative stress behavior in retinitis pigmentosa patients treated with ozone therapy over 20 years. Ozone Sci Engineering. 2012 Dec 5;34(6):476-83.

51. Cruz Barrios MA. Reacciones adversas del factor de transferencia y características de su prescripción. La Habana, 2001-2010 [thesis] [Internet]. [Havana]: Dr Miguel Enríquez Medical School; 2014 [cited 2017 Feb 21]. Available from: http:// tesis.repo.sld.cu/863/1/Cruz_Barrios.pdf. Spanish.

\section{THE AUTHORS}

Jacqueline Díaz-Luis (Corresponding author: jdiaz@hgm.cav.sld.cu), physician specializing in immunology, with a master's degree in infectious diseases, doctoral candidate. Associate professor and researcher Roberto Rodríguez Fernández Provincial General Teaching Hospital, Morón, Cuba.

Silvia Menéndez-Cepero, chemist. Senior researcher, National Scientific Research Center, Havana, Cuba.

Consuelo Macías-Abraham, physician specializing in immunology, with a doctorate in medical sciences. Full professor and senior researcher, Hematology and Immunology Institute, Havana, Cuba.

Lucía Fariñas-Rodríguez, biologist with a master's degree in anthropology. Adjunct professor and head, Oxidative Stress Laboratory, National Medical Genetics Center, Havana, Cuba.

Submitted: August 21, 2017

Approved for publication: December 18, 2017 Disclosures: None

\section{FOR A SAFER WORLD}

10th International Congress on Disaster Nursing and Disaster Management

6th International Firefighters Conference

July 2-8, 2018

Havana's International Convention Center
This conference brings together leading scholars to exchange experiences and research results on all aspects of disaster nursing and disaster management. It also provides a premier interdisciplinary platform for researchers, practitioners and educators to present and discuss recent innovations, trends, and concerns, as well as practical challenges encountered and solutions adopted.

Topics include, but are not limited to, climate change and disaster risk, disaster prevention, risk reduction for sustainable development, civil society and population preparedness, response planning, disaster response and post-disaster rehabilitation.

Languages: Spanish, English Information:wilmamj@palco.cu http://www.congresoDCcuba.com 


\title{
Attempted and Completed Suicide in Cuban Adolescents, 2011-2014
}

\author{
Beatriz Corona-Miranda MD MS, Karen Alfonso-Sagué, Mariela Hernández-Sánchez MD MS, Alba Cortés-Alfaro MD MS
}

\begin{abstract}
SUMMARY
INTRODUCTION Recent decades have seen an uptick in suicide attempts and completed suicides among adolescents and young adults worldwide. In the Americas, including Cuba, suicide is the third leading cause of death in adolescents (ages 10-19 years).

OBJECTIVE Characterize the epidemiology of attempted and completed suicide in Cuban adolescents from 2011 through 2014.

METHODS A descriptive epidemiological study was carried out. The information was gathered from morbidity records for suicide attempts and mortality records for suicide deaths in adolescents, taken from the Cuban Ministry of Public Health's Medical Records and Health Statistics Division database for January 1, 2011 through December 31 , 2014. Variables were sex, age, occupation or employment status, and suicide method. Suicide attempt incidence rates and suicide mortality rates by age group per 100,000 population (crude, adjusted and age/sex specific), mortality sex ratio and attempt/suicide ratio were calculated. Relative change was calculated as a percentage, as were frequencies by variable for attempted suicide and suicide, and by age and sex for method used.
\end{abstract}

RESULTS A total of 19,541 suicide attempts and 149 suicides were reported. Average annual numbers were $4,885.2$ suicide attempts and 37.2 suicides (131:1 ratio). There were 3,966 suicide attempts among boys, for a sex ratio of $0.25: 1$. Age-adjusted suicide attempt rates decreased from 391.8 per 100,000 population to $304.5(22.3 \%$ reduction over the study period). Boys accounted for 107 of 149 suicide deaths, for a sex ratio of 2.5:1. Age-adjusted suicide mortality rates

\section{INTRODUCTION}

Suicide is one of the most urgent problems that health professionals face today. Worldwide, suicide attempts and deaths increase each year, and so do their negative psychological and social effects on victims, their family members and their healthcare team. It is a multifactorial issue stemming from a complex mix of biological, genetic, psychological, social and environmental factors. Its impact in terms years of life lost and pain experienced by loved ones justifies the utmost attention.[1-3]

Suicide's impact is especially severe in adolescence, the portion of the life cycle between childhood and adulthood, and characterized by biological, psychological and sociological changes, many of which create crises, conflicts and contradictions. It includes two stages: early adolescence, 10-14 years and late adolescence, 15-19 years.[3]

Suicide in adolescents has been a growing problem for decades. [1] Suicide attempts are more frequent in adolescence than in adulthood and are more frequent than completed suicides. It is estimated that by 2020 , some $15-30$ million adolescents worldwide will deliberately hurt themselves. Suicide is one of the main causes of death in adolescents and, together with suicide attempts, represents $3 \%$ of adolescent burden of disease, higher decreased from 2.8 to 2.3 per 100,000 population (17.9\% reduction). The group aged 15-19 years had the highest age-adjusted suicide rate (3.9 per 100,000 population) and contributed the most deaths $(114 / 149,76.5 \%)$, although it did experience a $31.8 \%$ reduction over the study period. The group aged 10-14 years recorded a relative increase of $60 \%$ over the study period. Hanging was the most common suicide method $(116 / 149,77.9 \%)$. The suicide rate in Cuban adolescents (2.6 per 100,000 population, 3.7 in boys and 1.5 in girls) is less than that reported by the Region of the Americas between 2005 and $2009,3.7$ per 100,000 population $(5 / 100,000$ in boys and $2.3 / 100,000$ in girls).

CONCLUSIONS Suicide rates in Cuban adolescents are lower than reported elsewhere in the Americas. Suicide attempts and suicide rates decreased modestly between 2011 and 2014. Hanging is the most commonly used method. The highest rates occur in the group aged 15-19 years, but those aged 10-14 years showed a relative increase over the study period. These results update the epidemiology of suicide in Cuban adolescents and demonstrate the extent of the problem. Suicides and suicide attempts show opposite patterns in boys and girls; suicides are more frequent among boys while suicide attempts are more frequent among girls.

KEYWORDS Suicide; suicide, attempted; mortality rate; adolescents; Cuba

CONTRIBUTION OF THIS RESEARCH These results update the epidemiology of suicide in Cuban adolescents and reveal the extent of the problem for one of the main preventable causes of death in this age group.

than asthma, tuberculosis and AIDS, and comparable to drug abuse and violence.[2,3]

During the 2013 World Health Assembly, WHO's first mental health action plan proposed a goal of a $10 \%$ reduction of global suicide rates by 2020.[4] PAHO declared suicide an important public health problem and resolved that its indicators should be evaluated and monitored in the Americas.[5] In many countries, suicidal behavior among adolescents is a mental health issue that must be addressed.[6-11]

In Cuba, suicide is the third leading cause of death among adolescents.[12] The National Program for Prevention of Suicidal Behavior (created in the 1980s and upgraded several times since)[13] aims to decrease suicide mortality and morbidity from suicide attempts. It focuses on searching for risk factors, patient followup and assessment by multidisciplinary teams.[14] This study's objective was to characterize the epidemiology of suicide attempts and completed suicides in Cuban adolescents in 2011-2014.

\section{METHODS}

Study type and data sources A descriptive epidemiological study was carried out to characterize suicide attempt morbidity 
and suicide mortality in people aged 10-19 years in Cuba in 2011-2014. Data sources included morbidity records for suicide attempts from notifiable disease cards and suicide death certificates in the mortality database of the Cuban Ministry of Public Health's (MINSAP) National Medical Records and Health Statistics Division from January 1, 2011 through December 31, 2014.[12]

Variables For suicide attempts variables were sex (male, female) and age group (10-14 and 15-19 years). Variables for suicide were the same as for suicide attempts, plus occupation or employment status: student, unemployed, homemaker, with an incapacitating disability, and other (includes armed forces, skilled and unskilled workers, middle-level professional or technician, office workers and unknown) and methods used for suicide (hanging, poisoning, firearms, self-immolation, jumping from high places and intentional motor vehicle collision).
Table 1: Suicide attempts and suicides in Cuban adolescents, 2011-2014

\begin{tabular}{|c|c|c|c|c|c|c|c|}
\hline \multirow[b]{2}{*}{ Variable } & \multicolumn{3}{|c|}{ Suicide attempt } & \multicolumn{3}{|c|}{ Suicide } & \multirow{2}{*}{$\begin{array}{l}\text { Attempt: } \\
\text { suicide } \\
\text { ratio }\end{array}$} \\
\hline & Cases & $\begin{array}{l}\text { Crude } \\
\text { rate }^{\mathrm{a}}\end{array}$ & $\begin{array}{c}\text { Adjusted } \\
\text { rate }^{\mathrm{a}}\end{array}$ & Cases & $\begin{array}{l}\text { Crude } \\
\text { rate }^{\mathrm{a}}\end{array}$ & $\begin{array}{c}\text { Adjusted } \\
\text { rate }^{\mathrm{a}}\end{array}$ & \\
\hline \multicolumn{8}{|l|}{ Year } \\
\hline 2011 & 5,589 & 390.1 & 391.8 & 40 & 2.8 & 2.8 & 140 \\
\hline 2012 & 5,347 & 368.7 & 368.7 & 40 & 2.8 & 2.8 & 134 \\
\hline 2013 & 4,417 & 315.7 & 317.5 & 37 & 2.6 & 2.6 & 110 \\
\hline 2014 & 4,188 & 303.2 & 304.5 & 32 & 2.3 & 2.3 & 131 \\
\hline \multicolumn{8}{|l|}{ Sex } \\
\hline Male & 3,966 & 133.1 & 136.5 & 107 & 3.6 & 3.7 & 37 \\
\hline Female & 15,575 & 552.1 & 566.5 & 42 & 1.5 & 1.5 & 371 \\
\hline \multicolumn{8}{|l|}{ Age $^{b}$} \\
\hline $10-14$ & 6,484 & 230.0 & 232.7 & 35 & 1.2 & 1.2 & 185 \\
\hline $15-19$ & 13,057 & 437.8 & 452.4 & 114 & 3.8 & 3.9 & 115 \\
\hline Total & 19,541 & 336.8 & 345.6 & 149 & 2.5 & 2.6 & 132 \\
\hline
\end{tabular}

arates per 100,000 population ${ }^{\mathrm{b}}$ cumulative rates per 100,000 population
Data collection, processing and analysis Authorization was requested from MINSAP's Medical Records and Health Statistics Division to collect information. Notifiable disease cards and death certificates were the primary sources. To classify cause of death (intentionally self-inflicted injury), we used ICD 10 codes X60-X84.[15]

The following were calculated: suicide attempt and suicide mortality rates per 100,000 population by age group (crude, age adjusted and sex specific); sex ratio (male:female); and attempt:suicide ratio. Rates were directly standardized by age group and sex to Cuba's 2012 population. Relative change in rates was calculated and percentages were used to show distribution of variables (sex, age, occupation or employment status, and suicide methods) to indicate respective burden.

Medical Records and Health Statistics Division code books were used for the abovementioned variables. An Excel database was created to store and manage data and to generate tables and graphs.

Ethics Only morbidity and mortality records were used. Anonymity of patients and the deceased was preserved, and data were used exclusively for this research, which was approved by the National Hygiene, Epidemiology and Microbiology Institute Ethics Committee.

\section{RESULTS}

Suicide attempts There were 19,541 suicide attempts reported (4885.2 per year on average), a crude rate of 336.8 per 100,000 population for the period. The age-adjusted rate in 2011 was 391.8 per 100,000 population (hereinafter, rates reported are age adjusted, unless otherwise specified). In 2014, the rate dropped to 304.5 (Table 1 ), a $22.3 \%$ reduction.

At the beginning of the period, the rate for suicide attempts in boys was 139.2 per 100,000 , and decreased to 127.5 in 2014 (relative decrease of $8.4 \%$ ). In girls, the rate was 658.7 per 100,000 population in 2011 and decreased to 491.6 in 2014 (relative decrease of $25.4 \%$ ).
There were 6484 suicide attempts reported in the group aged 10-14 years, a rate of 232.7 per 100,000 population. The 2011 rate of 253.4 per 100,000 fell to 209.1 per 100,000 population in 2014 , a $17.5 \%$ reduction. In the group aged $15-19$ years, there were 13,057 attempts, for a rate of 452.4 per 100,000 population. In 2011 , the rate was 522.5 , decreasing to 394.8 per 100,000 population in 2014 , a $24.4 \%$ reduction. Sex ratio for attempted suicide was $0.25: 1$. The attempt:suicide ratio for the period was 131:1. Girls made 371 attempts per successful suicide and boys made 37 (Table 1).

Suicides Between 2011 and 2014, 149 suicides were reported (37.2 per year on average), for a rate of 2.6 per 100,000 population (Table 1). The rate was 2.8 per 100,000 population in 2011 and 2.3 in 2014 , a $17.9 \%$ reduction.

There were 107 suicide deaths among boys, for a rate of 3.7 per 100,000 population (Table 1). The rate in 2011 was 3.9 per 100,000 population, decreasing to 3.5 in 2014 , a $10.3 \%$ reduction.

Girls accounted for 42 suicides, for a rate of 1.5 per 100,000 population (Table 1). The 2011 rate was 1.6 per 100,000 population, dropping to 1 per 100,000 population in 2014 , a $37.5 \%$ reduction. The overall sex ratio for $2011-2014$ was $2.5: 1$ (107/42).

There were 35 suicides in the group aged 10-14 years, for a rate of 1.2 per 100,000 population (Table 1 ). In 2011 , the rate in this group was 1 per 100,000 population, increasing to 1.6 in 2014 , an increase of $60 \%$.

The group aged 15-19 years had the highest mortality, with 114 deaths and a rate of 3.9 per 100,000 (Table 1). The 2011 rate of 4.4 per 100,000 decreased to 3 per 100,000 population in 2014 , a $31.8 \%$ reduction. This group comprised $66.8 \%$ of the population but $76.5 \%$ of suicide deaths during the period (Table 2 ).

Students accounted for $54.4 \%$ of all suicide deaths (Table 2). Hanging was the most commonly used suicide method $(77.9 \%)$, in all age groups (Figure 1) and in both sexes (Table 2). 
Table 2: Suicide attempts and suicides in Cuban adolescents, by selected variables, 2011-2014

\begin{tabular}{|c|c|c|c|c|c|c|}
\hline \multirow{3}{*}{ Cases } & \multicolumn{4}{|c|}{ Sex } & \multirow{2}{*}{\multicolumn{2}{|c|}{ Total }} \\
\hline & \multicolumn{2}{|c|}{ Male } & \multicolumn{2}{|c|}{ Female } & & \\
\hline & $\mathbf{n}$ & $\%$ & $\mathbf{n}$ & $\%$ & $\mathbf{n}$ & $\%$ \\
\hline \multicolumn{7}{|c|}{ Suicide attempt ${ }^{a}$} \\
\hline Sex & 3,966 & 20.3 & 15,575 & 79.7 & 19,541 & $100.0^{b}$ \\
\hline \multicolumn{7}{|c|}{ Age (years) } \\
\hline $10-14$ & 1,141 & 28.8 & 5,343 & 34.3 & 6,484 & 33.2 \\
\hline 15-19 & 2,825 & 71.2 & 10,232 & 65.7 & 13,057 & 66.8 \\
\hline \multicolumn{7}{|c|}{ Suicide $^{c}$} \\
\hline Sex & 107 & 71.8 & 42 & 28.2 & 149 & $100^{b}$ \\
\hline \multicolumn{7}{|c|}{ Age (years) } \\
\hline $10-14$ & 24 & 22.4 & 11 & 26.2 & 35 & 23. \\
\hline $15-19$ & 83 & 77.6 & 31 & 73.8 & 114 & 76.5 \\
\hline
\end{tabular}

Occupation or employment status

\begin{tabular}{|l|r|r|r|r|r|r|}
\hline Student & 58 & 54.2 & 23 & 54.8 & 81 & 54.4 \\
\hline Unemployed & 26 & 24.3 & 2 & 4.8 & 28 & 18.8 \\
\hline Homemaker & 0 & 0.0 & 13 & 31.0 & 13 & 8.7 \\
\hline Disabled $^{\text {d }}$ & 4 & 3.7 & 0 & 0.0 & 4 & 2.7 \\
\hline Other $^{\text {M }}$ & 19 & 17.8 & 4 & 9.5 & 23 & 15.4 \\
\hline Method & & & & & & \\
\hline Hanging & 92 & 86.0 & 24 & 57.1 & 116 & 77.9 \\
\hline Poisoning & 4 & 3.7 & 9 & 21.4 & 13 & 8.7 \\
\hline Firearms & 11 & 10.3 & 0 & 0.0 & 11 & 7.4 \\
\hline Self-immolation & 0 & 0.0 & 7 & 16.7 & 7 & 4.7 \\
\hline Jumping from high & 0 & 0.0 & 1 & 2.4 & 1 & 0.7 \\
\hline
\end{tabular}

places

\begin{tabular}{|l|l|l|l|l|l|l|l|}
\hline Motor vehicle collision & 0 & 0.0 & 1 & 2.4 & 1 & 0.7 \\
\hline
\end{tabular}

\section{an $=19,541$}

bsummed horizontally (all other series sum vertically)

${ }^{\mathrm{c}} \mathrm{n}=149$

incapacitating

eincludes armed forces, skilled and unskilled workers, middle-level professionals or technicians, office workers and cases with unknown occupation

Figure 1: Suicide method by age group in Cuban adolescents, 2011-2014

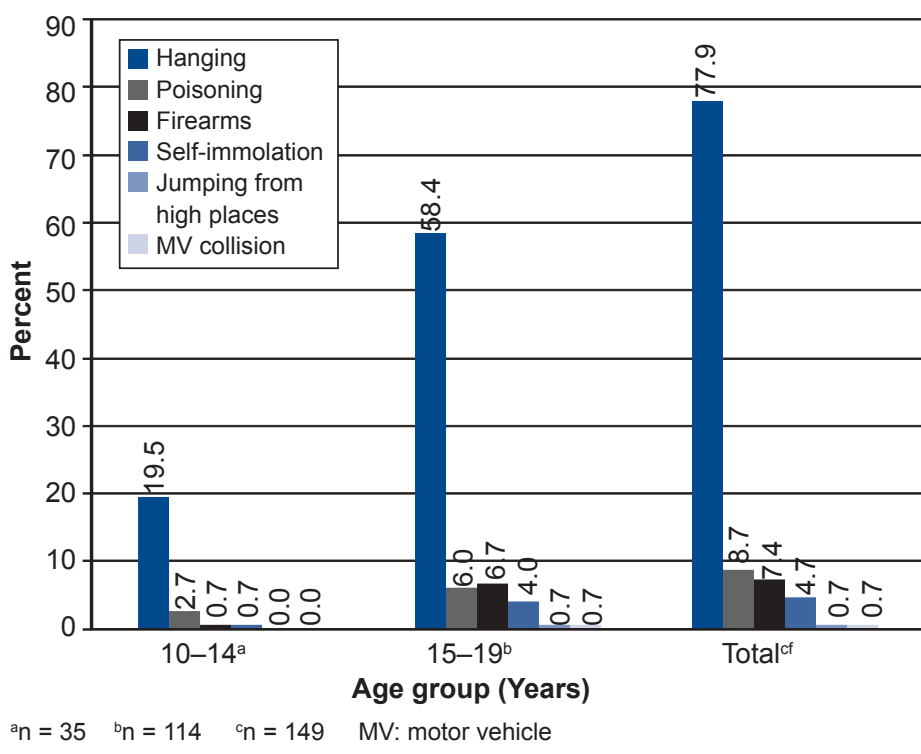

\section{DISCUSSION}

There is considerable recent literature on risk factors for suicide. Depression, desperation, impulsiveness, violence, alcohol and drug use, school failure, low cultural and economic levels, chronic diseases, immigration, bullying (psychological, moral and/or physical harassment at school, where one student exerts power over another systematically with intent to cause harm) are the most commonly invoked factors. [16-21]

Poor family communication, frequent quarrels, lack of affection and cohesion among family members and overall lack of support, are main factors that contribute to suicidal behavior in children and adolescents.[22] Home and school are the contexts in which most risk factors for suicidal behavior can develop, but at the same time can offer many opportunities to detect factors and stigmas that can lead to suicidal ideation.

Some researchers argue that the global economic crisis, globalization and advanced technologies contribute to increased suicidal behavior during adolescence, arguing that stress associated with a faster pace of life, conflicts and competition leads to desperation and tension during a critical period in life in which psychological, sociological and biological changes make adolescents especially vulnerable.[23] Despite its socially inclusive system and the special protection afforded vulnerable groups, these problems also affect Cuban adolescents.

In Cuba, young people are increasingly exposed to modern technologies and audiovisual products. A study of Cuban adolescents reported notable increases in video gaming and Internet addiction.[16] Such addictions are known to accentuate loneliness, reduce psychological wellbeing and affect socialization and psychomotor development in adolescents.[16] In addition, young people's increasing access to the Internet exposes them to images and other visual information about selfdestructive behavior, or other apocalyptic content, all of which can have quite harmful effects.[17,18]

The $60 \%$ increase over the study period in suicide rates in the group aged 10-14 years is consistent with international studies reporting that suicide is increasingly frequent in early adolescence. This may be due not only to traditional risk factors, but also to technological development in recent years. Modern technologies have changed our relationships. We no longer rely on face-to-face interactions. A child alone in their bedroom can be in touch with dozens of people, but this tends to foster weak connections, superficiality, short-term relationships and ultimately, social isolation.[24] Overreliance on technology, if combined with lack of parental supervision or a dysfunctional family environment, can have negative effects on adolescent behavior and might help explain why suicidal behavior and thoughts historically attributable to adults, are occurring among youth in our societies.[24]

Attempted suicide is considered a psychiatric emergency.[13,14] Cuba's National Program for Prevention of Suicidal Behavior has established a protocol for all such attempts. A mandatory note is entered on the notifiable disease card of those who attempt suicide, for followup by the patient's basic primary care team (family doctor, nurse, pediatrician, clinician, OB/GYN, psychologist) and mental health team (psychiatrist, psychologist, 
nurse, social worker) in their municipality. This aimed at timely treatment and monitoring by psychiatric specialists after initial assessment. Reports on assessment and evaluation of the Program in selected municipalities have revealed both strengths and weaknesses. One Program evaluation study reported that $72.9 \%$ of cases had been monitored satisfactorily in clinics and on-site visits, as stipulated, and that in the remainder of cases, monitoring was not possible due to incorrect addresses or family refusal.[25] Another report detected lack of compliance with the Program.[26] However, these results are not representative of Cuba as a whole. When the Program functions properly, it is a valuable resource for suicidal behavior prevention.

Previous studies in Cuba have reported increases in suicide attempts in Cuban adolescents in 2011 and 2012, but none of them had national coverage.[27-29] No such increase was apparent in our national study. On the contrary, there was some decline in suicide and suicide attempts in Cuba over the study period, less in boys than in girls, although boys had lower initial rates. Attempts declined more than completed suicides.

The suicide rate in Cuban adolescents (2.6 per 100,000 population) is less than that reported by the Region of the Americas between 2005 and 2009, 3.7 per 100,000 population (5 in boys and 2.3 in girls). Rates of 4.4 and 3.5 per 100,000 population were reported in North America, and Central America and the Spanish Caribbean, respectively.[30] In contrast, suicide rates in Spain are lower than those we found: in 2010, 0.1 per 100,000 population for the group aged $10-14$ years, and 1.2 per 100,000 population for the group aged 15-19 years.[24]

In Colombia, suicide attempts have been reported as early as age seven years, although with rates gradually increasing with age, and more frequent in girls.[31,32] The higher frequency of suicide attempts among girls is consistent with our findings.

Although children aged less than 10 years are not included in our study and will be the subject of another paper, there is considerable literature sounding an alert about suicidal behavior in children.[33-36]

As seen elsewhere, the number of suicide attempts far exceeded completed suicides; the attempt:suicide ratio was within the range of a Spanish study that found ratios of 100-200 attempts per suicide.[37]

The relation between suicide attempts and suicide is clearly sexrelated, with girls more likely to attempt and boys more likely to complete. Our finding that boys were more affected by suicide coincides with PAHO's technical report, which states that in the Americas Region, boys have higher suicide rates across all age groups.[38] In other regions, it has been reported that completed suicide is two to five times more frequent in boys, consistent with our findings.[39] In Cuba, the suicide sex ratio has been increasing among adolescents. [40] A study carried out in Mexico reported that $68.4 \%$ of suicides occurred in boys,[41] which is lower than in our study. A 2.2 sex ratio in this age group was reported for the Americas, while for Central America, Spanish Caribbean and Mexico, it was 1.7,[38] lower than ours. China and India are the only countries in which suicide rates in women are higher than in men.[42]
The highest number of attempted and completed suicides occurred in the group aged 15-19 years, consistent with other studies reflecting that risk is higher in late than in early adolescence.[24] In Mexico, this age group also presented the highest percentage of suicide cases $(78.2 \%)$, even higher than in our study.[41]

Most suicides occurred among students. This might simply reflect the fact that the vast majority of youngsters in Cuba are students.[43] Cuba offers free education for all, and school attendance is compulsory up to age 14 years; in 2015, $91 \%$ of secondary-school-aged youth were enrolled.[44] A Spanish study found that suicide risk was five-fold higher among youngsters who abandon school and eight-fold higher in those without postsecondary education.[45]

Suicide methods depend on availability and access. Our finding that the most commonly used suicide method in this study was hanging is in accord with other research reporting that hanging is most common in ages 10-19 years, as it is inexpensive, easy and does not require laborious planning.[32,41] Hanging is also the most frequent suicide method in Central America, the Spanish Caribbean and Mexico (65.2\%), as well as South America (59\%), although by smaller margins than in Cuba.[38]

Poisoning ranked second in our study, as it did in PAHO's Report on Suicide Mortality in the Americas, which placed poisoning at $23.5 \%$, more than double the percentage in Cuba. Poisoning is the most common method in the non-Spanish Caribbean, at 47.4\%.[38] In some high-income countries, different methods are more frequently used. In North America, predominantly in the United States, firearms were the number one suicide method among boys and young men.[38]

The study's main limitation was its inability to obtain reliable information from secondary sources on other geodemographic stratification criteria that could have helped create broader, more complete epidemiological insights into socially related causes of suicide or suicide attempts.

Despite this limitation, the study provides important baseline information on the characteristics of attempted and completed suicide among young people. It gives visibility to attempted suicide, a problem for which Cuba is one of the few countries reporting data to $\mathrm{PAHO} / \mathrm{WHO}$, although it is not included in MINSAP's annual statistical yearbook.[12] While current trends do not point to a marked decline in completed suicides, there have been substantial decreases in attempted suicide.

There are very few Cuban publications on suicide, especially among adolescents. The information obtained here provides an essential basis for other, more specific family or individual studies regarding causes of suicide and suicide attempts. Such studies will help Cuba design and implement more effective prevention strategies to address identified causes of preventable morbidity and death. As a collateral benefit for future research and surveillance, a complete database is now available for researchers to contact families and monitor adolescents at risk. Although our study does not and cannot purport to establish causal associations, it provides the epidemiological basis for further studies seeking causal factors. 


\section{CONCLUSIONS}

Suicide rates in Cuba are lower than those reported elsewhere in the Americas and overall suicide attempt and suicide rates decreased somewhat between 2011 and 2014. However, there is no room for complacency. The highest suicide rates occur in the group aged 15-19 years, but rates in those aged 10-14 years are increasing. Hanging is the most commonly used method. Boys are more likely to commit suicide, but girls more likely to attempt it. These results update the epidemiology of suicide in
Cuba in the group aged 10-19 years and demonstrate the extent of the problem for one of the main preventable causes of death in Cuban adolescents. Thus, these findings alert us to the need to take action to further reduce rates of suicide and suicide attempts in Cuban young people.

\section{ACKNOWLEDGMENTS}

Our thanks to Silvia Serrá Larín and María del Carmen Hinojosa Álvarez for assistance with the literature review. - 1

\section{REFERENCES}

1. World Health Organization. Prevención de la Conducta Suicida [Internet]. Washington, D.C.: World Health Organization; Pan American Health Organization; 2016 [cited 2017 Oct 2]. Available from: http://iris.paho.org/xmlui/bitstream/ handle/123456789/31167/9789275319192-spa pdf?sequence=1\&isAllowed=y. Spanish.

2. Collins PY, Patel V, Joestl SS, March D, Insel TR, Daar AS, et al. Grand challenges in global mental health. Nature [Internet]. 2011 Jul 6 [cited 2017 Mar 20];475(7354):27-3. Available from: http:// www.nature.com/nature/journal/v475/n7354/ full/475027a.html

3. Gore FM, Bloem PJ, Patton GC, Ferguson J, Joseph V, Coffey C, et al. Global burden of disease in young people aged 10-24 years: a systematic analysis. Lancet [Internet]. 2011 Jun 18 [cited 2017 Mar 20];377(9783):2093-102. Available from: https://linkinghub.elsevier.com/ retrieve/pii/S0140-6736(11)60512-6

4. World Health Organization. 53 Plan de Acción para la Salud Mental. Consejo directivo 66a Sesión del comité regional de la OMS para las Américas [Internet]. Washington, D.C.: World Health Organization; Pan American Health Organization; 2014 [cited 2017 Jan 2]. Available from: http://www.paho.org/HQ/ index.php?option $=$ com_content $\&$ view $=$ arti cle\&id=9774\%3A2014-53rd-directing-coun cil\&catid=7003\%3A53rd-directing-council-29 -sep-3-oct\&ltemid=41062\&lang=es. Spanish.

5. Pan American Health Organization. Marco de Referencia para la Implantación de la Estrategia Regional de Salud Mental. Washington, D.C.: Pan American Health Organization; 2011. p. 142-7. Spanish.

6. Medina MR, Vázquez de Anda GF, Valdespino Salinas E. Revisión de la conducta suicida en el sur del Estado de México. Med Int Mex [Internet]. 2013 May-Jun [cited 2017 Mar 20];29(3):25764. Available from: www.medigraphic.com/pdfs/ medintmex/mim-2013/mim133f.pdf. Spanish.

7. Piedrahital LE, García MA, Mesa JS, Stivalis Rosero I. Identificación de los factores relacionados con el intento de suicidio en niños y adolescentes a partir de la aplicación del Proceso de Atención de Enfermería. Colomb Med [Internet]. 2011 Jul-Sep [cited 2017 Mar 14];42(3):334-41. Available from: http://www .scielo.org.co/pdf/cm/v42n3/v42n3a10.pdf. Spanish.

8. Cendales R, Vanegas C, Fierro M, Córdoba R, Loiret A. Tendencias del suicidio en Colombia, 1985-2002. Rev Panam Salud Pública [Internet]. 2007 [cited 2017 Apr 9];22(4):231-8. Available from: http://www.scielosp.org/pdf/rpsp/v22n4/02 .pdf. Spanish.

9. Paniagua RE, González CM, Rueda SM. Orientación al suicidio en adolescentes en una zona de Medellín, Colombia. Rev Fac Nac Salud Pública [Internet]. 2014 Sep-Dec [cited 2017 Mar 14];32(3):314-21. Available from: http://www .redalyc.org/pdf/120/12031816008.pdf. Spanish.
10. Albores-Gallo L, Méndez-Santos JL, XochitilGarcía Luna A, Delgadillo-González L, ChávezFlores $\mathrm{Cl}$, Martínez OL. Nonsuicidal Self-Injury in a Community Sample of Older Children and Adolescents of México City. Actas Esp Psiquiatr[Internet]. 2014 Jul-Aug [cited 2017 Mar 20];42(4):159-68. Available from: http://www .actaspsiquiatria.es/repositorio//16/90/ENG/16 -90-ENG-159-168-700617.pdf. Spanish.

11. Trigylidas TE, Reynolds EM, Teshome G, Dykstra HK, Lichenstein R. Paediatric suicide in the USA: analysis of the National Child Death Case Reporting System. Inj Prev [Internet]. 2015 [cited 2016 Jun 7]. Epub ahead of print. Available from: http://injuryprevention.bmj.com/content/early/ 2016/01/18/injuryprev-2015-041796abstract

12. National Health Statistics and Medical Records Division (CU). Anuario Estadístico de Salud 2015 [Internet]. Havana: Ministry of Public Health (CU); 2016 [cited 2017 May 11]. 206 p. Available from: http://files .sld.cu/dne/files/2016/04/Anuario_2015_electro nico-1.pdf. Spanish.

13. Riera Betancourt C, Alonso Betancourt O, Masid Oramas E. La Conducta Suicida y su Prevención. Havana: Hygiene and Epidemiology National Center (CU); 1990. Spanish.

14. Lomba Acevedo P, Alfonso Carrillo E, Fernández Coto L. Prevención del suicidio en la comunidad. In: Medio Residencial y Salud. Havana: World Health Organization; Pan American Health Organization; 2013. p. 207-14. Spanish.

15. Pan American Health Organization. Clasificación internacional de enfermedades CIE-10. Causas externas de morbilidad y mortalidad. Lesiones auto infligidas intencionalmente. Capítulo 20 (X60-X84) [Internet]. Washington, D.C.: Pan American Health Organization; 2001 [cited 2017 Mar 2]. Available from: http://ais.paho.org/ classifications/Chapters/. Spanish.

16. Estévez García K, Velázquez Reinaldo $\mathrm{R}$. Conductas de riesgo en adolescentes y jóvenes. Videojuegos: ¿armas letales? ES [Internet]. 2014 Oct [cited 2017 Mar 14];11:43-96. Available from: http://209.177.156.169/libreria_cm/archivos/ pdf 1062.pdf. Spanish.

17. Durkee T, Hadlaczky G, Westerlund M, Carli V. Internet pathways in suicidality: a review of the evidence. Int J Environ Res Public Health. 2011 Oct;8(10):3938-52.

18. McCarthy MJ. Internet monitoring of suicide risk in the population. J Affect Disord. 2010 May; 122(3):277-9.

19. Cañón Buitrago SC. Factores de riesgo asociados a la conducta suicida en niños y adolescentes. Arch Med [Internet]. 2011 Jan-Jun [cited 2016 Mar 14];11(1):62-7. Available from: http://search.ebscohost.com/login.aspx?direct $=$ true $\& \mathrm{db}=\mid$ th $\& A N=82584789 \&$ lang $=e s \&$ site $=$ eho st-live. Spanish.

20. Acosta-Hernández M, Mancilla-Percino $T$, Correa-Basurto J, Saavedra-Vélez M, RamosMorales FR, Cruz-Sánchez JS, et al. Depresión en la infancia y adolescencia: enfermedad de nuestro tiempo. Arch Neurocien (Mex) [Internet]. 2011 Jul-Sep [cited 2016 Mar 14];16(3):156-61. Available from: http://search.ebscohost.com/ login.aspx?direct=true \&db=|th\&AN=88924012\&| ang=es\&site=ehost-live. Spanish.

21. Greydanus DE, Apple RW. The relationship between deliberate self-harm behavior, body dissatisfaction, and suicide in adolescents: current concepts. J Multidiscip Health [Internet]. 2011 [cited 2017 Mar 14];4:183-9. Available from: https://www.ncbi.nlm.nih.gov/pmc/articles/ PMC3141836/

22. Ruiz R. Familia, género y violencia doméstica. Diversas experiencias de investigación social. ES [Internet]. 2014 Oct [cited 2017 Mar 14];11:27:45. Available from: http://209.177.156.169/libreria cm/archivos/pdf_1062.pdf. Spanish.

23. Córdova Moreno MA, Cubillas Rodríguez MJ, Román Pérez R. ¿Es posible prevenir el suicidio? Evaluación de un programa de prevención en estudiantes de bachillerato. Pensamiento Psicol [Internet]. 2011 [cited 2017 Mar 13];9(17):21-32. Available from: http://revistas.javerianacali.edu .co/index.php/pensamientopsicologico/article/ download/153/455. Spanish.

24. Picazo-Zappino J. El suicidio infanto-juvenil: una revisión. Actas Españolas Psi [Internet]. 2014 May [cited 2017 Mar 14];42(3):125-32. Available from: http://search.ebscohost.com/login.aspx?di rect $=$ true $\& d b=\mid$ th \&AN $=96033542 \&$ lang $=e s \&$ site =ehost-live. Spanish.

25. Aguilar Hernández I, Louro Bernal I, Perera Milián SL. Ejecución del Programa de Prevención y Control de la Conducta Suicida en Nueva Paz. Rev Cubana Salud Pública [Internet]. 2012 Jan-Mar [cited 2014 Apr 6];38(1). Available from: http://scielo.sld.cu/scielo.php?pid=S0864 $-34662012000100008 \&$ script=sci. Spanish.

26. Toro Kondeff M, Hernández González Y, David Huerta B. Caracterización de la conducta suicida en adolescentes del municipio Cerro, 2009-2010. Rev Hosp Psiquiátrico de la Habana [Internet]. 2012 [cited 2015 Dec 14];9(2). Available from: http://www.revistahph.sld.cu/Revista\%202-2012/ hph03212.html. Spanish.

27. Acosta González A, Milián Martínez M, Viña Pérez $\mathrm{H}$. Factores de riesgo del intento suicida en adolescentes con esta conducta. Rev Hosp Psiquiátrico de la Habana [Internet]. 2012 [cited 2014 Apr 9];9(1). Available from: http://new.medigraphic.com/cgi-bin/resumen .cgi?IDARTICULO=34791. Spanish.

28. Moreno Campa C, Díaz Cantún CL, Soler Santana R, Brossard Cisnero M, Carbonell García IC. Caracterización epidemiológica de la conducta suicida en la provincia de Santiago de Cuba. MEDISAN [Internet]. 2012 [cited 2017 May 10];16(2):204-10. Available from: http://bvs sld.cu/revistas/san/vol 162 12/san08212.pdf. Spanish.

29. Cruz Rodríguez E, Moreira Rios I, Orraca Castillo $\mathrm{O}$, Pérez Moreno N, Hernández González P. Factores de riesgo del intento suicida en adolescentes, Pinar del Río. Rev Ciencias 
Médicas [Internet]. 2011 Oct-Dec [cited 2017 May 11];15(4):52-61. Available from: http:// scielo.sld.cu/scielo.php?script=sci_arttext\&pid =S1561-31942011000400007. Spanish.

30. Pan American Health Organization. Mortalidad por Suicidio en las Américas: Informe Regional [Internet]. Washington, D.C.: Pan American Health Organization; World Health Organization; 2014 [cited 2017 May 10]. p. 6-49. Available from: http://www.bvsde .paho.org/documentosdigitales/bvsde/texcom/ PAHOMortalidad-suicidio.pdf. Spanish.

31. Jiménez Quenguan $M$, Hidalgo Bravo J, Camargo Santacruz C, Dulce Rosero B. El intento de suicidio en la población pediátrica, una alarmante realidad. Rev Cienc Salud [Internet]. 2014 [cited 2017 May 11];12(1):63-87. Available from: http://www.scielo.org.co/pdf/recis/v12n1/ v12n1a06.pdf. Spanish.

32. Garavito Egea G. Autopsia psicológica en niños y adolescentes con conductas suicidas. Rev Cultura, Educación y Sociedad [Internet]. 2017 [cited 2017 Nov 27];2(1). Available from: http://revistascientificas.cuc.edu.co/index.php/ culturaeducacionysociedad/article/view/933. Spanish.

33. Pfeffer CR. Suicidal behavior in children: from the 1980s to the new millennium. In: Maris RW, Canetto SS, Mclntosh JM, Silverman MM, editors. Review of Suicidology. New York: Guilford; 2000. p. 159-69.

34. Matter DE, Matter RM. Suicide among elementary school children: a serious concern for counselors. Elem School Guidance Counseling. 1984;18:260-7.

35. Pompili M, Mancinelli I, Girardi P, Ruberto A, Tartarelli R. Childhood suicide: a major issue in pediatric health care. Issues Compr Pediatr Nurs. 2005;28:63-8.

36. Trad PV. Self-destructive preschool children In: O'Brien JD, Pilowski DJ, Lewis OW, editors. Psychotherapies with children and adolescents. Adapting the psychodynamic process. Northvale: Jason Aronson Inc.; 2000. p. 27-51.
37. Giner Jiménez L. Diferencias en la conducta suicida: estudio comparativo entre los intentos de suicidio y suicidio consumado [thesis] [Internet]. [Madrid]: Universidad Autónoma de Madrid; 2010 [cited 2017 May 17]. 243 p. Available from: https://repositorio.uam.es/ bitstream/handle/10486/5657/35431_giner jimenez_lucas.pdf?sequence=1. Spanish.

38. Pan American Health Organization. Mortalidad por Suicidio en las Américas: Informe Regional [Internet]. Washington, D.C.: Pan American Health Organization; World Health Organization; 2014 [cited 2017 May 10]. p. 6-49. Available from: http://www.bvsde .paho.org/documentosdigitales/bvsde/texcom/ PAHOMortalidad-suicidio.pdf. Spanish.

39. Freuchen A, Kjelsberg E, Grøholt B. Suicide or accident? A psychological autopsy study of suicide in youths under the age of 16 compared to deaths labeled as accidents. Child Adolesc Psychiatry Mental Health [Internet]. 2012 [cited 2016 Dec 2];30(6):[about 6 p.]. Available from: https://www.ncbi.nlm.nih.gov/pmc/articles/ PMC3526543/

40. Corona Miranda B, Alfonso Sagué K, Hernández Sánchez M, Lomba Acevedo P. Epidemiology of suicide in Cuba 1987-2014. MEDICC Rev [Internet]. 2016 Jul [cited 2017 Mar 20];18(3):1520. Available from: http://www.scielosp.org/pdf/ medicc/v18n3/1555-7960-medicc-18-03-0015 .pdf

41. Sánchez-Cervantes FS, Serrano-González RE, Márquez-Caraveo ME. Suicidios en menores de 20 años. México 1998-2011. Salud Ment. 2015 Sep-Oct;38(5):379-89. Spanish.

42. World Health Organization. Preventing suicide: A global imperative [Internet]. Luxembourg: World Health Organization; 2014 [cited 2015 Dec 2]. 92 p. Available from: http://www.who.int/mental health/suicide-prevention/world report 2014/

43. Rojas Ochoa F. Situación, sistema y recursos humanos en salud para el desarrollo en Cuba. Rev Cubana Salud Pública [Internet]. 2003 Apr-Jun [cited 13 Mar 2017];29(2): [about 6 p.]. Available from: http://scielo.sld.cu/scielo.php?script=sci _arttext\&pid=S0864-34662003000200011. Spanish.

44. National Statistics Bureau (CU). Anuario Estadístico de Cuba 2016. Educación [Internet]. Havana: National Statistics Bureau (CU); 2017 [cited 2018 Jan 15]. p. 28. Available from: http:// www.one.cu/aec2016/18\%20Educacion.pdf. Spanish.

45. Pérez Camarero S. El suicidio adolescente y juvenil en España. Rev Estudios de Juventud. 2009 Mar;84(2):126-42. Spanish.

\section{THE AUTHORS}

Beatriz Corona-Miranda (Corresponding author: bettycoro@infomed.sld.cu; beatrizc@ inhem.sld.cu), physician with dual specialties in family medicine and hygiene \& epidemiology, with a master's degree in environmental health, National Hygiene, Epidemiology and Microbiology Institute (INHEM), Havana, Cuba.

Karen Alfonso-Sagué, mathematician, INHEM, Havana, Cuba.

Mariela Hernández-Sánchez, physician specializing in school health, with a master's degree in epidemiology, INHEM, Havana, Cuba

Alba Cortés-Alfaro, physician specializing in school health, with a master's degree in epidemiology, INHEM, Havana, Cuba.

Submitted: May 19, 2017

Approved for publication: September 28, 2017 Disclosures: None

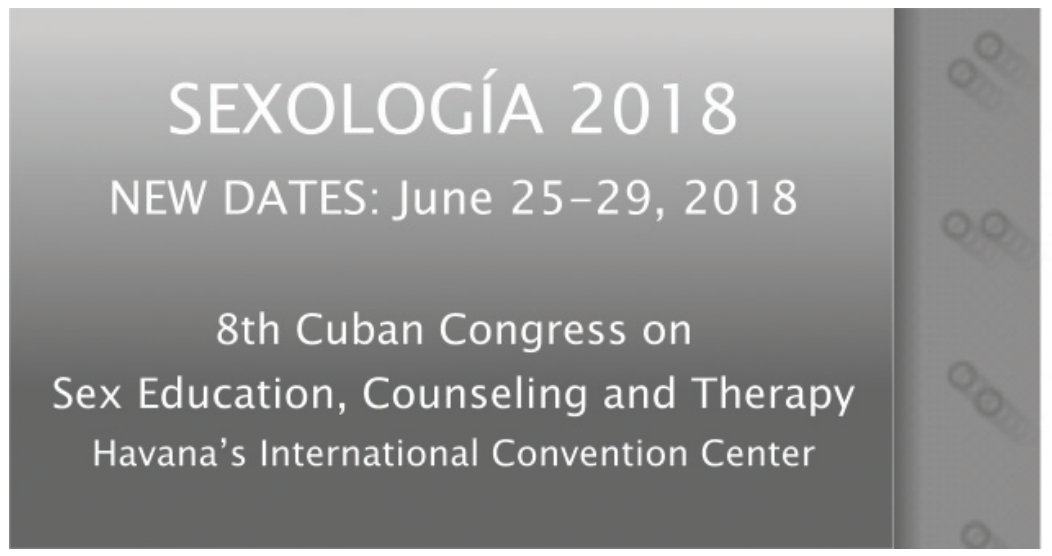

Hosts:

- National Sex Education Center (CU)

- Cuban Multidisciplinary Society for Sexuality Studies

Languages: Spanish, English

Information:

http://www.sexologiacuba.com/ 


\section{Dispatches from Haiti, 2010}

\section{Conner Gorry MA}

Haiti is a country that appears fleetingly in the Englishspeaking media, when stricken by disaster or more recently by epithets. Perhaps few are aware that Haiti was the first independent nation in Latin America and the Caribbean, and the world's first black republic-independence declared on January 1, 1804-in a revolution led by former slaves who defeated Napoleon's 40,000-strong colonial forces. Or that, when others abandoned the independence wars against Spain, Simón Bolívar appealed to Haitian president Alexandre Pétion and with Pétión's troops and material aid, went on to free slaves across Spanish-held colonies in Latin America.

Over the centuries, the Haitian people have indeed been beset by disasters, both natural and man-made. But they have also stood against daunting odds and have received solidarity from their hemispheric neighbors, Cuba among the countries allied with Haiti's attempts to provide for its people.

In this Retrospective, MEDICC Review reprints excerpts from a blog by Senior Editor Conner Gorry, who, during February and March 2010, was embedded in the disaster-response medical team sent from Cuba after the January 12 earthquake. The team reinforced nearly 500 Cuban health personnel already on the ground long term in 120 communities. Some 700 of the 1300 new arrivals were students or graduates of Cuba's Latin American School of Medicine from 27 countries. Haitian graduates now number 1044. The international contingent (named after Henry Reeve, a Brooklyn-born general in Cuba's own independence struggle)—became the largest medical relief effort assembled after the quake.

The vivid stories here take us back to the urgency and chaos of those first weeks and months after disaster struck. But Haitian, Cuban and other Cuban-trained doctors dedicated to Haiti's recovery-its long-term health care needs and strengthened public health system-provide an example of commitment to social equity and human solidarity in the face of enormous challenges. And their work with those from other countries proves effective cross-border, cross-cultural collaboration can work.

Today, there are 664 Cuban health professionals collaborating in Haiti, 175 of them doctors posted throughout the country. In 2017 alone, they carried out 2.64 million patient consults, performed 40,842 surgeries, and delivered 5788 babies (many times working with local midwives). They labor in 21 community reference hospitals built with funds from Venezuela; 31 rehabilitation centers, also built after the 2010 earthquake; 14 health centers; and 29 sentinel sites for epidemiological surveillance (mainly for cholera and vector-borne diseases). A national workshop for orthotics and prosthetics was also established to assist earthquake victims, with equipment and other resources provided by Cuba.

\section{The Editors}

\section{CUBAN MEDICAL TEAMS IN HAITI}

\begin{tabular}{|l|r|r|r|}
\hline Activity & $\begin{array}{r}\text { Post-earthquake } \\
\text { (to May 2nd, } \\
\text { 2010) }\end{array}$ & $\begin{array}{r}\text { Year } \\
\mathbf{2 0 1 7}\end{array}$ & $\begin{array}{r}\text { 1998-2017 } \\
\text { Cumulative }\end{array}$ \\
\hline Patient consults & 341,241 & $2,063,396$ & $28,516,413$ \\
\hline Births attended & 1,617 & 5,788 & 175,827 \\
\hline Surgeries & 8,715 & 40,842 & 607,337 \\
\hline Vaccinations & 111,250 & $n / a$ & $n / a$ \\
\hline $\begin{array}{l}\text { Physical therapy } \\
\text { sessions }\end{array}$ & 72,773 & $n / a$ & $n / a$ \\
\hline $\begin{array}{l}\text { Children provided } \\
\text { psychological services }\end{array}$ & 121,405 & $n / a$ & $n / a$ \\
\hline
\end{tabular}

Source: Central Medical Collaboration Unit, Ministry of Public Health, Cuba n/a: not available

"[There] were 480. . . Cuban health professionals in Haiti at the time of the earthquake. After the earthquake Cuba sent 1300 new ... additional health professionals ... Most of them . . . are in the province[s] and they are absolutely important for the country. Absolutely."

—Dr Henriette Chamouillet, WHO/PAHO Representative in Haiti, 2010

\section{A Day at the Leogâne Field Hospital}

Leaving Port-au-Prince is an exercise in self-defense: the assault of sights, sounds, smells and emotions requires closing your eyes, covering your nose, and shielding your heart from Haiti's brutal realities.

Haitian drivers-jumping dividers on their motorcycles into oncoming traffic or taking blind curves at high speed in colorful, emblematic taptaps-are additional hazards. On the map, Leogâne is only 20 miles west of Port-au-Prince, but pedestrian congestion and car traffic combine with the earthquake-buckled road to make it an hour-long trip. The city of 16,000 isn't far from the epicenter, and according to some estimates, $90 \%$ of the homes here were damaged in the quake. The widespread destruction caused by the disaster, compounded by the prequake health picture has manifested in a wide array of health problems, making it a logical location for a Henry Reeve Emergency Medical Contingent field hospital.

Staffed by Cuban doctors and graduates of Havana's Latin American Medical School (ELAM) from eight countries, plus five Haitian ELAM students who serve as translators and health promoters, the hospital in Leogâne offers free pediatric, ob-gyn, internal medicine and other services in individual tents divided by specialty; the most serious cases are referred to the hospital in nearby Saint Croix, while others are admitted to the limited-capacity tent wards on site.

"We had to adjust our strategy to reach more people," says Dr Wilbert Barral from Potosí, Bolivia (ELAM 2007) who heads the ELAM component of the Leogâne team. "Many Haitians haven't seen a doctor before or aren't sure how our services work. They think we may charge them, for instance, so we 
began going into the communities to provide consultations and tell people about the field hospital, explain the services, and that they're free." With this new strategy, the previous daily average of 500 patient visits has increased to 800 . Dr Barral told me that pregnant women and children are the priority since they are the ones at highest risk in post-disaster situations.

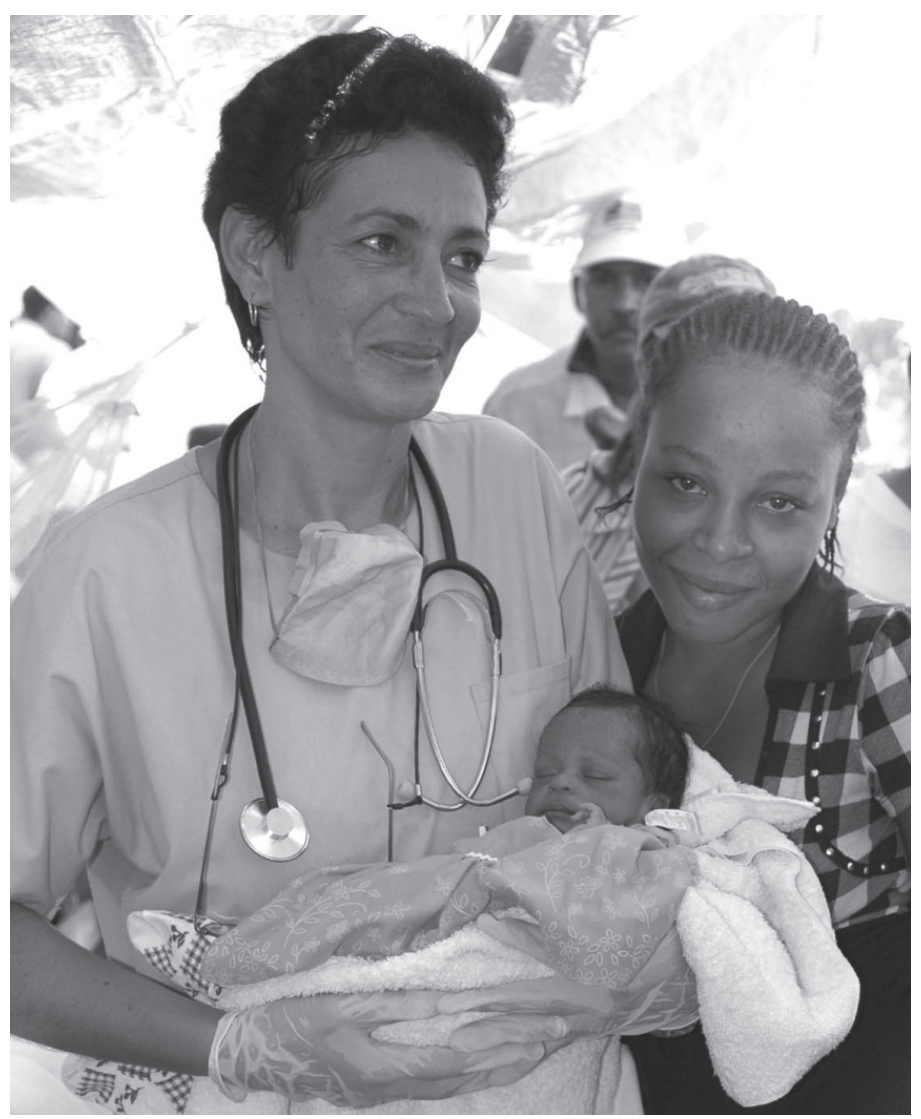

Cuban doctor with new mom and baby

Patients with chronic diseases are also a priority. "We're seeing a lot of hyperthyroidism, but not one case of leptospirosis, which is surprising since it's endemic in Haiti," explained Dr María Esther from Nicaragua (ELAM 2005).

The doctors at Leogâne emphasize that the emergency health phase has passed: The challenge now is to provide public health services that emphasize disease prevention and health promotion, including vaccination campaigns.

Today, the Leogâne hospital was full of song and dance, thanks to the voices, drums and infectious energy of Agrupación Vocal Desandann, a musical group of Cubans of Haitian descent. Hailing from Cuba's Camagüey province, the group is part of the Henry Reeve's mental health project, and came to Leogâne to sing traditional Creole songs, accompanied by dancing and lots of audience participation. The group first visited Haiti in 1996 and has been back over half a dozen times since to perform and deepen their ties with their ancestral roots. Many members speak Creole, including Director Amelia Díaz and composer Marcel Andrés whose 50th birthday is today. Slowly but surely, as the melodic strains came floating over the camp, community members began gathering. Before long,

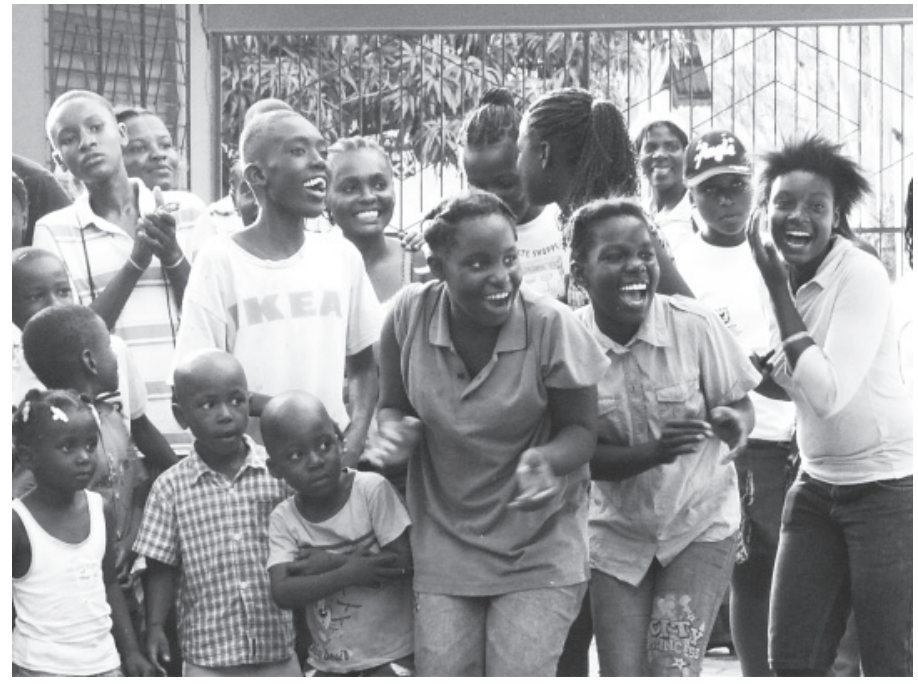

A day of song and dance at the Leogâne hospital

children were clapping, teens were dancing, and a terribly shy grandmother broke into a gap-toothed, ear-to-ear grin. March 4th is the 16th anniversary of Agrupación Vocal Desandann, and what a way to celebrate-in Haiti, bringing smiles and laughter to Haitians.

\section{From Emergency to Building Health: Hundreds of Cuban-Trained MDs Posted Throughout Haiti}

The commitment to Haitian health care made by graduates of ELAM after the earthquake entered a second phase today as more than 250 doctors fanned out to take up their new posts at health centers and hospitals around the country.

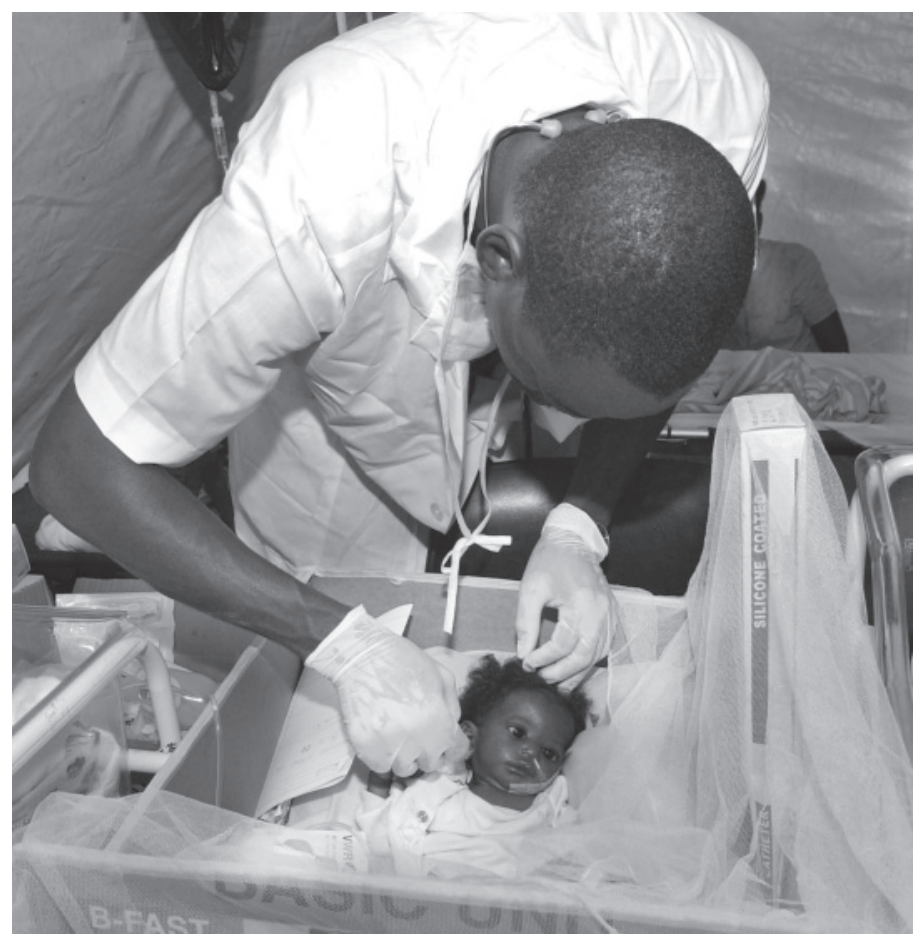

Haitian ELAM graduate at work 


\section{Retrospective}

These Cuban-trained doctors-joining the Cuban medical teams in Haiti-hail from over 25 countries in Africa, North and South America, the Middle East and Asia. And, of course Haiti itself.

The new assignments for these ELAM grads mark the formal transition from the emergency medical phase of the Cuban-led effort-addressing immediate problems such as wounds, burns and acute respiratory infections-to the next, more sustainable phase of providing long-term health care. The young doctors are being folded into Cuban health teams that have been working in the Haitian public health system without interruption since 1998.

Each ELAM doctor has chosen to stay in Haiti from three months to a year. "I've committed to six months, but I really want to stay a year," says $\mathrm{Dr}$ Sindy Gómez from El Salvador (ELAM 2008), "After that," she told me, "I'll discuss with my husband the possibility of staying longer. The Haitian people need us." ELAM doctors from Colombia, Panama and Brazil echoed Dr Gómez's sentiments-all the more noteworthy, since many of these young physicians come from low-income families that depend on them.

"All of them were motivated and willing to stay," said Eladio Balcarcel, Cuban coordinator of the ELAM graduates in Haiti. "Some are now going to more remote communities, but the conditions will be better. Living in tent camps for a couple of months is tolerable, but it's not sustainable over the long term," he explained in the midst of the sendoff. In their new posts, the doctors will be living in houses with electricity and water, and working in health centers and hospitals providing primary care services.

\section{One of the 170,000+ "Cases"}

I do a lot of listening here, asking far fewer questions than I usually would, and I never inquire about family...

There's a light drizzle falling as the busload of doctors, nurses, and fifth-year medical students head out for the morning's work in the Cuban health posts known as Belair I and Belair II. Stuttering through the clogged, rubble-strewn streets of Port-au-Prince, the bus is a veritable United Nations of medical personnel: there are Cuban doctors of course, but also Colombian, Brazilian and Panamanian physicians, plus Cuban nurses and Haitian MDs and students from ELAM-all trained in Cuba. Ironically, as we inch past elders selling charcoal from reed baskets and young toughs peddling black market antibiotics, an armored vehicle full of UN blue bonnets chugs past.

Belair I and Belair || are misnomers-these are not pretty places and the air is anything but. The camps are sprawling, muddy settlements with shelters made from plastic sheets and sticks, cardboard and corrugated metal packed cheek by jowl. Small children, barefoot and bare-bottomed often, beautiful and innocent always, suck their thumbs and watch as we walk past. In the middle of this stark reality stand the health posts: simple tents with a couple of rough-hewn benches and chairs where patients wait to be seen and treated for free by the Henry Reeve Emergency Medical Contingent.
"We were told this was a very rough area, with a lot of crime, when we learned where we would be working," said Arnaldo Santa Cruz, a physical therapist from Havana. But with over six weeks in operation, the Cubans are respected and protected by Belair's community. Today, like every day, women with babies and their young children, grandmothers and the odd man, wait patiently to see one of the "Cuban doctors" as the entire group is known. At the end of a long morning diagnosing and treating acute respiratory infections, scabies, and other common conditions plaguing Port-auPrince's population, a young girl arrives with a too-small bundle swaddled in a towel.

The girl is eight, her baby brother, the swaddled bundle, is just four months old. Dr Yahimely Pezcalderón, a family doctor from Cuba's Cienfuegos Province, lays the infant gently on the table. He's clearly malnourished and is running a fever of $103^{\circ}$. With Jude Celerin, a fifth-year Haitian ELAM student translating, $\mathrm{Dr}$ Pezcalderón learns that this eight-year-old girl has been taking care of her baby brother and little sister since the earthquake. Their mother is in the hospital and the prognosis isn't good. Dr Pezcalderón prescribes the medicines the baby needs to control the fever, but she is doubtful. "I don't like seeing children come to the health posts alone. They usually don't read and it's hard for them to understand the dosage and how to take the medicine. I'll make sure they come back tomorrow and follow up, but..."We haven't seen them since, but it has been raining, and patients typically stay away in the rain.

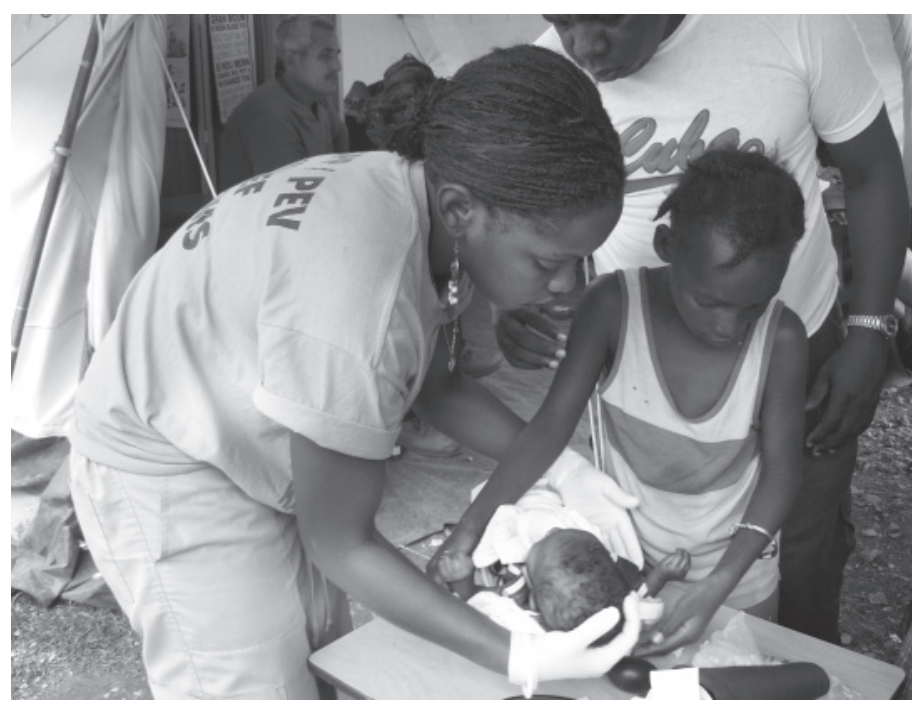

Yahimely Pezcalderón with 4-month-old and his sister

\section{An Ounce of Prevention:}

\section{Port-au-Prince Vaccination Campaign}

"At the beginning, we were vaccinating around 250 people a day, but it's tapered off to 70 or so," Raysoly Yacob Flores, a Salvadoran nurse trained in Cuba, tells me as we set out for the displaced persons camp where the Henry Reeve Contingent will vaccinate all comers. I'll admit I'm slightly disappointed that I'm catching the tail end of the action. I've heard a lot about the massive vaccinations carried out by the Cubans and their ELAM-trained colleagues in the weeks immediately following the earthquake, when multiple teams fanned out through the 
sprawling encampments that hundreds of thousands of Haitians now call "home."

But my disappointment is premature: instead of tagging along with Raysoly or the other team to areas where vaccinations have already been initiated, I'm accompanying Cuban nurse (and head of the Port-au-Prince vaccination effort) Esmeris Atiñol to a camp where no one has yet been vaccinated. It should be interesting to watch the team inaugurate a new location. A recent report filed on the blog Haiti: Operational Biosurveillance by $\mathrm{Dr}$ James Wilson describes health actions, including vaccinations, at a displaced persons camp in Pétion-Ville: "when word spread about sore arms and the occasional post-vaccination fever, very few showed up for the second day of vaccinations. Red Cross left the area, leaving a best estimate of only $20 \%$ of the population vaccinated." Given the limited experience many Haitians have with health care in general and vaccinations specifically, I'm especially anxious to see the community's reaction to this basic preventive health measure.

Delmas 15 (as it's called by the Cubans) is formally known as La Place Dame Carrefour Aéroport in the post-quake language of Port-au-Prince. It's a postage stamp plaza at the city's major intersection of Rte de Delmas and Blvd Toussaint Louverture where 1060 people live in donated tents pitched on bare, blazing hot concrete.

Before we're even beyond the first line of dust-covered tents, nurse Esmeris is chatting up mothers in lyrical Creole, asking if they've been vaccinated. Though she hails from the remote Cuban municipality of Tercer Frente in Santiago de Cuba, Esmeris' forbearers were Haitian and she has been working in Haiti as part of Cuba's Comprehensive Health Program for the past year. She traverses the divide between Spanish and Creole easily and I can see the relief etched on the mothers' faces as they converse in their native language. They follow this Cuban nurse to the vaccination post eagerly, small children in tow.

"Post" is an exaggeration. Each time the Henry Reeve Contingent initiates vaccinations in a new location, they have to find an accessible (and hopefully shady/rain-proof) location to set up. Luckily, La Place Dame is anchored by a pastel-colored gazebo that overlooks the fenced-in camp. The columns are cracked and crumbling from the quake, the rebar laid bare like an open wound, but no matter: its visibility and staircases at either end provide natural patient flow, plus it's refreshingly sun-free. From nowhere, a pair of clean-cut youths, badges of the camp's organizing committee dangling from their necks, appear carrying two chairs-each with three legs. Seems everything in Haiti these days is a balancing act. Once a table materializes (again I'm amazed at Haitian solidarity-that people so destitute and physically and emotionally battered still have the energy to share both among themselves and with us), the team is set to go to work.

The Henry Reeve Emergency Medical Contingent currently offers three vaccines: a trivalent DPT (diphtheria, pertussis and tetanus) for babies one-and-a-half months to eight months old; a DPT/measles/rubella combination, paired with vitamin A for children nine months to seven years old; and a diphtheriatetanus duo for everyone eight and over. Once again, the supplies used by the Cuban team represent a kaleidoscope of international health cooperation with vaccines from India, Canada and the WHO Essential Medicines Program; disposable syringes from the United Arab Emirates; and nifty collapsible biohazard safety boxes from Finland.

Conducting an effective vaccination campaign in conditions like those in post-quake Haiti is extraordinarily complex. There are issues related to the vaccines themselves (primarily the maintenance of the cold chain and safe disposal of hazardous biowaste), but also to the particular health culture and context of the host country. And Haiti is as intricate and layered as they come. Fortunately, scores of Cuban health professionalsdoctors, nurses, specialists and technicians-in Port-au-Prince have been serving in Haiti for a year or more as part of Cuba's Comprehensive Health Program. Veterans on these shores, they exhibit a rare affinity for this strikingly different culture. Importantly, nurse Esmeris and several of her colleagues working on the capital's vaccination campaign were posted in Gonaïves before the earthquake. There, they vaccinated over 40,000 people between October and January 12, meeting the country's obligation made to $\mathrm{PAHO}$ as part of the national immunization program.

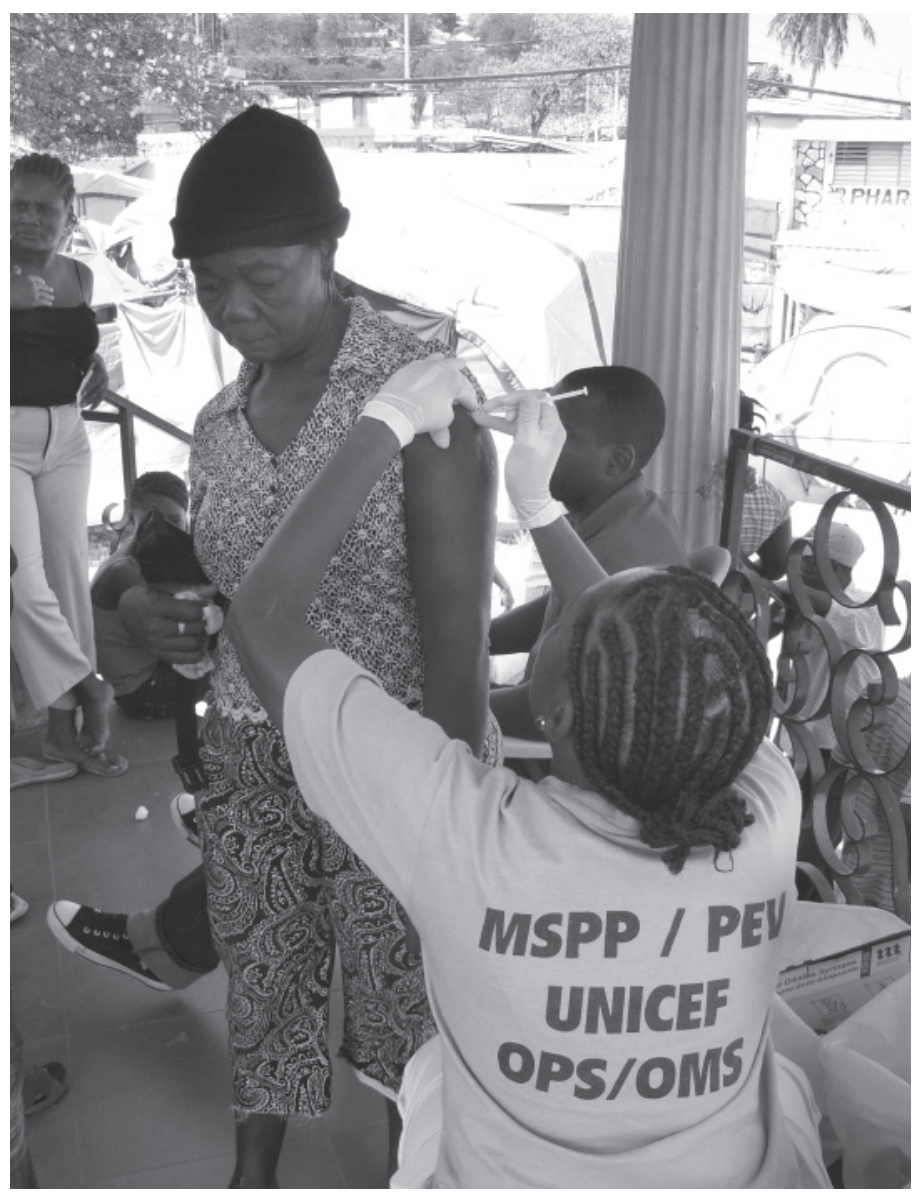

Nurse Lucía Zapata vaccinating at Place de Dame

Given all this back story, I shouldn't be surprised when the trickle of people to be vaccinated turns into a stream and eventually a torrent of the Place de Dame community. A teacher lines up her grade-school class for the free vaccines (school still hasn't 
started, but this camp is well organized, with young people especially assuming whatever responsibilities required, like this teacher caring for her out-of-school students), and there are grannies and well-dressed men too-even the camp tough guys are rolling up their sleeves, anticipating the jab with a squint and a smile.

But it's Elvire Constant who really ratchets up the work flow. Once she happens on the scene, people start arriving in droves, from other camps and the street even, belying Raysoly's 70-orso prediction. A strong, wiry woman with the intricate braids favored by many Haitian women, Elvire is president of the organizing committee of a nearby camp where the Cuban teams previously worked. "Thanks to her, we vaccinated that entire camp," Esmeris tells me. I can see why there has been such great acceptance: Elvire arrives, picks up a bullhorn, presses 'talk' and begins singing in a lovely, lilting Creole about the 'free vaccinations, available here all morning, given by Cuban doctors.' She threads her way between tents and out to the street calling on vendors, office workers and passersby to get vaccinated, like some muezzin of better health.

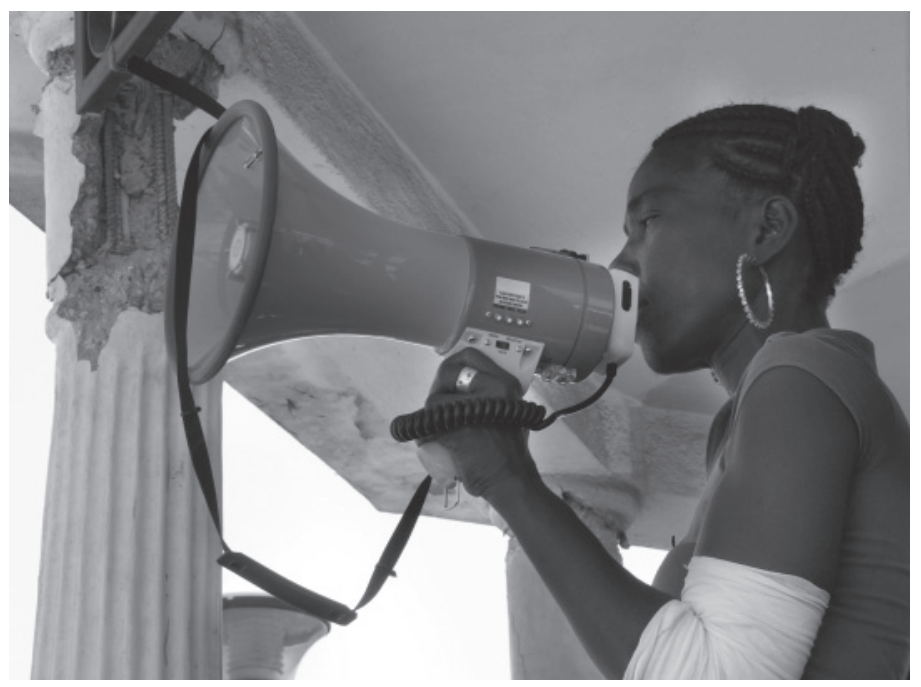

\section{Elvire Constant}

Each person receives a yellow vaccination card with the seal of the Haitian Ministry of Public Health, indicating their name, age, and vaccine administered (and schedule of additional shots in the case of DPT). Everything is in Creole and explained by the Cubans with the help of Haitian volunteers who lend a hand wherever the medical teams are found. Today, Jackson Pierre Louis and Gladimir Alexime, members of the Place de Dame camp organizing committee, appear unsolicited to help fill out the yellow cards and explain the procedure.

Given the language barrier and the novelty of the vaccination concept (several people from Place de Dame line up for a second vaccination for example), I ask Esmeris how the program is administered. "We keep detailed records of where we've been and how many people of each age group we've vaccinated. In two months' time, we'll revisit each area to administer second doses for those requiring them. After that the Haitian health system provides the booster shots." I raise an eyebrow at this last part, given that the public health system is in such disarray. She tells me that's the ideal. Still, there is hope: the
Haitian government and the Bolivarian Alliance for the People of the Americas (ALBA) presented a plan for reconstructing the Haitian health system to the WHO last week. In today's Haiti, it's imperative that such ideals get translated into realities.

In the meantime, the work of the Cuban teams takes on increasing urgency as the rainy season approaches, says $\mathrm{Dr}$ Jorge Pérez, Director of the hospital at the Pedro Kourí Tropical Medicine Institute, Cuba's reference center for infectious diseases. In Haiti to conduct an epidemiological assessment, Dr Pérez told me vaccination, health promotion and prevention are the most important tasks right now. "It's important to be vigilant. The epidemiological picture is going to get much more complicated when the rains come."

With this in mind, Cuban health professionals, accompanied by graduates of ELAM and innumerable Haitian volunteers, continue their massive vaccination efforts in post-quake Haiti. And Raysoly's estimate? That day in Place de Dame, the Cuban team vaccinated over 400 people. And the folks keep on coming: Esmeris just visited my tent to report that they broke a record in another camp where the teams are working. "We vaccinated over 500 people in Delmas 83 today. We worked from 9 to 2 and had to ask people to come back tomorrow."

\section{Love, Laughter \& Art in Post-Quake Haiti}

"Where there's love, there's life," said Gandhi, and Port-auPrince has been overflowing with both since the arrival of the Martha Machado Artists' Brigade here. The brainchild of Cuban artist Alexis Leyva Machado (Kcho-pronounced KAHcho) the artists' group aims to alleviate the psychological and emotional effects of natural disasters. Watching children's beaming smiles and hearing squeals of delight peal from teens and adults alike as the group performs, l'd say it's working.

Founded after a trio of hurricanes hit Cuba in 2008 causing $\$ 10$ billion in damages, the Brigade features a rotating roster of painters, musicians, magicians, clowns, puppeteers and circus performers.

Fifty of these Cuban artists are now in Haiti to help heal through laughter, dance, art and play; many are veterans of the original Brigade that visited the Cuban regions hardest hit by the 2008 hurricanes. One of those was the Isle of Youth Special Municipality, from where Kcho hails. The Brigade is named after the artist's mother who gave shelter to family, friends and neighbors affected by the storms.

The healing properties of laughter and play are well documented and serve particularly well for children in post-disaster situations. Young survivors are often unable to express the resulting trauma verbally, complicating mental health diagnoses and the work of health care professionals. For this reason, the Martha Machado Brigade is formally a part of Cuba's post-disaster mental health program in Haiti, coordinated by psychologist Alexis Lorenzo of the Latin American Center for Disaster Medicine (CLAMED) in Havana. "Much of what we're seeing are normal reactions to abnormal circumstances," he told me, including anxiety, fear, stress and sadness-a trio that gets blown to the four cardinal points when people become engaged with the Cuban artists in their midst. 


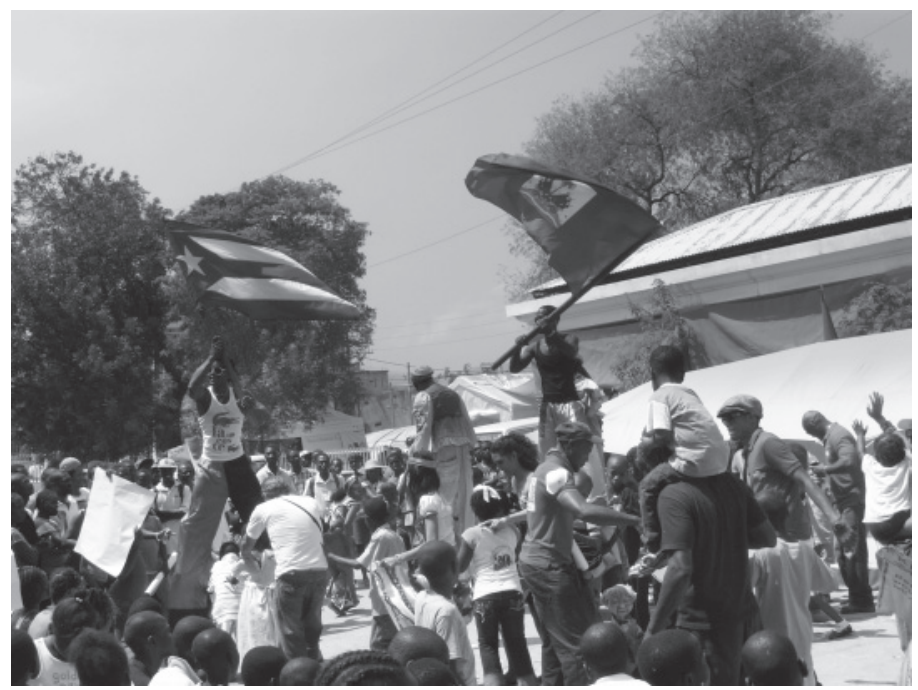

Conga line at Hôpital Renaissance

"The situation is so sad here, but you can feel the energy shift when the Brigade shows up. The kids enter a new world," artist Ernesto Rancaño told me as we watched an event unfold at the Hôpital Renaissance. A magic trick deftly executed; stilt walkers rocking babies, and clowns kidding teens; a Cuban artist and Haitian child painting side by side-these are the building blocks of happier memories for Haitians traumatized by the January earthquake. The more the children can express their feelings the better, according to psychologists, since drawing and other types of creativity help them gain symbolic control over confusing and frightening events.

One of Cuba's most talented contemporary painters and original member of the group in Cuba, Rancaño and several other painters supplied all the materials for the post-hurricane work in Cuba, creating alongside Cuban children affected by the storms. This experience is being replicated in Haiti; the resulting works of art by Haitian children, together with over a dozen paintings by Cuban children brought by the Brigade for this purpose, will be installed in public hospitals in Haiti. Twentyfive works of art by Kcho, Rancaño, Sander Gonzales and Juan Carlos Balseiro will likewise be permanently installed in Haitian hospitals. All told, the collection comprises over 150 works of art.

"This goes beyond Cuba, beyond Haiti. Our mission is to bring smiles and hope to people who have suffered natural disasters. The healing power of art and laughter is universal, and this is what our Brigade tries to do," said Kcho later at an event at the Cuban field hospital in Carrefour, west of Port-au-Prince. The group of artists has pledged to stay as long as necessary.

Still made up as clown and musician, Ronny Fernández from Havana told me why he joined the team in Haiti: "It's beautiful to be able to use our skills to take these people away from the catastrophe, if only for a moment.... We're living in tents and conditions can be tough, but the smiles on the kids' facesthat's plenty compensation."

Combining caring and science is part of psychologist Díaz's work, including a methodological framework for addressing disaster-related mental health disorders. As coordinator of CLAMED's master's degree program in mental health and disasters, Díaz is accompanied in Haiti by the two-year program's first graduate. Also in Haiti to address the mental health needs of earthquake survivors are four psychologists, 12 child psychiatrists and 7 general psychiatrists.

Psychologist Mariela Almenares is among these Cuban volunteers working with Haitian children and teens who survived the quake. In an initiative launched on March 17, Mariela leads a team comprised of Argentine and Haitian doctors and fifthyear students trained at ELAM. They are providing integrated medical and psychological services to several orphanages in Port-au-Prince, where the Artists' Brigade also performs. All agree this is one of their hardest assignments. "Yet, ten years down the line, hopefully these kids will remember today and have at least this one good memory from this terrible tragedy," Rancaño told me. I'm betting he's right.

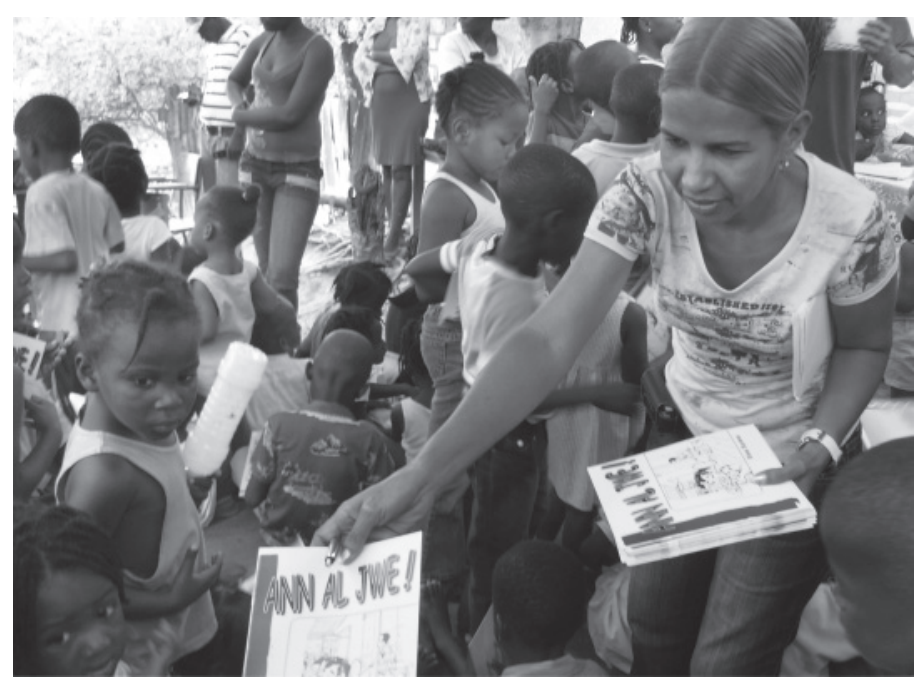

Psychologist Mariela Almenares distributes coloring books at the Canape Vert orphanage.

\section{Making the Rounds:}

\section{Hôpital Universitaire de la Paix}

It's not even 7:30 and already it's hot and close as we board the bus for the circuitous, rubble-pocked ride to Hôpital Universitaire de la Paix. As the crow flies, it's probably less than a mile from our tent camp to Port-au-Prince's university teaching hospital, but weaving between vendors and tents pitched in the street, and then caught behind a tractor or backhoe, means it takes almost an hour to get to the front gate.

I'm traveling with the Cuban medical team that will staff the ER for the next 24 hours, relieving other members of the Henry Reeve Contingent. My fellow passengers include nurses, lab technicians, family physicians and a few other specialists, like Dr Douglas Valverde, an energetic orthopedic surgical resident who received his training at ELAM. Costa Rican by birth, Dr Valverde is one of the more than 700 ELAM-trained health professionals, including young Haitian MDs, in the Cuban-led international team.

Haitians of all ages are waiting their turn at medical tents pitched in the courtyard when we arrive. Things are fairly well 
organized, which is a dramatic improvement over the situation in the days following January 12. Hôpital Universitaire de la Paix was at or near capacity when the earthquake struck; it was quickly overwhelmed as the tremors subsided and new patients made their way in droves to the facility.

"The courtyard was filled with wounded people. To cross it we had to step over and around them saying 'excuse me, excuse me, excuse me' the whole time," Dr Wilson Canton, a Haitian graduate of the ELAM told me. "The building was in decent condition, but there was no light and no water. We delivered babies using the lights on our cell phones. There were patients everywhere," he tells me in that stoic, but compassionate way Haitians have. This image of the aftermath settles over our conversation.

\section{In the Post-Op, Post Quake}

I'm sure what I'll see today at Hôpital de la Paix won't compare to those first days and even weeks after the earthquake. Still, coming into the postoperative ward where orthopedic resident Dr Valverde and Cuban colleagues Dr Mariela Rodríguez and Dr Rafael Roque visit with patients, I'm rocked back on my heels.

The heat in the 14-bed unit hovers over amputees of all ages, some moaning in what I imagine is pain mixed with frustration (and undoubtedly fear). This guttural chorus is joined by a clutch of women in the center of the room chanting and undulating, lost in energetic prayer. Daughters, girlfriends, nephews and neighbors wave kerchiefs and swaths of cardboard over their loved ones to keep the flies away. A piercing odor of human waste permeates the scene as an older woman, both legs cut off at the knee, talks to herself in a loud, stricken voice.

The first bed is occupied by one of Dr Valverde's patients: a beautiful 18-year old who was hit by a car several days ago and presented with a broken femur. Although some of the 84 members of the Henry Reeve team working at this hospital speak Creole, Dr Valverde enlists translating help from one of the women who comes to pray for patients in this hospital several times a week. "She's in pain and wants to know when you'll operate," the woman translates for us. Dr Valverde explains that they can't operate until her femur is correctly realigned, something that without the proper traction equipment, will take a week-or more. The girl lets out a loud wail when this news is translated. Dr Valverde looks at me with wrinkled brow: "We rigged up this manual weight with a cinder block to help the healing process, but she's obviously in a lot of pain." He shifts her body a bit and adjusts the height of the block, asking via the translator if that felt better. It did.

We pass along the other beds, occupied by soft-eyed gentlemen paralyzed the instant their houses fell on them in the quake, and young laborers hit by trucks in the disorder that has gripped the Haitian capital since January 12. Trailing behind the trio of surgeons, I learn about complications seen in their daily work here, including infections, phantom limbs (patients feeling pain in their amputated limbs) and depression. Shortages of even basic supplies, despite international donations that continue to roll in, are also a challenge.

A Haitian surgeon and nurse team consults with Dr Rodríguez about another case. Once they're out of ear shot, I ask about her experience as a female surgeon in this very masculine setting. She tells me about her two years working in Cap-Haïtien in Cuba's Comprehensive Health Program-the international program that has bolstered public health systems around the world since 1998, including Haiti's.

"The hospital I worked in was founded in 1812. In nearly 200 years, I was the first female surgeon they'd ever had," she explains to me in the laidback manner common to Cubans from the eastern provinces. "It wasn't a problem that I was a woman, but I had to prove myself in the operating room. Once I did, we got busy."

\section{Emergency Room Snapshot}

With the morning hours dwindling, Rodríguez, Roque, and Valverde shift their attention from the post-op recovery rooms to the hospital's emergency area. They join colleagues from Nicaragua, Panama, and Cuba's Villa Clara and Pinar del Río provinces (all Henry Reeve members), to attend arrivals in the partially screened area with four metal beds. Haitian nurses and medical students lend a hand translating, among their other duties.

There is a steady stream of patients. As in most emergency rooms, (especially post disaster in the Global South), most patients are extremely sick, including some who won't see tomorrow. This is the prognosis for the emaciated anemic grandfather and the young woman in a pretty pink dress who has had a high fever for two weeks. Malaria will soon consume her. It's not only the severity of the conditions these doctors see day after day that is disconcerting; it's that many of them are preventable. That anguish is written on the face of Dr Adac Mendoza, the ELAM doctor attending the young woman.

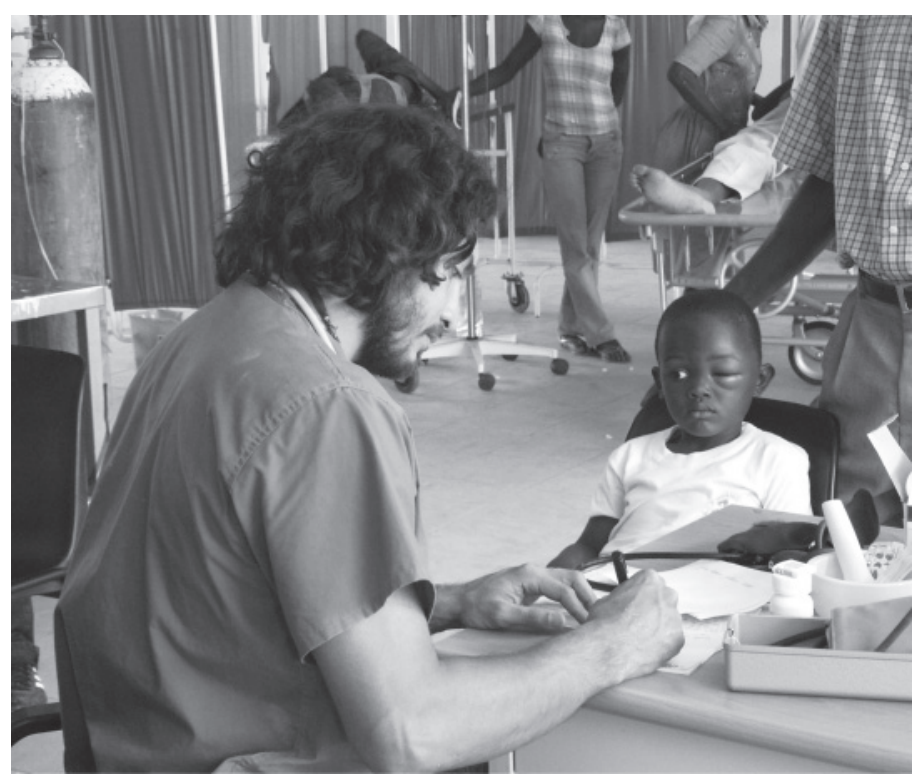

Dr Adac Mendoza (ELAM) attends a young patient in the emergency "room" of Hôpital Universitaire de la Paix.

Accident victims and chronic disease are common in this ER, and between stitching a child's split chin and taking the blood pressure of Haitian matrons, the doctors treat the aftershocks of natural disaster. A barefoot young boy hops over to the 
doctors with a badly infected wound on his left calf. Tears stream down his face as the gash is cleaned of dirt, stones, unidentifiable objects (glass? bread crusts? I can't tell and neither can the attending physician), and finally necrotic tissue. He's given a shot of antibiotics and told to come back in the evening for another injection, though the doctors admit they probably won't see him again: Transport is too scarce and life too precarious here in post-quake Haiti for many patients to pursue followup. Just then, an 18-year old girl staggers in and collapses on one of the metal beds. "She tried to poison herself," her escort tells me in English. When I ask why, his response is as disturbing as it is vague: "she was sad."

\section{Improving Health is Collaborative}

As in all disaster response efforts, medical teams from around the world collaborate both formally and informally in Haiti. I'm not surprised then as a blond-haired, blue-eyed woman in hospital scrubs turns up in the emergency area asking to consult on a patient with $\mathrm{Dr}$ Valverde. Janice Centurione is a physiotherapist from St Joseph's Health Centre in Guelph, Ontario, Canada. 'St Joe's', she tells me, has been "sister hospitals" with the Hôpital Universitaire de la Paix for the past 20 years in a pairing intended to "train Haitians to offer a standard of care." This extends to specialty services and after examining Ms Centurione's patient, Dr Valverde consults with Dr Arthur Porte, an orthopedic surgeon also from St Joe's.

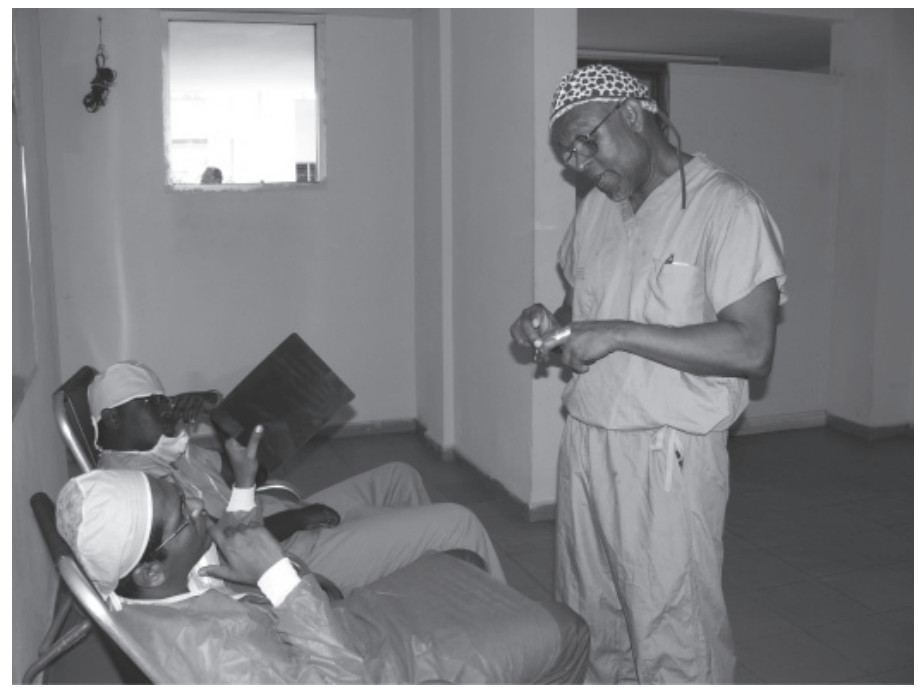

Canadian surgeon Dr Arthur Porte explains a surgical technique to Dr Valverde (ELAM) and Haitian medical student Xavier Kernizan.

"This is my third time in Haiti, but I have no previous disaster response experience, so I was reluctant to come at first," Dr Porte tells me while looking at an x-ray of the chronically dislocated finger he is about to correct surgically. Dr Valverde, Dr Porte, and Xavier Kernizan, a sixth-year medical student training in Haiti, discuss the incisions to be made and the aluminum finger splint they'll use to immobilize it following surgery. It's fascinating to watch the three-from different countries and cultures-collaborate.

"The circumstances are so difficult here in Haiti. Normally I can't do the operation you're proposing because we don't have that type of splint," Kernizan says to the Canadian surgeon. "Sure you can," offers Dr Valverde. "You can use anything-sticks, tongue depressors, whatever-to immobilize it." Dr Porte (who brought the splints, along with other higher-tech tools and materials from Canada) concurs. A Canadian OR nurse enters the anteroom, cutting the conversation short: "We're ready to go, doctors." And with that, the trio vanishes into the operating theater.

Following the quick, successful surgery, Dr Valverde tells me: "Working with the international teams here is a great learning experience. I can bounce ideas off the surgeons and they explain their techniques." Heading back to the ER, Dr Valverde has a near skip in his step. "I love waking up and going to work in the morning."

We're met by a boy needing many stitches, including for a severed vein, and $\mathrm{Dr}$ Valverde sets to work. Night is already falling, but the patients keep coming. "Another one?!" he asks when a young boy hops into the ER. But it's his young patient from earlier with the infected wound, returning for his second antibiotic shot. The young surgeon compliments the boy for coming back as he finishes mending the vein of his current patient. "This was my most satisfying day in Haiti to date."

\section{Staying the Course in Haiti}

(Havana, July 9, 2010) Predictably, the headlines have shifted away from post-quake Haiti. While millions wait for the billions pledged in March at the UN donor's conference, emergency medical staff continue to retire from the country. For many Haitians, survival is uncertain. For others, death is inevitable. Tens of thousands of families still struggle for shelter, food, water and a sense of safety. Even a modicum of security-a lock on a bathroom door, a clean bucket of water- is received as a small blessing in this most unearthly of circumstances.

A rather big blessing to come from this unprecedented disaster, however, is the emergence of new South-South partnerships to help rebuild the Haitian health system. In March, a tripartite accord among Haiti, Cuba and Brazil was signed to this end, with Brazil pledging US $\$ 80$ million-the South American country's biggest international health cooperation commitment to date. The first stage of that cooperation provides for construction and equipping of ten hospitals; four are already near completion. The second stage focuses on training health professionals to staff the Haitian public health system-a huge and pressing challenge considering Haiti has only 2.7 physicians for every 10,000 inhabitants, far shy of the minimum 25 recommended by WHO.

This effort is complemented by other South-South cooperation, including a commitment led by Venezuela under the auspices of ALBA. The ongoing plan calls for the construction of 30 comprehensive health centers, 30 community hospitals with state-of-the-art technology, 30 physical therapy centers, a prosthetics factory and 3 medical equipment repair workshops. So far, 20 of the health centers, 28 of the hospitals and all the physical therapy centers-staffed by Cuban doctors and ELAM graduates, including Haitians-are already treating patients. All services are free of charge. The generosity of this commitment 
was highlighted by Dominican President Leonel Fernández at the recent World Summit for the Future of Haiti, where Cuba presented its emergency medical effort, valued at US\$690 million, and results thus far.

Since 1998, through tropical storms, floods, social unrest and now the hemisphere's most deadly earthquake, Cuban health professionals have been providing free care throughout Haiti. A month after the January 12 quake, these Cuban doctors, nurses and health technicians were joined by over 700 graduates and students of ELAM from 27 countries. Each of these young professionals pledged to work in Haiti at least through the emergency phase.

Many, however, committed to a year of service during which they have the option of earning credit toward their family medicine, internal medicine or surgical specialty, studying under Cuban professors.

On May 11, a ceremony was held on the outskirts of Havana for some of the ELAM-trained doctors returning from Haiti. They were joined by colleagues from Brazil, Bolivia, Mexico and elsewhere, ELAM graduates who were about to depart for a year of service in Haiti. The group was received by a phalanx of Cuban dignitaries including Minister of Public Health Dr José Ramón Balaguer, Vice Minister Marcia Cobas, ELAM Rector Dr Juan Carrizo and Dr Midalys Castilla, ELAM Academic Vice Rector

The simple ceremony featured no speeches by the health officials, but rather the personal stories of the returning doctors.

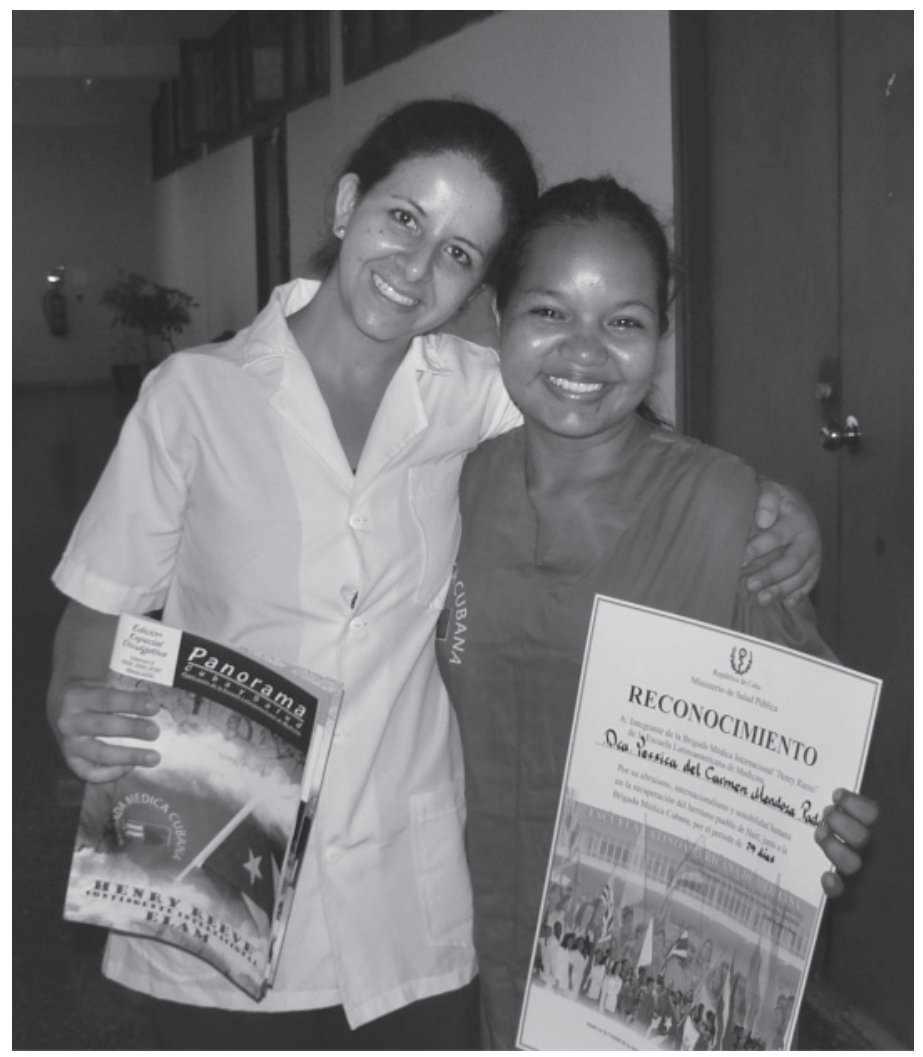

Dr Yobana Carmenza on the eve of her departure and Dr Yesica Mendoza, just back from Haiti
"Your life will be divided into before and after Haiti," Dr Ana Rosa Santa Anna Tavares from Brazil told her colleagues about to depart. "I see things differently now." According to these doctors, what they saw wasn't always pretty-or reported.

"The epidemiological situation is very complicated. Families have no way to boil water. Children have no shoes," said Dr Yesica Mendoza from Colombia. "You're going to see diseases you've never seen before and you'll have to go into the field, into people's homes and tents, because patients don't have the money to go to the hospital. The only cadaver I saw in Haiti was an 18-year old boy who wasn't taken to the hospital because his family was too poor." Dr Mendoza emphasized that this is why the Cuban-led contingent's free treatment of patients is so important.

But the dire Haitian reality experienced by these ELAM graduates is tempered by their dedication and training, ELAM adheres to a socially driven curriculum that combines evidencebased medical education with a humanistic understanding of health as a right for all. This too, came through loud and clear as the doctors spoke.

"This is our dream... to work as doctors with people who need care," said Dr Mendoza. Another ELAMtrained doctor from Argentina echoed this sense of fulfillment "These people just can't be abandoned. . . What future do these babies have? What will become of their lives? They deserve more. They deserve the best in the world."

and obligation: "Haiti has so many needs. These people just can't be abandoned." The emotion was palpable in the auditorium as one doctor after another shared their feelings. "What future do these babies have? What will become of their lives? They deserve more. They deserve the best in the world," said Dr Santa Anna Tavares.

"We had the most beautiful experiences working in the field," the young Brazilian doctor continued. "The Haitians never, ever rejected us. We were always welcomed into their homes, invited to sit, and treated like family. You'll see difficulties in Haiti," she told her colleagues, "but you'll also forge solutions."

Like all of us in attendance that afternoon, the panel of Cuban dignitaries was visibly moved. Minister Balaguer leaned into the microphone: "You cannot imagine the satisfaction it gives us to see you applying your practical knowledge to improve the health of Haitians. Everything you've shared here nourishes our vision, gives us energy to transform the world. The world needs transformation and you are the ones capable of making it happen."

For Dr Mendoza from Colombia, this wasn't just rhetoric: "Haiti was an incredible learning experience for me, personally and professionally. I learned that you have to look for tools and ways to make things work. I learned that if you knock on doors, those doors will open. In Haiti, I felt one step closer to my dream of changing the world." - 1 -

Photos: C. Gorry and J. Balán 


\section{Publish in MEDICC Review!}

Peer reviewed and widely indexed, 40,000+ article reads monthly assure your paper broad circulation to readers in over $140+$ countries.
See www.medicc.org/mediccreview for author instructions. Manuscripts are accepted in English or Spanish from international authors on a wide range of topics related to research and perspectives on health strategies, clinical medicine, health sciences education and health equity.

For more, write editors@medicc.org

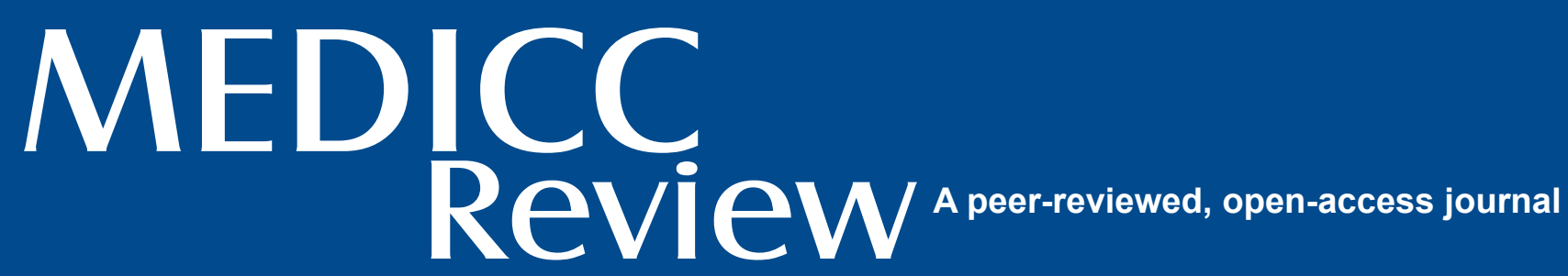

WRITE! REVIEW! READ! ： Join the MEDICC Review community...

- Publish your research, reviews and evidence-based commentary

- Become a peer reviewer

- Join online and print readers from over 140 countries worldwide

Watch for our special issue on US-Cuban cooperation in April 2018!
Available in MEDLINE/PubMed, Thomson Reuters Web of Science, Elsevier's SCOPUS and EMBASE, CABI Global Health \& Tropical Diseases Bulletin, Latindex and Redalyc

\section{Online at}

(3) www.medicc.org/mediccreview

Manuscripts are accepted in Spanish or English.

Write editors@medicc.org for more information, or consult www.medicc.org/mediccreview for author instructions.

\section{Author Guidelines}

See

www.medicc.org/mediccreview

for author instructions 


\section{A US Student Reflects on Her Cuban Medical Education}

\section{Natalia Orihuela}

At first I was skeptical about the opportunity for international candidates to study medicine for free in Cuba. Did the land of son cubano, cigars and sugar have the resources to host thousands of young men and women aspiring to get their medical degree? I was acquainted with the history of the country, and the prospect intrigued me. Having grown up in Mexico City and been raised by progressive parents, I had heard about Cuba's health care system and educational model. After finishing my undergraduate degree in California, I started scouting for medical colleges that advocated a holistic approach to medicine.

This search led me to Havana's Latin American School of Medicine (ELAM), an international medical school founded to train doctors devoted to practice in vulnerable, underserved communities. The Cuban government makes a global humanitarian commitment by providing full, six-year scholarships to train individuals from these same communities. After inquiring into the program, I did not hesitate. I applied and was accepted. It has become one of the most enriching experiences of my life.

When I arrived at José Martí International Airport, the scent of rain-soaked soil heralded summer in Havana. Most of the firstyear US students traveled together and completed the required 24-hour quarantine at the ELAM clinic before being transferred to the dorms. Quarantine, to monitor for spread of infectious disease, is part of the intake protocol for all foreign medical students and Cuban medical personnel returning from overseas assignments. This was our first lesson in preventive medicine.

As the days went by, students from all over the world started arriving on campus. The dormitories' close quarters gave us a chance to get to know each other better. After a six-month intensive Spanish course, the language barrier between us melted away. Living in a foreign country and studying in a language unknown to many helped us become a family and adjust to sometimes challenging conditions.

My pre-med class comprised young people from different latitudes, including Western Sahara, Palestine, Belize, Syria, Brazil, Nicaragua, Antigua, Zimbabwe, Chad and Angola. I discovered that how I perceived life back home was entirely different from the way some of my classmates did-their loved ones endured severe poverty or ruthless violence. Well-being, I realized, encompasses psychosocial conditions as well as biology.

Nonetheless, we all shared a common goal. Like most of the US students who came from historically neglected and impoverished communities, the other young people matriculating at ELAM believed that access to health care is a basic human right-no matter from where they hailed; our experiences forged friendships that affected how I understood reality and my place in the world.

The program itself, with its emphasis on community medicine, clinical skills and primary care, laid the groundwork for attaining this common goal. The pedagogical approach is team-oriented, with projects and evaluations occurring in groups. Thus, each teammate is responsible for ensuring everyone comprehends the concepts being taught. In contrast to most US educational models, at ELAM, collective achievement is a fundamental contribution to individual academic success. Starting in first year we visited patients in their homes, inquiring into their current state of health, their sources of stress as well as their social activities.

After second year we transitioned into clinical settings at one of several Havana teaching hospitals. Extensive interaction with patients taught us to treat them within their biopsychosocial contexts. These methods helped us hone our rapport-building skills, aiding in our transition to the hospital, where patient interaction happens on a daily basis.

Moreover, students have the opportunity for in-service learning from phyisican professors throughout our six years of study. Cuban physicians strive to bequeath as much knowledge as possible to students because, in contrast to the professional competitiveness characteristic of US academic culture, they do not perceive us as future competitors, but rather as another building block in their commitment to healing. In addition to health sciences, through their examples we learned compassion, altruism and-most importantly-our responsibility as medical practitioners towards those in need, regardless of their socioeconomic status.

Now, four years into my medical studies I believe living and studying in Cuba has shaped who I am and given me a host of applicable lessons of personal and academic growth. I am convinced that no other school would have offered

\section{I am certain I will be empowered with tools that will make a difference in my community} me the support system, challenges and wisdom this experience entails. ELAM not only represents the place where I am getting my medical education; it is a place where I have found a family, become bilingual and made extraordinary memories.

Most importantly, however, ELAM stands as a paragon of social consciousness where science meets human compassion forging the physician I aspire to become one day. I am eager to apply everything I have learned back in the United States for I am certain I will be empowered with tools that will make a difference in my community.

Cuban medical schools take pride in educating physicians de ciencia y consciencia, (of science and conscience) because the essence of medicine lies in its humanistic nature and healing is our duty, despite any hardship. This is what I will take home.-1M-

\footnotetext{
Submitted: October 27, 2017

Approved for publication: January 10, 2018

Disclosures: None

Correspondence: norihuela@nauta.cu
} 


\section{MELIÄ \\ HABANA \\ CUBA \\ THEHLEVEL}

Havana as a world-dass intemational destination is further enhanced with The Level, a service that boasts attention to detall for business meetings, sclentific events and successful negotiations. The Mella Habana shows its best colours, promising an unforgettable experience.

wow.mella-habana.com

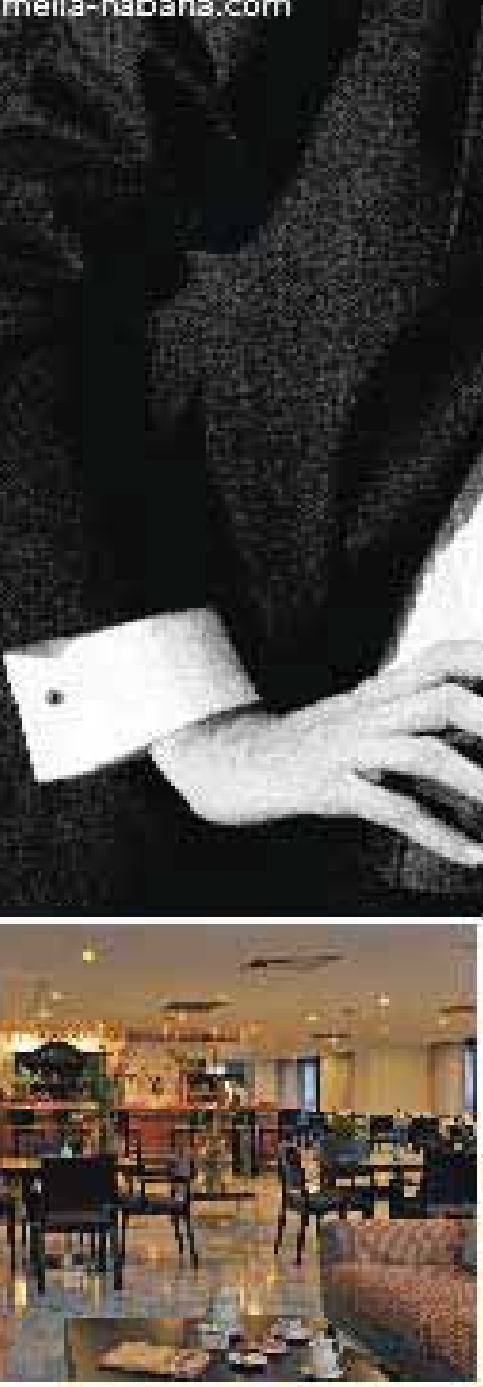

$E X \odot E P T I O N A L$

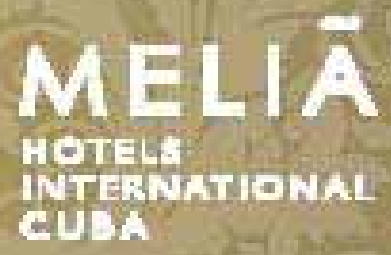


